WORKING PAPER - NO. 2020-52

\title{
Did the Paycheck Protection Program Hit the Target?
}

João Granja, Christos Makridis, Constantine Yannelis, and Eric Zwick

JULY 2020

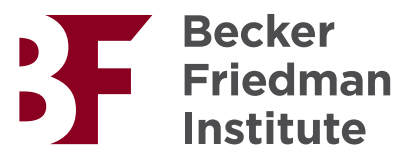




\title{
Did the Paycheck Protection Program Hit the Target?*
}

\author{
João Granja \\ Chicago Booth \\ joaogranja@chicagobooth.edu \\ Constantine Yannelis \\ Chicago Booth and NBER \\ constantine.yannelis@chicagobooth.edu
}

\author{
Christos Makridis \\ MIT Sloan \\ makridis@mit . edu \\ Eric Zwick \\ Chicago Booth and NBER \\ ezwick@chicagobooth.edu
}

July 3rd 2020

\begin{abstract}
This paper takes an early look at the Paycheck Protection Program (PPP), a large and novel small business support program that was part of the initial policy response to the COVID-19 pandemic. We use new data on the distribution of the first round of PPP loans and high-frequency micro-level employment data to consider two dimensions of program targeting. First, we do not find evidence that funds flowed to areas more adversely affected by the economic effects of the pandemic, as measured by declines in hours worked or business shutdowns. If anything, funds flowed to areas less hard hit. Second, we find significant heterogeneity across banks in terms of disbursing PPP funds, which does not only reflect differences in underlying loan demand. The top-4 banks alone account for $36 \%$ of total pre-policy small business loans, but disbursed less than $3 \%$ of all PPP loans in the first round. Areas that were significantly more exposed to low-PPP banks received much lower loan allocations. We do not find evidence that the PPP had a substantial effect on local economic outcomes-including declines in hours worked, business shutdowns, initial unemployment insurance claims, and small business revenues-during the first round of the program. Firms appear to use first round funds to build up savings and meet loan and other commitments, which points to possible medium-run impacts. As data become available, we will continue to study employment and establishment responses to the program and the impact of PPP support on the economic recovery. Measuring these responses is critical for evaluating the social insurance value of the PPP and similar policies.
\end{abstract}

*We thank seminar participants at the University of Chicago Booth School of Business, the Stigler Center Economic Effects of COVID-19 Workshop, the Federal Reserve Bank of New York, the Federal Reserve Bank of Philadelphia and the Bank of Portugal as well as Scott Baker, Sylvain Catherine, Jediphi Cabal, Raj Chetty, Mike Faulkender, Sam Hanson, Steve Kaplan, Mike Minnis, Tiago Pinheiro, Larry Schmidt, Adi Sunderam, and Luigi Zingales for comments. Laurence O’Brien and Igor Kuznetsov provided excellent research assistance. João Granja gratefully acknowledges support from the Jane and Basil Vasiliou Faculty Scholarship and from the Booth School of Business at the University of Chicago. Yannelis and Zwick gratefully acknowledges financial support from the Booth School of Business at the University of Chicago. We are grateful to the Small Business Administration, Womply, and Homebase for providing data. This draft is preliminary and comments are welcome. 


\section{Introduction}

The COVID-19 pandemic triggered an unprecedented economic freeze and a massive immediate policy response. Among the firms most affected by the freeze were millions of small businesses without access to public financial markets or other ways to manage short-term costs. Without an existing system of social insurance to support these firms, policymakers rushed to develop new programs to help contain the damage, culminating in the CARES Act.

This paper takes an early look at a large and novel small business support program that was part of the initial crisis response package, the Paycheck Protection Program (PPP). The PPP offered guaranteed loans to small businesses through the Small Business Administration (SBA) in order to stimulate lending to liquidity constrained firms. The loans are forgivable if firms do not lay off workers or change their compensation. Our first goal is to describe the targeting of the first round of PPP funding. We then build on our targeting results to evaluate the short-term economic impacts of the first round (i.e., from April 2nd to May 2nd). As data become available, we will continue to expand this work by studying the second round of funding, the medium-term economic impacts, and ultimately the social insurance value of the program.

We bring new data from two sources to study the PPP. First, we obtained data from the SBA on the number and amount of PPP loans disbursed by each participating lender during the first round of the program. The data offer a clear look at which lenders were most active in disbursing loans and at the geographic distribution of PPP lending across the U.S. economy. Second, we obtained high-frequency employment data from Homebase, a software company that provides free scheduling, payroll reporting and other services to small businesses, primarily in the

retail and hospitality sectors. The granularity of the data, coupled with the focus on sectors most adversely affected by the pandemic, allows us to trace out the response of employment, wages, hours worked, and business closures in almost real-time and evaluate the effects of PPP support.

In the first part of the paper, we consider two dimensions of program targeting. First, did the funds flow to where the economic shock was greatest? A central policy goal is to prevent unnecessary mass layoffs and firm bankruptcies by injecting liquidity into firms. These potential benefits are likely greatest in areas with more pre-policy economic dislocation and disease spread. We find no evidence that funds flowed to areas that were more adversely 
affected by the economic effects of the pandemic, as measured by declines in hours worked or business shutdowns. If anything, we find some suggestive evidence that funds flowed to areas less hard hit. The fraction of establishments receiving PPP loans is greater in areas with better employment outcomes, fewer COVID-19 related infections and deaths, and less social distancing.

Second, given that the PPP used the banking system as a conduit to access firms, what role did the banks play in mediating policy targeting? Anecdotal evidence suggests some banks were eager to participate in the program, while others were unable or unwilling to process large numbers of loans in the short program window. ${ }^{1}$ Given the magnitude and pace of the evolving pandemic and the resulting disruptions in the marketplace, it is important for policymakers to understand whether banks of different sizes and lending strategies had equal access to the lending program. In particular, we ask whether there are systematic differences in program targeting at the aggregate level driven by bank behavior and then quantify the resulting bank allocation effect on the labor market.

Lender heterogeneity in PPP participation appears to be one reason why we find a weak correlation between economic declines and PPP lending. We find significant heterogeneity across banks in terms of disbursing PPP funds, which reflects more than mere differences in underlying loan demand. For example, because of an asset cap restriction in place since 2018, Wells Fargo disbursed a significantly smaller portion of PPP loans relative to their market share of small business loans. We construct a measure of geographic exposure to bank performance in the PPP using the distribution of deposits across geographic regions. The measure exploits the fact that most small business lending is local (Brevoort, Holmes and Wolken, 2010; Granja, Leuz and Rajan, 2018), comparing lenders that did more PPP lending, relative to other small business lending, versus their counterparts who did less. We find that areas that were significantly more exposed to banks whose PPP lending shares exceeded their small business lending market shares received disproportionately larger allocations of PPP loans.

Overall, our findings shed light on the nature of and mechanism for how the first round of PPP loans were distributed. PPP loans were disproportionately allocated to areas least affected by the crisis: fifteen percent of establishments in the regions most affected by declines in

\footnotetext{
${ }^{1}$ For example an article from Forbes notes that in the days preceding the launch of the program, Fifth-Third Bank did not initially participate in the program, while Old National only processed loans for customers that had an existing account. Bank of America was the first bank to process PPP loans, and they only took loans from customers with "pre-existing business lending and business deposit relationship with Bank of America, as of February 15, 2020."
} 
hours worked and business shutdowns received PPP funding; in contrast, thirty percent of all establishments received PPP funding in the least affected regions. A major factor behind this pattern was the significant heterogeneity in the intensity of PPP participation across lenders. Our findings indicate that underperforming banks-whose participation in the PPP underperformed their share of the small business lending market-account for two-thirds of the small business lending market, but only twenty percent of total PPP disbursements in the first round. The top-4 banks in the U.S. economy (JPMorgan Chase, Bank of America, Wells Fargo, and Citibank) alone accounted for $36 \%$ of the total number of small business loans but disbursed less than $3 \%$ of all PPP loans. These banks were disproportionately located in areas that received less PPP funding. We also find that, while the regional funding gap narrowed during the second round, a large gap persisted across states for at least another month after the initial funds were exhausted.

In the second part of the paper, we study the effect of the PPP on economic outcomes during the first round of the program. Our results on bank participation motivate a research design to evaluate the PPP using bank-driven differences in regional exposure to the program. This variation across regions allows us to isolate the effect of the PPP from differences in loan demand or confounding correlations between PPP funding and local economic outcomes. Our research design relies on the assumption that pre-policy bank deposit shares in particular regions are not correlated with the various outcomes we study. This assumption holds once we condition on relevant observables, such as the relationship between PPP funding and the initial severity of the crisis. We use this research design to study business shutdowns, reductions in hours worked, initial unemployment insurance (UI) claims, and small business revenues at the congressional district and county levels.

We present two findings. First, we do not find evidence that the PPP had a substantial effect on local economic outcomes during the first round of the program. We establish this finding using weekly firm-level employment and shutdown data from Homebase, which covers small retail establishments especially hard hit by the crisis. We confirm the firm-level evidence using initial unemployment insurance claims at the county level. Given that one motivation for the program was to provide an escape valve for congested state UI systems, the absence of a significant effect on UI claims during the initial weeks of the program is striking. Our confidence intervals on employment outcomes are wide enough to permit modest effects of the program, but precise enough to reject large effects. The fact that the program disbursed 
significant funds, yet had little effect on employment, leads to the natural question of what firms did with additional cash on hand.

Our second finding draws on the Census Small Business Pulse Survey to show that PPP funds during the first round allowed firms to build up liquidity and to meet loan and other non-payroll spending commitments. For these firms, the PPP may have strengthened balance sheets at a time when shelter-in-place orders prevented workers from doing work and when unemployment insurance was more generous than wages for a large share of workers. This finding is important because it implies that, while employment effects are small in the short run, they may well be positive in the medium run because firms are less likely to close permanently. At the same time, because program eligibility was defined broadly, many less affected firms received PPP funding and may have continued as they would have in the absence of the funds, either by spending less out of retained earnings or by borrowing less from other sources. Our results likely reflect a mix of these factors.

This paper is part of a broader research program to evaluate the impacts of COVID-19 economic policy responses that target private firms and households. As data become available, we will build on these findings to evaluate the employment responses, to look at firm closures, and to study the speed and nature of the economic recovery. Measuring these responses is critical for evaluating the social insurance value of the PPP and similar policies.

Related Literature. This paper joins a literature focusing on how government interventions following crises impact recovery and the broader economy. Agarwal, Amromin, Ben-David, Chomsisengphet, Piskorski and Seru (2017) and Ganong and Noel (2018) study the impact of mortgage modifications following the Great Recession. House and Shapiro (2008) and Zwick and Mahon (2017) study the effect of fiscal stimulus in the form of temporary tax incentives for business investment, and Zwick (Forthcoming) documents the role of delegated agents in mediating take-up of tax-based liquidity support for small firms. Mian and Sufi (2012), Parker, Souleles, Johnson and McClelland (2013), Kaplan and Violante (2014) and Baker, Farrokhnia, Meyer, Pagel and Yannelis (2020b) study how stimulus payments following recessions affect household consumption. This paper evaluates a very large stimulus program aimed at providing liquidity and support to small firms.

Specifically, this paper also joins a rapidly growing literature studying the impact of the 2020 COVID-19 pandemic on the economy. Jones, Philippon and Venkateswaran (2020), 
Barro, Ursua and Weng (2020), Eichenbaum, Rebelo and Trabandt (2020), and Berger, Herkenhoff and Mongey (2020) study the macroeconomics of infectious disease outbreaks and Gormsen and Koijen (2020) use asset prices to back out growth expectations. ${ }^{2}$ Baker, Bloom, Davis and Terry (2020) study changes in risk expectations induced by the COVID-19 pandemic. Barrios and Hochberg (2020), Allcott, Boxell, Conway, Gentzkow, Thaler and Yang (2020), and Makridis and Rothwell (2020) study how partisan affiliation impacts the response to the pandemic, and Coibion, Gorodnichenko and Weber (2020), Cajner, Crane, Decker, Grigsby, Hamins-Puertolas, Hurst, Kurz and Yildirmaz (2020), and Bartik, Betrand, Lin, Rothstein and Unrath (2020) use a combination of administrative and survey data to study short term labor market impacts. Baker, Farrokhnia, Meyer, Pagel and Yannelis (2020a), Chetty, Friedman, Hendren and Stepner (2020), and Cox, Ganong, Noel, Vavra, Wong, Farrell and Greig (2020) study consumption during the COVID-19 pandemic using high-frequency household transaction data, documenting a deeper decline in and slower recovery of consumption among higher income areas and earners. Taking a more aggregate approach, Mulligan (2020) and Makridis and Hartley (2020) estimate baseline annual GDP effects of COVID-19 of \$7 and \$2.14 trillion, respectively. Guerrieri, Lorenzoni, Straub and Werning (2020) show how supply-side shocks can generate substantial shocks to demand and aggregate output. Similarly, Papanikolaou and Schmidt (2020) explore how industry differences in remote work can explain revenue forecasts and other supply-side disruptions, building on approaches to measuring the task content of occupations as in Dingel and Neiman (2020) and Gallipoli and Makridis (2018). Humphries, Neilson and Ulyssea (2020) take a different approach using a social media survey on nearly 3,000 small and medium size businesses to document large differences in expectations and awareness of the PPP. We join this emerging literature by providing early microeconomic evidence on how firms and employees were affected as a function of credit supply in the first stages of the pandemic.

Finally, the paper joins work studying loan guarantees, an important and widely used form of government intervention in credit markets. Classic work such as Smith (1983), Gale (1990) and Gale (1991) focus on modeling government credit interventions such as loan guarantees.

\footnotetext{
${ }^{2} \mathrm{~A}$ related emerging empirical literature also explores the role of non-pecuniary factors, like social capital, as mediating factors during the pandemic. For example, Makridis and Wu (2020) show how counties with greater social capital have had fewer infections and a slower spread of infection, conditional on local demographic factors. Similarly, Barrios, Benmelech, Hochberg and Zingales (2020) and Ding, Levine, Lin and Xie (2020) both show how areas with greater social capital were more likely to engage in disease-mitigating activities because their residents have greater trust in institutions and collective efficacy.
} 
Early empirical work focused on loan guarantee programs in France (Lelarge, Sraer and Thesmar, 2010). Recent theoretical work has focused on government guarantees to banks (Atkeson, d'Avernas, Eisfeldt and Weill, 2018; Kelly, Lustig and Van Nieuwerburgh, 2016), economic stimulus (Lucas, 2016) and a burgeoning empirical literature examines the effects of loan guarantees on credit supply, employment and small business outcomes (Bachas, Kim and Yannelis, 2020; Barrot, Martin, Sauvagnat and Vallee, 2019; Mullins and Toro, 2017; Gonzalez-Uribe and Wang, 2019). Barrios, Minnis, Minnis and Sijthoff (2020) provide an empirical framework and Elenev, Landvoigt and Van Nieuwerburgh (2020) focus on theoretical considerations

for assessing the optimal targeting of PPP loans during the pandemic and its role in expanding credit supply to small versus larger firms that differ in their liquidity constraints. Cororaton and Rosen (2020) examine the firm characteristics of public firms that have received PPP loans, underscoring the importance of targeting loans towards the firms that need liquidity most. These patterns contrast in some ways with the rollout of a similar lending program in Italy where smaller firms and those in more adversely affected areas were more likely to receive support (De Marco, 2020). Along these lines, we provide a comprehensive assessment of an important and large loan guarantee program, evaluating its impacts during a period of economic contraction and uncertainty.

The remainder of this draft is organized as follows. Section 2 describes the PPP. Section 3 discusses the main data sources used. Section 4 describes how the distribution of relative performance in the PPP is correlated with bank and other characteristics. Section 5 documents how differences across banks in PPP activity imply geographic differences in PPP exposure. Section 6 explores the implications for PPP targeting to different geographic areas. Section 7 analyzes the early effects of the PPP on employment, and section 8 explores mechanisms. Section 9 concludes.

\section{The Paycheck Protection Program (PPP)}

The Paycheck Protection Program (PPP) began on April 3rd, 2020 as part of the 2020 CARES Act as a temporary source of liquidity for small businesses, authorizing $\$ 349$ billion in forgivable loans to help small businesses pay their employees and additional fixed expenses during the COVID-19 pandemic. Firms apply for support through banks and the Small Business Administration (SBA) is responsible for overseeing the program and processing loan guarantees 
and forgiveness. An advantage of using the banking system (including FinTech) as a conduit for providing liquidity to firms is that, because nearly all small businesses have pre-existing relationships with banks, this connection could be used to ensure timely transmission of funds.

The lending program is generally targeted toward small businesses of 500 or fewer employees. ${ }^{3}$ Although the initial round of funding was exhausted on April 16th, funds were drawn from the Economic Injury Disaster Loan Program (EIDL) in the interim to continue funding small businesses until the second round of $\$ 310$ billion in PPP funding was passed by Congress as part of the fourth COVID-19 aid bill. ${ }^{4}$ Small businesses were eligible as of April 3rd and independent contractors and self-employed workers were eligible as of April 10th.

The terms of the loan are the same for all businesses. The maximum amount of a PPP loan is the lesser of 2.5 times the average monthly payroll costs or $\$ 10$ million. The average monthly payroll is based on prior year's payroll after subtracting the portion of compensation to individual employees that exceeds $\$ 100,000 .^{5}$ The interest rate on all loans is $1 \%$ and their maturity is two years. The loans will be forgiven if two conditions are met. First, the loan proceeds must be used to cover payroll costs, mortgage interest, rent, and utility costs over the eight-week period following the provision of the loan, but not more than 25 percent of the loan forgiveness amount may be attributable to non-payroll costs. Second, employee counts and compensation levels must be maintained. If companies cut pay or employment levels, loans may not be forgiven. ${ }^{6}$ However, if companies lay off workers or cut compensation between February 15th and April 26th, but subsequently restore their employment levels and employee compensation, their standing can be restored.

An important feature of the program is that the SBA waived its standard "credit elsewhere" test used to grant regular SBA 7(a) loans. This test determines whether the borrower has the ability to obtain the requested loan funds from alternative sources and amounts to a significant barrier in the access to regular SBA loans. Instead, in the PPP, applicants were only required to

\footnotetext{
${ }^{3}$ A notable exception was made for firms operating in NAICS Code 72 (accommodations and food services), which are eligible to apply insofar as they employ under 500 employees per physical location. Firms whose maximum tangible net worth is not more than \$15 million and average net income after Federal income taxes (excluding any carry-over losses) of the business for the two full fiscal years before the date of the application is not more than $\$ 5$ million can also apply. See the SBA for further information about the program.

${ }^{4}$ Recipients of an EIDL loan can receive a $\$ 10,000$ loan advance that does not need to be paid back. The EIDL loan itself is capped at a maximum of $\$ 2$ million, is not forgivable, and the funds can be used flexibly for operating expenses.

${ }^{5}$ Payroll costs include wages and salaries but also payments for vacation, family and medical leave, healthcare coverage, retirement benefits, and state and local taxes.

${ }^{6}$ Loan payments on the remainder of the loan can be deferred for six months and interest accrues at $1 \%$.
} 
provide documentation of their payroll and other expenses, together with a simple two-page application process where they certify that the documents are true and that current economic uncertainty makes this loan request necessary to support ongoing operations. In sum, the PPP program was designed to be a "first-come-first-served" program with eligibility guidelines that allowed it to reach a broad spectrum of small businesses.

During the first weeks of April, demand for PPP loans outstripped supply, which was limited by statute. Between April 3 and 16 all of the initial $\$ 349$ billion was disbursed, and the program stopped issuing loans for a period of time. The House and Senate passed a bill to add an additional $\$ 320$ billion in funding on April 21 and 23 respectively, which was signed into law on the 24th. The PPP began accepting applications on April 27 for the second round of funding. Under the second round, funds were disbursed much less quickly, with unallocated PPP funds being available in late June.

\section{Data}

We obtained confidential data on the number of approved PPP loans and approved PPP amounts from the Small Business Administration during the first round through a Freedom of Information Act request. The data set contains information on the amounts and number of loans approved by each lender, amounts and number of loans received by small businesses in each state, and total amounts and number of PPP loans received by small businesses in each congressional district as of April 15, 2020. The PPP loan amounts in our records account for 336 billion of the 349 billion allocated to the program under the first round of the CARES Act.

We hand-match this data set with the Reports of Condition and Income (Call Reports) filed by all active commercial banks as of the fourth quarter of 2019 . We are able to match 4,228 out of 4,980 distinct participants in the PPP program to the Call Reports data set. We did not match 1,031 commercial and savings banks that filed a Call Report in the fourth quarter of 2019. We assume that these banks did not participate in the PPP program and made no PPP loans. We further classified 631 PPP program participants as credit unions and the remaining 121 participants as non-bank PPP lenders. This group includes small community development funds, as well as some large non-bank Fintech lenders. The commercial banks in the PPP sample that we matched to the Call Report account for 93.7\% of all PPP loans and $96.8 \%$ of the total amount of loans disbursed under the PPP. By contrast, the group of PPP lenders that 
we classified as credit unions accounted for 3.3\% of all loans and 1.4\% of the total PPP lending amounts. Non-bank PPP lenders accounted for $3 \%$ of all loans and 1.8\% of total PPP lending amounts.

We obtain financial characteristics of all banks from the Call Report filed by commercial and savings banks in the fourth quarter of 2019. The Call Report provides detailed data on the size, capital structure, and asset composition of each commercial and savings bank operating in the United States. Importantly, we obtain information on the number and amount of small business loans outstanding of each commercial and savings bank from the Loans to Small Business and Small Farms Schedule of the Call Reports. Using this information, we benchmark the participation of all commercial and savings banks in the PPP program relative to their share of the small business lending market.

To compute measures of exposure of each state, congressional district, and county to PPP lenders, we match the matched-PPP-call reports data set with Summary of Deposits data containing the location of all branches and respective deposit amounts of all depository institutions operating in the United States as of June 30th, 2019. A significant number of depository institutions merged in the second half of 2019, which means that some branches are assigned to commercial and savings banks that no longer exist as stand-alone institutions. Notably, SunTrust Banks, Inc. merged with Branch Banking and Trust Company (BB\&T) to create the sixth largest financial institutions in the United States. We use the bank mergers file from the National Information Center to adjust the branch network of merged institutions and account for these mergers. We take advantage of the idea that most small business lending is mostly local (e.g. Granja, Leuz and Rajan (2018)) and use the distribution of deposits across geographic regions to create a measure of exposure of these regions to lenders that did more versus less PPP lending than the expected small business lending share benchmark.

To evaluate whether PPP amounts were allocated to areas that were hardest-hit by the COVID-19 crisis, we use data from multiple available sources on the employment, social distancing, and health impact of the crisis. We obtained detailed data on hours worked among employees of firms that use Homebase to manage their scheduling and time clock. Homebase processes exact hours worked by the employees of a large number of businesses in the United States. We use information obtained from Homebase to track employment indicators at a daily frequency across different states and congressional districts. The Homebase data set disproportionately covers small firms in food service, retail, and other sectors (Bartik, Bertrand, Lin, 
Rothstein, and Unrath, 2020). ${ }^{7}$ We complement the Homebase data set with official weekly state unemployment insurance filings from the Department of Labor. We conduct our main analyses at the congressional district level because that is the finest level of geographic disaggregation for which we have aggregate PPP lending. We use data from the County Business Patterns dataset to approximate the number of establishments in the congressional district and compute measures of the average amount of PPP lending per establishment and the fraction of establishments receiving PPP loans in the region.

Because Homebase primarily covers small retail, beverage, and food service establishments, it is not representative of aggregate employment. Nevertheless, the Homebase data are quite useful for evaluating the employment impacts of the PPP specifically, as many hard-hit firms are in the industries Homebase does cover and much of the early employment losses came from these firms. ${ }^{8}$

To broaden our picture of the employment effects, we supplement the Homebase data with two additional data sources. First, we obtain county-by-week initial unemployment insurance claims from state web sites or by contacting state employment offices for data. We utilize initial unemployment insurance claims as a measure of flows into unemployment. We additionally supplement the Homebase data with data from Womply, a company that aggregates data from credit card processors. The Womply data includes card spending at small businesses at the county level, defined by the location where a transaction occurred. Small businesses are defined as businesses with revenues below SBA thresholds.

To understand the mechanisms underlying our results, we also draw on newly-available data from the Census Bureau's Small Business Pulse Survey (SBPS), launched within seven weeks of the national emergency declaration in March (Buffington, Dennis, Dinlersoz, Foster and Klimek, 2020). To obtain real-time information tailored towards small businesses, the SBPS is run weekly and entirely online that takes less than 10 minutes to complete and relies largely on checkboxes, rather than numerical responses. Rather than contacting businesses with an official letter, they were reached via email based on the Census Bureau's Business Register that has been populated using responses to the Economic Census across the 50 states

\footnotetext{
${ }^{7}$ More information about Homebase can be found at www.joinhomebase.com.

${ }^{8}$ We note that we were made aware of an error in the current raw formulation of the HomeBase data. This resulted in doubling the number of hours three sectors: retail, professional services and transportation. The error only affects the level, not the relative difference, across industries or states and hence should not change our two primary outcomes, business shutdowns and the ratio of hours worked. However, these results should be treated with some caution and the issue is scheduled to be corrected in the next data release.
} 
(and D.C. and Puerto Rico). Furthermore, the SBPS focuses on businesses with receipts that are greater than or equal to $\$ 1,000$, but retain 500 employees or fewer. Each week, the sample weights are adjusted to maintain representativeness.

While we focus our analysis on aggregations of small businesses across states and metropolitan areas over time, we observe a wide array of information. For example, we observe changes in revenues (increase, decrease, and no change) and the actual level of revenues. We also observe how firms are changing their labor force through temporary business closures, employment, or hours worked. Finally, and most importantly for our purposes, we draw upon responses to questions about liquidity (e.g., cash on hand), loans, defaults, and applications for financial assistance. We observe separate responses to questions about use of the PPP, EIDL, and SBA loan forgiveness programs. We note that Humphries, Neilson and Ulyssea (2020) and Bartik, Bertrand, Cullen, Glaeser, Luca and Stanton (2020) have pursued similar approaches through other channels aimed at gathering information about small businesses.

Finally, we obtain counts of COVID-19 cases by county and state from the Center for Disease Control and use data on the effectiveness of social distancing from Unacast. Unacast provides a social distancing scoreboard that describes daily changes in average mobility. Unacast measures the change in average distance travelled using individual's GPS signals. The data is availably on a daily basis, at the county level. We obtain information on the effective dates of statewide shelter-in-place orders from the New York Times. ${ }^{9}$

\section{PPPE and Bank Characteristics}

\subsection{Paycheck Protection Program Exposure}

Table 1 shows summary statistics for the 20 largest financial institutions in the United States, as measured by total assets. The left-most column gives the institution's name, while the first column of the table gives total assets as of the fourth quarter of 2019. The second and third columns, respectively, show the share of total PPP volume and the share of the small business loan (SBL) market of each institution. The fifth column presents relative bank performance

\footnotetext{
${ }^{9}$ The New York Times presents some aggregates on shelter-in-place orders.
} 
which is measured as

$$
P P P E_{b}=\frac{\text { ShareVol.PPP }- \text { ShareSBLMarket }}{(\text { ShareVol.PPP }+ \text { ShareSBLMarket })} \times 0.5
$$

where ShareVol.PPP the share of PPP volume held by bank $b$, and ShareSBLMarket is their total small business loan volume market share. The next three columns present similar information to columns (2) through (4), using the market share of total number of loans rather than their volume, where

$$
P P P E_{b}=\frac{\text { ShareNbr.PPP }- \text { ShareNbr.SBLMarket }}{(\text { ShareNbr.PPP }+ \text { ShareNbr.SBLMarket })} \times 0.5 .
$$

Here ShareNbr.PPP the share of the number of PPP loans held by bank $b$, and the term ShareNbr.SBLMarket is their total small business loan market share, based on the number of loans outstanding in each bank's balance sheet as of the fourth quarter of 2019.

Figure 1 shows the distribution of relative performance in the PPP comparing PPP market share against the overall stock of small business loans. The top panel shows the distribution of relative bank performance in the PPP, based on the total volume of PPP loans granted. The bottom panel shows the distribution of relative bank performance in the PPP, based on the number of PPP loans granted. Both figures show a wide dispersion of relative performance, with the distribution of performance based on the total number of loans showing greater mass at the tails.

Figure 2 plots the bank measure of relative performance in the PPP by percentile of bank size. The top panel shows relative performance based on the total volume of PPP loans granted, the middle panel shows relative performance based on the number of PPP loans issued, while the bottom panel shows average PPP loan size. All three panels indicate a similar patternlarger banks issued more PPP loans than expected given their share of the small business market, whether by volume, number of loans, or average loan size. This pattern could be consistent with larger banks being better suited to take advantage of the PPP program as it was rolled out. This pattern reverses at the very top of the bank size distribution. The very largest banks, those in the top percentile of bank size, significantly underperformed in PPP lending relative to their pre-policy share of small business lending. This underperformance is clear both in terms of lending volume (Panel A) and number of loans (Panel B). Panel C suggests that the underperformance of the top percentile of banks occurs despite their making the largest PPP 
loans in the sample in terms of average loan amount.

Figure 3 provides evidence concerning the significant dislocations between the share of PPP lending of underperforming banks and the share of PPP that we would expect had these banks issued PPP loans in proportion to their share of the small business lending market. The blue hollow triangles and red hollow circles represent, respectively, the cumulative share of the PPP and small business lending of banks whose PPPE is below a certain threshold. The figure shows that commercial and savings banks, representing $20 \%$ of the small business lending market, simply did not participate in the PPP lending program, ( $P P P E=-0.5)$. The plot further shows that the group of banks whose PPP share is below their share of the small business lending market, ( PPPE < 0), made less than 20\% of the PPP loans, but account for approximately two-thirds of the entire small business lending market. Overall, the evidence is consistent with substantial heterogeneity across lenders in their responses to the program's rollout.

The fact that lenders were significantly heterogeneous in accepting and processing PPP loans would not necessarily result in aggregate differences in PPP lending across geographic areas if small businesses could easily substitute and place their PPP applications to lenders that were willing to accept and quickly expedite them. If many lenders, however, prioritize their existing business relationships in the processing of PPP applications, firms' pre-existing relationships might determine to a large extent whether they are able to tap into PPP funds. In this case, the exposure of geographic areas to banks that over/underperformed in the deployment of the PPP might significantly determine the aggregate PPP amounts received by small businesses located in these areas. Next, we examine if geographic areas that were exposed to banks with weak PPP performance received less PPP lending overall.

\section{Geographic Exposure to Bank PPP Performance}

We next explore how the geography of the PPPE is related to PPP lending outcomes. Figure 4 presents a map of county level exposure to PPPE based on the share of deposits of each bank in the county. Exposure varies across the United States with some Western areas containing a large Wells Fargo presence that exhibit lower levels of PPPE, suggesting greater exposure to lenders that underperformed in the PPP program relative to their small business lending benchmark. By contrast, the counties with lower median household income ( $\rho=-0.13)$, a lower share of college educated individuals ( $\rho=-0.16$ ), and a smaller COVID-19 shock were 
more likely to be exposed to lenders that overperformed in the PPP roll-out.

Figure 5 explores the relationship between PPPE exposure and PPP lending. The top panel of Figure 5 plots aggregate PPP volume per small business by exposure to PPPE for each state, while the bottom panel shows the fraction of all small businesses receiving PPP loans in the state. Both panels present a similar pattern-there is a strong positive relationship between PPP lending and PPPE exposure at the state level. States with higher exposure to banks that performed well in terms of PPPE also saw greater PPP lending. Figure 7 presents a similar pattern at the congressional district level, and a similar correlation emerges.

Table 2 makes this graphical evidence explicit. The top panel shows the relationship between PPPE and aggregate lending, at the congressional district level. Column (1) shows the correlation between aggregate PPP lending and PPPE at the congressional district level. The relationship is highly statistically significant, with an F-statistic of approximately 45. A one-standard deviation increase in the congressional district exposure to PPPE based on total amounts of outstanding PPP and small business loans and weighted by the share of deposits of each bank leads to a 16.1 percent increase in PPP lending. Column (2) adds in aggregate employment and payroll controls, and column (3) adds in industry shares. The results remain highly statistically significant at the 1 percent level. Column (4) shows that the correlation holds even within states when we add state fixed effects, although the coefficient remains significant at only the 10 percent level.

The bottom panel repeats the analysis, replacing aggregate lending per business with the fraction of establishments receiving PPP loans in each congressional district. This panel also indicates a very strong relationship between our PPPE measure and lending. In column (1), the first stage F-statistic is now above 200, and even with state fixed effects in column (4) the relationship is highly statistically significant at the 1 percent level. A one-standard deviation increase in our measure of congressional district exposure to bank PPP performance is associated with an increase of 4.3 percentage points in the fraction of establishments receiving loans in a congressional district. These results suggest that businesses were much more likely to receive a PPP loan simply because they were located closer to banks that processed a large share of PPP loans relative to their benchmark share of small business loans.

A potential concern with the above results is that the causality runs reverse. That is, banks do relatively better where demand for PPP loans is abundant. To address this concern, we 
compare survey measures on firm applications and PPP receipt. ${ }^{10}$ The Census Small Business Pulse survey measures small businesses conditions in relation to the COVID-19 crisis at the state by sector level, including PPP application and receipt. We compare the difference between application and receipt to our measure of bank exposure.

The top panel of Figure 6 shows volume-based PPPE exposure and the difference between the percentage of businesses reporting having applied to PPP and percentage of business that received PPP in each state. The bottom panel shows PPPE based on the number of loans and the difference between the percentage of businesses reporting having applied to PPP and the percentage of business that received PPP in each state. Both panels show a very similar pattern, the difference between PPP application and receipt is much lower in states with higher exposure to banks that allocated more PPP funds. In other words, conditional on applying, businesses were more likely to receive PPP funds in states where there were more banks allocating funds.

Appendix A presents a case study, which demonstrates the importance of financial intermediation in the allocation of PPP funds. Wells Fargo was severely constrained from expanding its balance sheet as a result of an asset cap imposed by the Fed in the aftermath of the fake accounts scandal. This asset cap was only lifted on April 10 when the Fed excluded PPP loans from the formula it uses to restrict Wells Fargo's growth. The asset cap limited Wells Fargo's ability to lend under the PPP in the early days for the first phase of the program. Wells Fargo performed poorly in terms of allocating PPP funds during the first wave and firms located in areas with higher Wells Fargo market share see lower PPP allocations, both in terms of overall aggregate loan volume per business and in the fraction of businesses receiving PPP loans.

The collection of results in this section suggests that exposure to bank-specific heterogeneity in their willingness and ability to extend PPP loans was a significant determinant of the allocation of PPP loans in the economy. Next, we examine how the PPP allocation and exposure to over/underperforming banks correlated with the local magnitude of the epidemic.

\section{Are PPP Allocations Targeted to the Hardest Hit Regions?}

Were PPP funds disbursed to geographic areas that were most affected by the epidemic? Figure 8 shows the relationship between PPP allocations, exposure to Bank PPP performance, and the fraction of businesses in each congressional district that shut down during the week of March

\footnotetext{
${ }^{10}$ Census Small Business Pulse survey data can be found here.
} 
29th to April 4th, just before PPP funds were disbursed. ${ }^{11}$ We estimate business shutdowns in the congressional district using the high-frequency data set obtained from Homebase. The figure indicates little if any correlation between PPP allocation or relative bank performance and hours worked or business shutdowns. In Figure 9, we follow Bartik, Bertrand, Cullen, Glaeser, Luca and Stanton (2020) and repeat the analysis using the ratio of hours worked on March 31st, 2020 relative to a baseline of the average hours worked in the same weekday of the last two weeks of January. Again, we find that PPP allocations across congressional districts are very weakly correlated to the impact of the epidemic crisis on labor markets and aggregate firm outcomes. We have also investigated the robustness of these results to alternative cutoffs when measuring the decline in hours worked and employment (e.g., as of April). ${ }^{12}$

To better illustrate the relation between firm and employment outcomes at the congressional district level and PPP allocations, we stratify congressional districts into 20 bins based on the impact of the COVID-19 epidemic on the fraction of businesses that shut down and on the average decline in hours worked in the congressional district. Figure 10 plots the average fraction of business receiving PPP loans in each business shutdown bin (top panel) and hours worked bin (bottom panel). The plots suggest that approximately 15\% percent of businesses located in the most affected congressional districts were able to obtain PPP funding until April 15th, 2020. By contrast, more than $30 \%$ of all businesses operating in the least affected congressional districts were able to tap into PPP funding.

The results suggest that PPP funds were not targeted towards geographic areas that were most affected by the pandemic, at least in terms of small business employment drops. This fact could be a result of the pre-existing bank relationships across counties, rather than a problem with implementation: banks were caught off guard by the pandemic and the corresponding actions taken to social distance. A related factor likely influencing these geographic patterns is differential loan demand in harder hit areas. Because PPP support is more generous for firms that maintain their payroll, the program likely appealed more to firms with smaller reductions in their business. To the extent these geographic patterns reflect such differences in loan de-

\footnotetext{
${ }^{11}$ Following Bartik, Betrand, Lin, Rothstein and Unrath (2020), we define a business shutdown as businesses that report zero hours worked during a week.

${ }^{12}$ In Tables A.2 and A.3, we employ cross-sectional specifications at the congressional district to further support the idea that the PPP funding did not flow to areas with largest pre-PPP declines in employment and ratios of shutdown businesses. The tables report the results of ordinary least squares (OLS) regressions examining the relation between the allocation of PPP funds and the share of businesses that shut down operations in the last week of March, and the decline in hours worked between January and the last week of March.
} 
mand, the evidence suggests the PPP functioned less as social insurance to support the hardest hit areas and more as liquidity support for less affected firms. Nevertheless, our bank-level results point to an important loan supply channel distorting the distribution of PPP loans.

The appendix presents suggestive evidence that, if anything, funds were disproportionately allocated to geographic areas that were less hard hit by the virus. Figures A.2 and A.3 repeat the analyses of Figures 8 and 9 at the state-level. Figures A.4 and A.5 show that there is a slight negative correlation between loans and PPPE with COVID-19 confirmed cases and deaths. This fact is consistent with Figure A.6, which indicates that states with earlier shelter-in-place orders-which were presumably harder hit by the epidemic — saw lower fund allocations. Figure A.7 shows that there is little correlation between the magnitude of social distancing at the state level and PPP allocation and bank exposure. Finally, Figure A.8 confirms our findings using the Homebase data with another public data source-we find no consistent relationship between PPP allocation and bank exposure with state UI claims. The totality of the evidence suggests that there was little targeting of funds to geographic areas that were harder bit by the epidemic and, if anything, areas hit harder by the virus and subsequent economic impacts received smaller portions of PPP funds.

\section{The Early Effects of PPP on Employment and Local Eco- nomic Activity}

\subsection{Research Design}

Our results on PPP performance differences across banks motivate a research design for evaluating the PPP. The basic idea is to use differences in local area PPP exposure (PPPE) to partition geographies and compare the evolution of local outcomes for high versus low PPPE regions. By exploiting differential exposure to banks that performed poorly in distributing PPP funding during the first round of the program, we can isolate the effect of the PPP from other differences across regions that may drive differences in PPP loan demand. As described above, we map bank level aggregates for PPP lending from the SBA data onto local geographies using measures of local bank branch presence. The research design is akin to a Bartik instrument and therefore relies on the assumption that pre-policy bank deposit shares in particular regions are not correlated with the various outcomes we study, conditional on observables. 
We focus our analysis in the time period between the third week of January and the last week of April to study the short-term effects of the PPP in the immediate aftermath of the pandemic when the injection of liquidity was thought to matter the most. We choose this time window for three reasons. First, starting our sample period in January allows to establish a baseline period prior to the full economic impact of the virus hitting US firms. Second, the PPP began disbursing funds on April 3 and all of the initial \$349 billion was allocated by April 16 . During this period, banks played a key role in allocating limited funds, creating the variation we exploit to identify the effects of the program. Third, beginning on April 27 a second round of PPP funding began. Partly because PPP funding limits were no longer binding, the second wave closed some of the gap between initially high and low PPPE exposure regions. Thus, were we to use PPPE to study the effect of the program later in May and June, we would need to interpret the research design as assigning some firms funding with a lag, instead of as assigning some firms no funding at all. ${ }^{13}$

Given the rapid nature and size of the economic shock, we highlight an important consideration when analyzing data from this time period. Our targeting analysis shows that regions receiving more PPP funding were less hard hit by the initial shock, in part due to the banking channel we emphasize. Thus, it is important to properly condition on this non-random assignment of PPP funding. For example, if one does not break out the data finely enough or condition properly for targeting differences-for example by treating all of March as a pre-period benchmark or by looking at the correlation between PPP receipt and employment outcomesthen one might detect a spurious effect of the program. We show this issue is very clear in week-by-week outcomes around the policy window.

To account for these targeting differences, we estimate the effects of the program using the period prior to large scale lockdowns as a base period and separately report "effects" for the "Pre-Lockdown Covid" period, "Post-Lockdown Pre-PPP" period and "Post-PPP" period. We then compare the post-PPP period effects to the "Post-Lockdown Pre-PPP" period to estimate the causal effect of the program. We also include time-varying controls and state-by-timeby-industry fixed effects to estimate treatment effects under weaker versions of the Bartik assumption. Once we adjust for targeting differences, including these more restrictive controls has little effect on our estimates.

In our main analysis, we present reduced form regressions of local economic outcomes on

\footnotetext{
${ }^{13}$ We plan to extend our analysis to study the second round as new data become available.
} 
PPPE. We choose this approach because we only have PPP funding for certain geographic levels, namely, state and congressional district. ${ }^{14}$ In particular, we estimate variants of the following specification

$$
\begin{aligned}
E_{\text {isnt }}=\alpha_{i}+\delta_{\text {snt }} & +\beta_{1} \mathbb{1}[\text { Pre-Lockdown }] \times P P P E_{c} \\
& +\beta_{2} \mathbb{1}[\text { Post-Lockdown \& Pre-PPP }] \times P P P E_{c} \\
& +\beta_{3} \mathbb{1}[\text { Post-PPP }] \times P P P E_{c}+\gamma X_{c}+\varepsilon_{\text {isnt }},
\end{aligned}
$$

where $E_{\text {isnt }}$ is an outcome, business shutdowns or the decline in hours worked in our main specification for firm $i$ operating in state $s$ and industry $n$ in week $t$. The term $\alpha_{i}$ captures firm fixed effects, while $\delta_{s n t}$ are state-by-industry-by-week fixed effects, $P P P E_{c}$ is PPP exposure at the congressional district level measured using the number of firms exposed, and $\varepsilon_{i s n t}$ is an error term. $\mathbb{1}$ [Pre-Lockdown] is an indicator variable that takes the value of one between the weeks of March 1st-March 7th and March 15th-March21st, $\mathbb{1}$ [Post-Lockdown, Pre-PPP] is an indicator variable that takes the value of one during the weeks of March 22nd-March 28th and March 29th-April 4th, and $\mathbb{1}[$ Post-PPP] is an indicator variable that takes the value of one following the week of April 5th-April 12th.

The coefficients $\beta_{1}, \beta_{2}$, and $\beta_{3}$ capture the differential effect of PPP exposure on the outcome of interest during each time period relative to the baseline period. The identifying assumption is that the firms differentially exposed would have trended similarly in the absence of the PPP, conditional on fixed effects and controls. Due to the inclusion of state-by-industryby-week fixed effects, we are comparing trajectories for firms within state-by-industry groups and allowing general time trends within these groups. The coefficient $\beta_{1}$ captures differences between firms after the initial spread of COVID-19 but prior to subsequent lockdowns. The coefficient $\beta_{2}$ captures targeting effects-differences in outcomes related to PPP exposure prior to the disbursement of funds-while the coefficient $\beta_{3}$ captures the differential effect of PPP exposure on the outcome of interest after the PPP launched. The difference between the coefficients $\beta_{3}-\beta_{2}$ identifies the effect of PPP exposure conditional on targeting.

\footnotetext{
${ }^{14}$ Appendix Table A.4 reports instrumental variable regressions to study Homebase outcomes at the congressional district level, and we briefly interpret these results below. We also use instrumental variable regressions to study Census survey outcomes at the state level.
} 


\subsection{Small Business Employment}

A significant portion of the policy and media attention regarding the PPP focused on the program's potential employment effects. We examine business shutdowns (i.e., hours worked reduced to zero during the entire week), declines in hours worked, and unemployment insurance claims and find no evidence of substantial effects of the PPP on these outcomes.

Recall that our targeting analysis revealed that if anything a larger fraction of businesses located in areas that were less hard hit received PPP funding during the first round. Specifically, the plots of Figure 10 indicate that in congressional districts that saw least decline in hours worked and the lowest rates of business shutdowns saw a greater fraction of their small businesses receiving small business loans.

Figure 11 presents simple difference-in-difference graphs for each of our employment and local activity outcomes. We divide all firms in the sample based on whether they are located in congressional districts with above- or below-median high and low PPPEs. We use vertical markers to demarcate the post-lockdown, pre-PPP period; the post-PPP launch; when the first round of PPP funds are exhausted; and when the second round of PPP funding begins. For both measures of small business employment, we see a dramatic decline in employment starting in the week prior to the lockdowns. Consistent with our targeting results, this decline is modestly larger for regions with low PPPE. Importantly, during the first round of PPP, the gap between high and low PPPE areas does not widen further, indicating little incremental impact of PPP during this time.

Figure 12 plots weekly coefficients and standard error bands for regressions of each outcome on congressional district PPPE. Specifically, we estimate regressions of the form

$$
E_{i s n t}=\alpha_{i}+\delta_{s n t}+\beta_{t} P P P E_{c} \times \mathbb{1}[\text { Week=t }]+\varepsilon_{i s n t}
$$

where $E_{i t}$ is business shutdowns or the decline in hours worked for firm $i$ operating in state $s$ and industry $n$ in week $t, \alpha_{i}$ are firm fixed effects, $\alpha_{s n t}$ are state-by-industry-by-week fixed effects, $P P P E_{c}$ is PPP exposure at the congressional district level measured using the number of firms exposed, $\mathbb{1}[\mathrm{Week}=\mathrm{t}]$ is an indicator variable that takes the value of one during week $t$ and $\varepsilon_{i s n t}$ is an error term. The coefficients $\beta_{t}$ capture the effect of PPP exposure on the outcome of interest under the identifying assumption the firms differentially exposed would have trended similarly in the absence of the PPP. The baseline week is the first week of the sample period 
(January 19th-January 25th). The state-by-industry-by-week fixed effects imply that we are comparing trajectories for firms within state-by-industry groups and allowing general time trends within these groups.

The results align with the raw differences across high and low PPPE regions in Figure 11. Common trends hold until the week of the declaration of the national emergency and lockdowns take effect. At this point, higher PPPE is associated with better employment outcomes in terms of fewer business shutdowns and smaller reductions in hours worked. When the PPP is launched and funds start to reach firms, we see no incremental effects of the program on these outcomes relative to pre-PPP levels. ${ }^{15}$

Table 3 presents our difference-in-difference estimates, in which we pool the weekly effects into four time intervals reflecting the pre-Covid-19 crisis period; the pre-lockdown - post-Covid19 period; the post-lockdown, pre-PPP period; and the post-PPP period. We measure the effect of the PPP by comparing the coefficients for the latter two intervals. In the top panel, the outcome of interest is business shutdowns, while in the bottom panel it is the decline in hours worked. The first two columns and second two columns exclude and include firm fixed effects, respectively. The first and third columns use the fraction of firms receiving PPP as the program exposure variable. The second and fourth columns use congressional district PPPE as the program exposure variable, and thus can be thought of as reduced form regressions. ${ }^{16}$

The table confirms the finding of no statistically or economically significant relationship between PPP loans or PPP bank exposure and these employment outcomes. Moreover, our least squares estimates are not simply statistically insignificant with large confidence intervals; rather, they are precise zeros. To address potential concerns about the strength of the research design, Appendix Table A.4 instruments the fraction of firms receiving PPP loans with the PPPE measure. Again, we find nearly identical results. While one concern is that our first-stage effect is weak, we show that our $F$-statistic is above the rule-of-thumb and highly significant: a 10 percentage point increase in PPPE is associated with a 3.4 to 3.8 percentage point increase in the share of firms receiving PPP.

As another way of interpreting our magnitudes, consider the following comparison. The

\footnotetext{
${ }^{15}$ Appendix Figure A.9 shows that our instrument improves the reliability of inferences by mitigating pre-trends, likely driven by differences in loan demand. However, the results when we use PPP funding instead of PPPE as the right-hand-side variable are consistent with our preferred specification: we see little evidence of substantial effects of PPP on these outcomes relative to pre-PPP outcomes.

${ }^{16}$ Appendix Table A.4 estimates 2SLS regressions in first differences comparing the post-PPP period to the postlockdown, pre-PPP period. The effects are qualitatively identical but with modestly larger standard errors.
} 
difference between PPPE for top versus bottom quartile congressional districts is 0.42 . This difference implies an increase in the share of establishments receiving PPP funding of 14.3 percentage points. ${ }^{17}$ Using the reduced form estimates in Table 3, column (4), this change in funding implies a change in the probability of firm shutdown of -0.08 percentage points $(=(-0.042-0.040) \times 0.42)$. The lower bound of the $95 \%$ confidence interval is well below a one percentage point effect. An analogous calculation for the decline in hours worked gives similarly small effect sizes. Thus, relative to the aggregate patterns in Figure 11 -a 40 percentage point increase in the probability of firm shutdown and 60 percentage point reduction in the ratio of hours worked relative to January-we can reject modest effect sizes during this time period.

Table 4 presents similar results using another separate measure of employment outcomes: UI claims. The dependent variable is the ratio between the weekly initial unemployment insurance filings hand-collected from several state labor departments and county employment measured using the Bureau of Labor and Statistics January County Employment data. The results paint a very similar picture to those in Table 3. Again, there is no statistically or economically significant relationship between PPP loans or PPP bank exposure and UI claims. Again, the first and third columns use the fraction of firms receiving PPP as the program exposure variable while the second and fourth columns use the respective county PPPE as the program exposure variable. While the results are slightly less precise than those using outcomes from the Homebase data, the coefficient on the interaction post the rollout of the PPP program indicates no discernable changes in the number of UI filings, relative to the post-lockdown period.

\subsection{Local Economic Activity}

While much of the focus of the PPP was in countering a surge in unemployment and business closures, we now explore the potential effects of PPP on the evolution of small business revenues as a proxy for local consumption activity. Table 5 presents analogous results. For example, in columns (1) and (3), we find no statistically significant association between county PPPE and consumption expenditures. Here, we control for state $\times$ industry $\times$ week fixed effects, exploiting differences in the exposure of firms to PPP across counties within the same state and industry. This rules out potential concerns about the passage of stay-at-home and

\footnotetext{
${ }^{17}$ This calculation comes from $0.42 \times 0.34$ from Appendix Table A.4, Panel A, establishment-level results, column (1).
} 
nonessential business closure laws at the state-level, which could otherwise confound our estimates. Columns (2) and (4) subsequently add county $\times$ industry fixed effects, thus absorbing invariant characteristics of small businesses at the county $\times$ industry level. Again, we find no evidence of a positive association with consumption expenditures. Moreover, column (4) controls for weekly infections and deaths per capita, as well as an index of social distancing (measured by distance traveled among residents) to control for other time-varying county-specific shocks present during these weeks.

\section{Interpretation and Mechanisms}

Additional funds from the PPP do not have significant effects on employment or local economic activity during the first round of the program. If firms did not maintain or increase employment, what did they do with these funds?

There are several non-mutually exclusive channels through which businesses may have absorbed the funds without immediate employment effects. First, program eligibility was defined broadly, so many less affected firms likely received funds and continued as they would have in the absence of the funds. In these cases, the program's benefits accrue to the firm's owners. Related to this idea, it is possible that PPP funds crowded out private market borrowing, as firms or banks may substitute publicly guaranteed PPP loans for other lending that would have happened otherwise (Holmstrom and Tirole, 1998).

Second, despite restrictions on the share of funds ultimately forgiven that needed to be spent on payroll, firms retained significant flexibility in how they could use the funds over time. Firms could elect to use funds for required payments initially, to leave the funds in the bank, or to use only the share that they are able to use when they can. For these firms, the PPP may have strengthened balance sheets at a time when shelter-in-place orders prevented workers from doing work and when unemployment insurance was more generous than wages for a large share of workers. An implication of this channel is that, while employment effects are zero in the short run, they may well be positive in the medium run because firms are less likely to close permanently.

There was also likely considerable uncertainty about how to use the funds, either because of evolving regulatory guidance or because small businesses struggled to understand the rules in the first place. Moreover, firms may respond to periods of high uncertainty, such as the 
ongoing pandemic (Baker, Bloom, Davis and Terry, 2020), by holding cash as a precautionary buffer.

Third, some firms may have increased employment or called back workers. Small effects for these firms are indeed consistent with our null overall result. These effects may be particularly muted given historic expansion of UI benefits, causing former employees to prefer unemployment over a return to work (Chetty, 2008). Nevertheless, it is unlikely that the PPP was responsible for large changes in employment at the end of April and into the first week in May. However, we caution that more data are likely needed to better support this claim.

Overall, we find evidence that PPP funds during the time period we study are used as liquidity support and to meet loan and other spending commitments.

\subsection{Payments}

While we do not find short term effects on employment and firm revenue, the PPP may have had significant effects promoting financial stability and the long-term recovery by extending a lifeline to small businesses and preventing a rapid wave of small business bankruptcies and liquidations. In Table 6 and Figure 13, we use information from the Census Small Business Pulse Survey to relate the state PPPE with the percentage of businesses reporting having received PPP in each state-industry group. The results suggest that between April 26th and June 6th, the period covered by the weekly surveys, state PPPE is strongly and positively related to the percentage of businesses reporting receiving PPPE within a state and industry. Over the entire sample period, a one-unit increase in state PPPE is associated with a 35\% increase in the share of businesses who report receiving PPP. Consistent with the idea that the second round of funding lessened some of the geographic imbalance in the allocation of PPP disbursements, we also see that the effect of state PPPE on the percentage of businesses reporting receiving PPP is more pronounced in the early waves of the survey. Between April 26 to May 2, a comparable unit increase in PPPE is associated with an 85\% increase in PPP received. By May 31 to June 6 , the coefficient declines to $24 \%$, although it remains statistically significant.

We repeat this exercise using the percentage of businesses reporting requesting, but not receiving PPP in each state and industry. As discussed in Section 5, this exercise also assuages concerns that the relation between state PPPE and the percentage of businesses receiving PPP could be driven by demand effects whereby firms and industries that did not request PPP funds 
were disproportionately located in areas whose local banks have low PPPE. We report the results of this analysis in Table A.5 and Appendix Figure A.10. The results indicate that states with low PPPE had a greater proportion of businesses applying for but not receiving funds under the program thus suggesting that the lower fraction of firms receiving PPP in those areas is driven not by lower demand for funds from the program, but rather by their lower access to banks that processed applications during the first round. ${ }^{18}$

Having confirmed that PPPE is significantly related with access to PPP funds, we further explore the information in the Small Business Pulse Survey to examine whether receipt of PPP allowed firms to avoid becoming delinquent on scheduled payments (either loan or non-loan). In Table 8, we show regressions examining the relationship between the allocation of PPP funds and the percentage of firms reporting missing loan payments at the state-industry level. In Table 7, we show similar regressions using the percentage of firms missing other scheduled payments such as rent, utilities, supplier payments, and payroll. ${ }^{19}$ In light of our targeting results, these regressions add controls for pre-PPP measures of crisis severity, including the pre-PPP decline in hours worked from Homebase, the pre-PPP counts of COVID cases and deaths per capita, and the pre-PPP social distancing index.

The results in Table 8, column (1), indicate that a percentage point increase in the share of firms reporting receiving PPP is not significantly associated with a decline in the percentage of firms missing loan payments. This result, however, could indicate that areas and industries with a lower percentage of businesses receiving PPP had a larger fraction of businesses that did not apply because they were not eligible to apply or decided they did not need the funds. To address this issue, we use state PPPE to capture geographic differences in access to the supply of PPP funds resulting from differences across regions in their exposure to bank PPP performance. These differences are plausibly unrelated to demand factors and therefore less likely to be confounded by them. In column (2), we run a similar specification, but instead focus on the relation between percentage of firms reporting missing payments with state PPPE. In this case, an increase in state PPPE is associated with a significantly lower percentage firms

\footnotetext{
${ }^{18}$ In the Appendix, we further repeat these empirical exercises at the level of the Metropolitan Statistical Area (MSA) rather than at the State-Industry level and we find similar results in that MSAs with lower exposure to PPP see a lower percentage of small businesses receiving PPP.

${ }^{19}$ Unfortunately, the Pulse survey does not separate this category of other payments into payroll versus nonpayroll components. However, it does focus on "required" payments, which firms may interpret as referring to payments for past labor rather than discretionary payments based on retaining workers going forward. Results for this measure should be interpreted with some uncertainty about respondents' interpretation of the question.
} 
reporting missing loans payments. In columns (3) and (4), we present results of an IV strategy whereby we instrument for the percentage of firms receiving PPP using state PPPE. Using this strategy, we find that a ten percentage point increase in firms receiving PPP is associated with 1.7 percentage point decline in missing loan payments.

In Table 7, we find that a ten percentage point increase in the share of firms receiving PPP is associated with an even larger effect on missed non-loan payments. This result might not be surprising when we consider that a large fraction of small businesses do not necessarily have loans. We find that, across all specifications, an increase in the percentage of firms receiving PPP or in the access to PPP funds is associated with a lower percentage of firms reporting missing these types of payments. Specifically, the results of the IV strategy in columns (3) and (4) suggest that a ten percentage point increase in firms receiving PPP is associated with a 5.5 percentage point decline in the number of firms reporting missing any type of scheduled payments. The relationship is highly statistically significant at the 1 percent level.

Finally, we show in Appendix Table A.7 that the share of firms reporting missing payments is positively related to the fraction of small businesses reporting having applied, but not having received PPP funds. The percentage of firms that applied, but not did not receive, PPP funding is plausibly less related to differences in demand for PPP funds across geographies and industries and likely better captures timely access of small businesses to the supply of PPP funds. These results further suggest that PPP might have been crucial in allowing small businesses to make scheduled payments and survive the economic crisis without permanently closing. ${ }^{20}$

\subsection{Liquidity Support and Precautionary Savings}

We additionally find that the PPP funds increased firms' cash on hand. We use the Census Small Business Pulse Survey to investigate whether access to PPP funds is associated with a greater percentage of firms reporting having greater liquidity support. Table A.16 shows regressions results examining the relation between access to PPP funds during the first round and the percentage of businesses reporting having at least two months of cash-on-hand. This exercise also offers a useful sanity check of the informativeness of the survey data. As above, these regressions include controls for pre-PPP measures of crisis severity.

Similar to results presented above, the coefficients reported in column (1) of Table 9 do

\footnotetext{
${ }^{20}$ We also show in the appendix that these results are economically and statistically similar when we use MSAlevel observations.
} 
not indicate an economically or statistically significant relation between cash-on-hand and the percentage of firms in that state and industry that reported receiving PPP. However, when we turn our attention to the relation between state PPPE, which better isolates access to the supply of PPP funds, access to PPP is economically and significantly related to the share of firms reporting significant liquidity. In the reduced form specification presented in column (2), we find that a unit increase in state PPPE is associated with a ten percentage point increase in the share of firms reporting significant liquidity. In the IV regression, which uses state PPPE to instrument for the share of firms receiving PPP, a ten percentage point increase in the share of firms receiving PPP is associated with a 2.9 percentage point increase in the share of firms reporting at least two months of cash to cover business operations. Moreover, in the appendix we report similar results when we use the share of small businesses that applied, but did not receive, PPP as our main right-hand-side variable of interest.

Overall, these results are consistent with the idea that the PPP provided firms with an important liquidity cushion that they used to navigate the turmoil of the initial months of the pandemic. Another possible interpretation, given our evidence that PPP did not induce increases in employment or declines in initial unemployment filings, is that these businesses are maintaining the loaned PPP funds in bank accounts as precautionary savings until they are ready to resume activities, perhaps as demand for their goods and services return to normal or as relaxed shelter-in-place orders permit them to reopen for business. Generally, the results are not consistent with the idea that the PPP served as a large-scale alternative to unemployment insurance for delivering funds directly to affected workers.

\section{Concluding Remarks and Next Steps}

This paper takes an early look at a large and novel small business support program that was part of the initial crisis response package, the Paycheck Protection Program (PPP). We consider two dimensions of program targeting. First, did the funds flow to where the economic shock was greatest? Second, given the PPP used the banking system as a conduit to access firms, we ask what role did the banks play in mediating policy targeting? We also explore effects on employment and other firm outcomes.

We find little evidence that funds were targeted towards geographic regions more severely affected by the pandemic. If anything, preliminary evidence indicates that the opposite is 
true and funds were targeted towards areas less severely affected by the virus. We do find that bank heterogeneity played an important role in mediating funds. We construct a new measure of geographic exposure of regions to banks that over or underperformed in terms of PPP allocation relative to their share of small business lending. States with higher exposure to banks that performed well in terms of bank PPP exposure also saw higher levels of PPP lending. ${ }^{21}$

Using a number of data sources, we do not find evidence that the PPP had a substantial effect on employment during the first round of the program. Our estimates are precise enough to rule out modest employment effects. While there appears to be little effect of the program on employment, the program may have played an important role in promoting financial stability. Firms with greater exposure to the PPP hold more cash on hand, and are more likely to make loan and other scheduled payments. Measuring these responses is critical for evaluating the social insurance value of the PPP and similar policies and designing them effectively. As data become available, we will continue to examine whether the program merely delayed firms' inability to meet commitments or whether there are other medium-term and long-term effects.

\footnotetext{
${ }^{21}$ The analysis here focuses on ex ante targeting of the PPP, that is, the distribution of funding provided at the start of the program. Ultimate targeting will depend on the extent of loan forgiveness and defaults, as well as subsequent changes to the PPP, including conditions for recoupment based on ex post economic hardship and changes to program eligibility criteria going forward. See Hanson, Stein, Sunderam and Zwick (2020) for a discussion of these dynamic policy considerations in the design of business liquidity support during the pandemic.
} 


\section{References}

Agarwal, Sumit, Gene Amromin, Itzhak Ben-David, Souphala Chomsisengphet, Tomasz Piskorski, and Amit Seru. 2017. "Policy Intervention in Debt Renegotiation: Evidence from the Home Affordable Modification Program.” Journal of Political Economy, 125(3): 654-712.

Allcott, Hunt, Levi Boxell, Jacob Conway, Matthew Gentzkow, Michael Thaler, and David Y Yang. 2020. "Polarization and Public Health: Partisan Differences in Social Distancing during the Coronavirus Pandemic." NBER Working Paper, , (w26946).

Atkeson, Andrew, Adrien d'Avernas, Andrea Eisfeldt, and Pierre-Olivier Weill. 2018. "Government Guarantees and the Valuation of American Banks." NBER Macroeconomics Annual.

Bachas, Natalie, Olivia Kim, and Constantine Yannelis. 2020. "Loan Guarantees and Credit Supply." Journal of Financial Economics.

Baker, Scott R, Nicholas Bloom, Steven J Davis, and Stephen J Terry. 2020. "Covid-Induced Economic Uncertainty." National Bureau of Economic Research.

Baker, Scott R, Robert A Farrokhnia, Steffen Meyer, Michaela Pagel, and Constantine Yannelis. 2020a. "How Does Household Spending Respond to an Epidemic? Consumption During the 2020 COVID-19 Pandemic." National Bureau of Economic Research.

Baker, Scott R, Robert A Farrokhnia, Steffen Meyer, Michaela Pagel, and Constantine Yannelis. 2020b. "Income, Liquidity, and the Consumption Response to the 2020 Economic Stimulus Payments." National Bureau of Economic Research.

Barrios, John, and Yael Hochberg. 2020. "Risk Perception Through the Lens Of Politics in the Time of the COVID-19 Pandemic." Working Paper.

Barrios, John M., Efraim Benmelech, Yael V. Hochberg, and Luigi Zingales. 2020. "Civic Capital and Social Distancing During the COVID-19 Pandemic." NBER working paper.

Barrios, John, Michael Minnis, William Minnis, and Joost Sijthoff. 2020. "Assessing the Payroll Protection Program: A Framework and Preliminary Results.” Working paper.

Barro, Robert J, José F Ursua, and Joanna Weng. 2020. "The Coronavirus and the Great Influenza Epidemic." 
Barrot, Jean-Noel, Thorsten Martin, Julien Sauvagnat, and Boris Vallee. 2019. "Employment Effects of Alleviating Financing Frictions: Worker-level Evidence from a Loan Guarantee Program." Working Paper.

Bartik, Alexander W., Marianne Bertrand, Zoe B. Cullen, Edward L. Glaeser, Michael Luca, and Christopher T. Stanton. 2020. "How Are Small Businesses Adjusting to COVID-19? Early Evidence from a Survey." Proceedings of the National Academy of Sciences.

Bartik, Alexander W., Marianne Betrand, Feng Lin, Jesse Rothstein, and Matt Unrath. 2020. "Measuring the labor market at the onset of the COVID-19 crisis." Brookings Papers on Economic Activity.

Berger, David W, Kyle F Herkenhoff, and Simon Mongey. 2020. "An SEIR Infectious Disease Model with Testing and Conditional Quarantine." National Bureau of Economic Research Working Paper 26901.

Brevoort, Kenneth P., John A. Holmes, and John D. Wolken. 2010. "Distance Still Matters: The Information Revolution in Small Business Lending and the Persistent Role of Location, 1993-2003." Board of Governors of the Federal Reserve System.

Buffington, Catherine, Carrie Dennis, Emin Dinlersoz, Lucia Foster, and Shawn Klimek. 2020. "Measuring the Effect of COVID-19 on U.S. Small Businesses: The Small Business Pulse Survey." Census for Economic Studies, working paper.

Cajner, Tomaz, Leland Crane, Ryan A. Decker, John Grigsby, Adrian Hamins-Puertolas, Erik Hurst, Christopher Kurz, and Ahu Yildirmaz. 2020. "The U.S. Labor Market During the Beginning of the Pandemic Recession." NBER working paper.

Chetty, Raj. 2008. "Moral Hazard Versus Liquidity and Optimal Unemployment Insurance." Journal of Political Economy, 116(2): 173-234.

Chetty, Raj, John N. Friedman, Nathaniel Hendren, and Michael Stepner. 2020. "How did COVID-19 and Stabilization Policies Affect Spending and Employment? A New Real-time Economic Tracker Based on Private Sector Data." NBER working paper.

Coibion, Olivier, Yuriy Gorodnichenko, and Michael Weber. 2020. "Labor Markets During the COVID-19 Crisis: A Preliminary View." Fama-Miller Working Paper.

Cororaton, Anna, and Samuel Rosen. 2020. "Public Firm Borrowers of the US Paycheck Protection Program." SSRN working paper. 
Cox, Natalie, Peter Ganong, Pascal Noel, Joseph Vavra, Arlene Wong, Diana Farrell, and Fiona Greig. 2020. "Initial Impacts of the Pandemic on Consumer Behavior: Evidence from Linked Income, Spending, and Savings Data." Brookings Papers on Economic Activity.

De Marco, Filippo. 2020. "Public Guarantees for Small Businesses in Italy during COVID-19." SSRN working paper.

Dingel, Jonathan I., and Brent Neiman. 2020. "How Many Jobs Can Be Done at Home." Journal of Public Economics.

Ding, Wenzhi, Ross Levine, Chen Lin, and Wensi Xie. 2020. "Social Distancing and Social Capital: Why U.S. Counties Respond Differently to COVID-19." NBER working paper.

Eichenbaum, Martin S, Sergio Rebelo, and Mathias Trabandt. 2020. "The Macroeconomics of Epidemics." National Bureau of Economic Research.

Elenev, Vadim, Tim Landvoigt, and Stijn Van Nieuwerburgh. 2020. "Can the Covid Bailouts Save the Economy?" National Bureau of Economic Research.

Gale, William. 1990. "Federal Lending and the Market for Credit." Journal of Public Economics, , (42): 177-93.

Gale, William. 1991. "Economic Effects of Federal Credit Programs." American Economic Review, 81(1): 133-52.

Gallipoli, Giovanni, and Christos Makridis. 2018. "Structural Transformation and the Rise of Information Technology." Journal of Monetary Economics, 97: 91-110.

Ganong, Peter, and Pascal Noel. 2018. "Liquidity vs. Wealth in Household Debt Obligations: Evidence from Housing Policy in the Great Recession." National Bureau of Economic Research.

Gonzalez-Uribe, Juanita, and Su Wang. 2019. "Dissecting the Effect of Financial Constraints on Small Firms." Working Paper.

Gormsen, Niels Joachim, and Ralph SJ Koijen. 2020. "Coronavirus: Impact on Stock Prices and Growth Expectations." University of Chicago, Becker Friedman Institute for Economics Working Paper, , (2020-22).

Granja, João, Christian Leuz, and Raghuram Rajan. 2018. "Going the Extra Mile: Distant Lending and Credit Cycles." National Bureau of Economic Research. 
Guerrieri, Veronica, Guido Lorenzoni, Ludwig Straub, and Ivan Werning. 2020. "Macroeconomic Implications of COVID-19: Can Negative Supply Shocks Cause Demand Shortages." Working paper.

Hanson, Samuel, Jeremy Stein, Adi Sunderam, and Eric Zwick. 2020. "Business Continuity Insurance and Business Continuity Loans: Keeping America's Lights on During the Pandemic." Policy Brief.

Holmstrom, Bengt, and Jean Tirole. 1998. "Private and Public Supply of Liquidity." Journal of Political Economy, 106(1): 1-40.

House, Christopher, and Matthew Shapiro. 2008. “Temporary Investment Tax Incentives: Theory with Evidence from Bonus Depreciation." American Economic Review, 98(3): 737768.

Humphries, John Eric, Christopher Neilson, and Gabriel Ulyssea. 2020. "Information Frictions and Access to the Paycheck Protection Program."

Jones, Callum, Thomas Philippon, and Venky Venkateswaran. 2020. "Optimal Mitigation Policies in a Pandemic." Working Paper.

Kaplan, Greg, and Gianluca Violante. 2014. "A Model of the Consumption Response to Fiscal Stimulus Payments." Econometrica, 82(4): 1199-1239.

Kelly, Bryan, Hanno Lustig, and Stijn Van Nieuwerburgh. 2016. "Too-Systemic-to-Fail: What Option Markets Imply about Sector-Wide Government Guarantees." American Economic Review, 106(6): 1278-1319.

Lelarge, Clair, David Sraer, and David Thesmar. 2010. "Entrepreneurship and Credit Constraints: Evidence From a French Loan Guarantee Program.” International Differences in Entrepreneurship, 243-273.

Lucas, Deborah. 2016. "Credit Policy as Fiscal Policy." Brookings Papers on Economic Activity, , (Spring): 1-57.

Makridis, Christos A., and Cary Wu. 2020. "Ties that Bind (and Social Distance): How Social Capital Helps Communities Weather the COVID-19 Pandemic." SSRN working paper.

Makridis, Christos A., and Jonathan Hartley. 2020. "The Cost of COVID-19: A Rough Estimate of the 2020 GDP Impact." Mercatus Center, Policy Brief Special Edition. 
Makridis, Christos A., and Jonathan Rothwell. 2020. "The Real Cost of Political Polarization: Evidence from the COVID-19 Pandemic." SSRN working paper.

Mian, Atif, and Amir Sufi. 2012. "The Effects of Fiscal Stimulus: Evidence from the 2009 Cash for Clunkers Program." Quarterly Journal of Economics, 127: 1107-1142.

Mulligan, Casey B. 2020. "Economic Activity and the Value of Medical Innovation During a Pandemic." NBER Working paper.

Mullins, William, and Patricio Toro. 2017. "Credit Guarantees and New Bank Relationships." Policy Research Working Paper No, 8241.

Papanikolaou, Dimitris, and Lawrence D. W. Schmidt. 2020. "Working Remotely and the Supply-side Impact of COVID-19." Working paper.

Parker, Jonathan A, Nicholas S Souleles, David S Johnson, and Robert McClelland. 2013. "Consumer Spending and the Economic Stimulus Payments of 2008." American Economic Review, 103(6): 2530-53.

Smith, Bruce. 1983. "Limited Information, Credit Rationing, and Optimal Government Lending Policy." American Economic Review, 73(3): 305-18.

Zwick, Eric. Forthcoming. "The Costs of Corporate Tax Complexity." American Economic Journal: Economic Policy.

Zwick, Eric, and James Mahon. 2017. "Tax Policy and Heterogeneous Investment Behavior." American Economic Review, 107(1): 217-248. 


\section{Figure 1: Histogram of Bank Paycheck Protection Program Exposure (PPPE)}

Panel A of Figure 1 plots the distribution of the measure of relative bank performance in the PPP based on the volume of PPP loans granted and stock of small business loans at the bank as of fourth quarter of 2019. We compute this measure as: $P P P E_{b}=\frac{\text { ShareVol.PPP-ShareSBLMarket }}{(\text { ShareVol PPP+ShareSBLMarket }) \times 0.5}$. Panel B of Figure 1 plots the distribution of the measure of relative bank performance in the PPP based on the number of PPP loans granted and number of small business loans held by the bank as of fourth quarter of 2019 . We compute this measure as: $P P P E_{b}=$ $\frac{\text { ShareNbr.PPP-ShareNbr.SBLMarket }}{\text { ShareNbr.PPP+ShareNbr.SBLMarket }) \times 0.5}$. Data is obtained from the SBA and call reports.

Panel A: Histogram of Volume-based PPPE

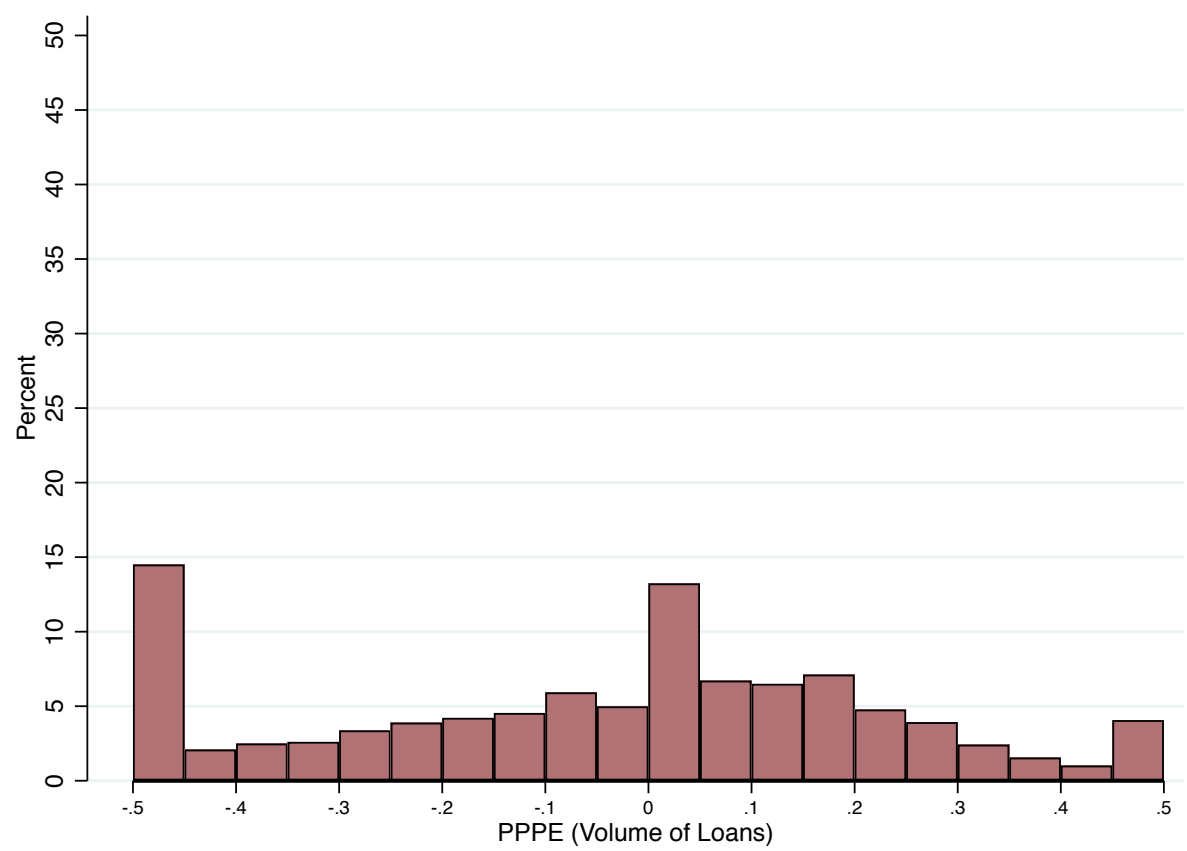

Panel B: Histogram of Number Loans-based PPPE

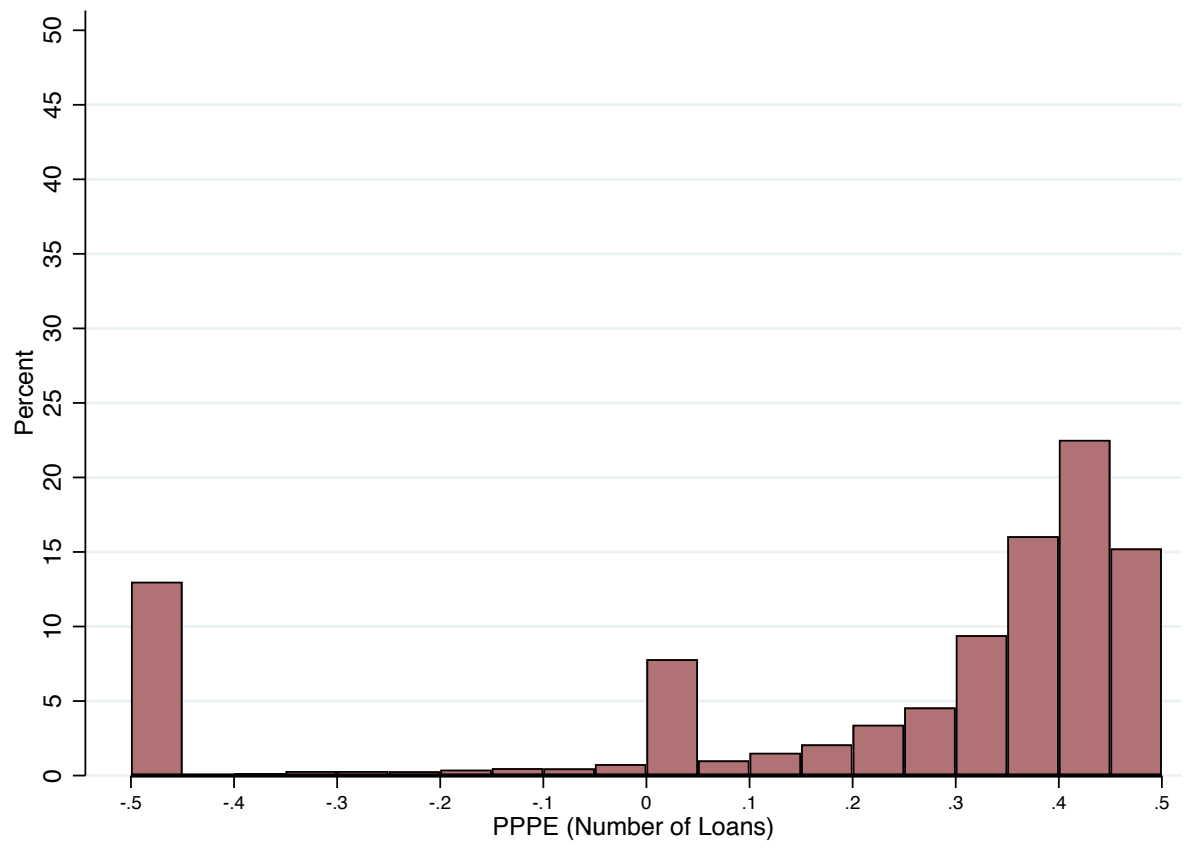




\section{Figure 2: PPPE and Commercial Bank Size}

Figure 2 plots average PPPE based on volume of PPP loans (Panel A) number of PPP loans (Panel B) and average amount of PPP loan (Panel C) in each percentile size bin. The size bins stratify all commercial banks operating as of the fourth quarter of 2019 based on their total assets. Data is obtained from the SBA and call reports.

Panel A: Volume-based PPPE and Size

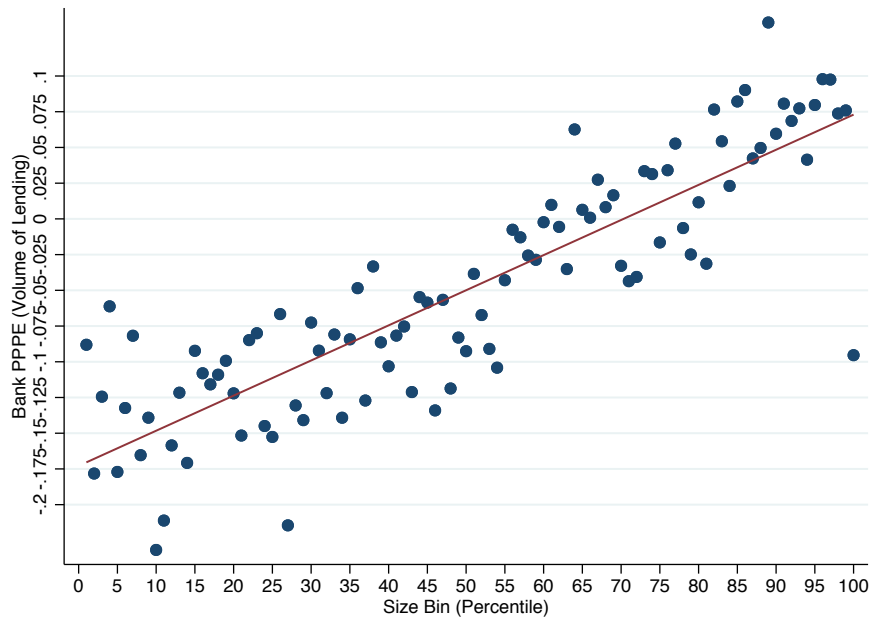

Panel B: Number of Loans-based PPPE and Size

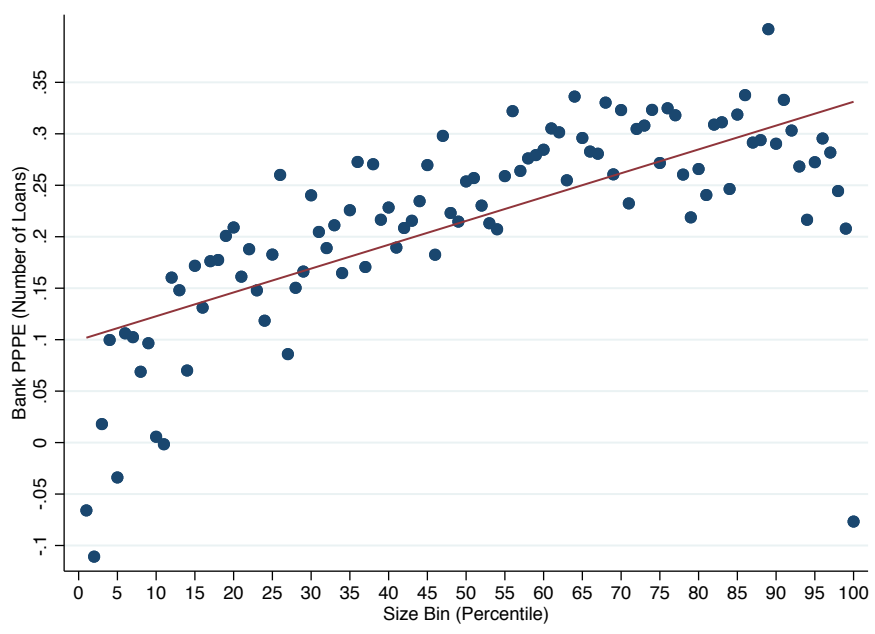

Panel C: Average Amount of Loan and Size

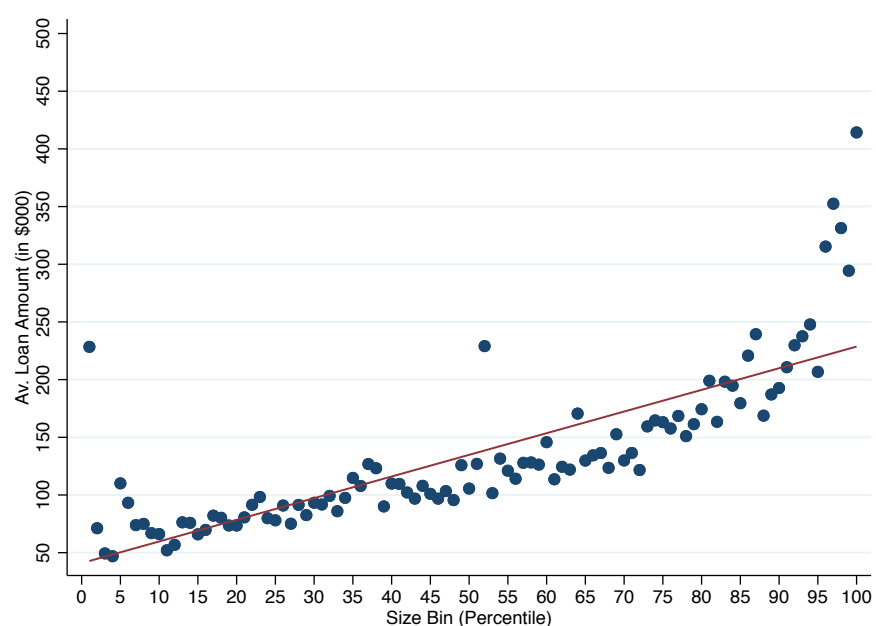


Figure 3: PPPE and PPP Allocation

Figure 3 plots the cumulative share of PPP and SBL lending by all banks whose PPPE is below $x$, where $x \in(-0.5,0.5)$. Data is obtained from the SBA and call reports.

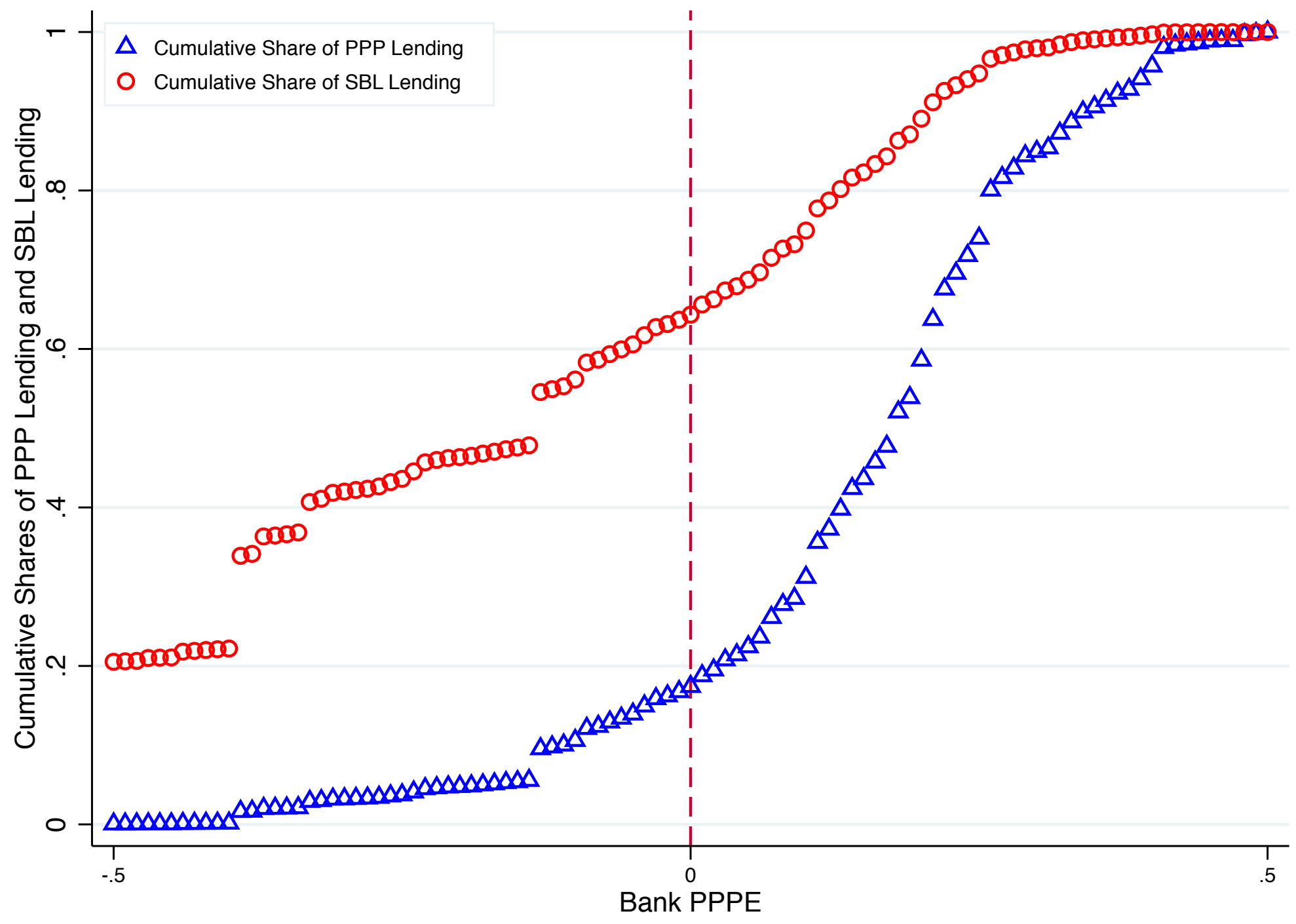


Figure 4: Map of County Exposure to PPPE

Figure 4 plots the average exposure of each county to the volume-based PPPE. County exposure to PPPE is computed as the average of the PPPE of each bank with a branch presence in the county. The PPPE of each bank is weighted by the share of deposits of the bank in the county as of June 30th, 2019. Data is from the SBA, Call Reports, and FDIC's Summary of Deposits.

\section{All U.S. Counties}

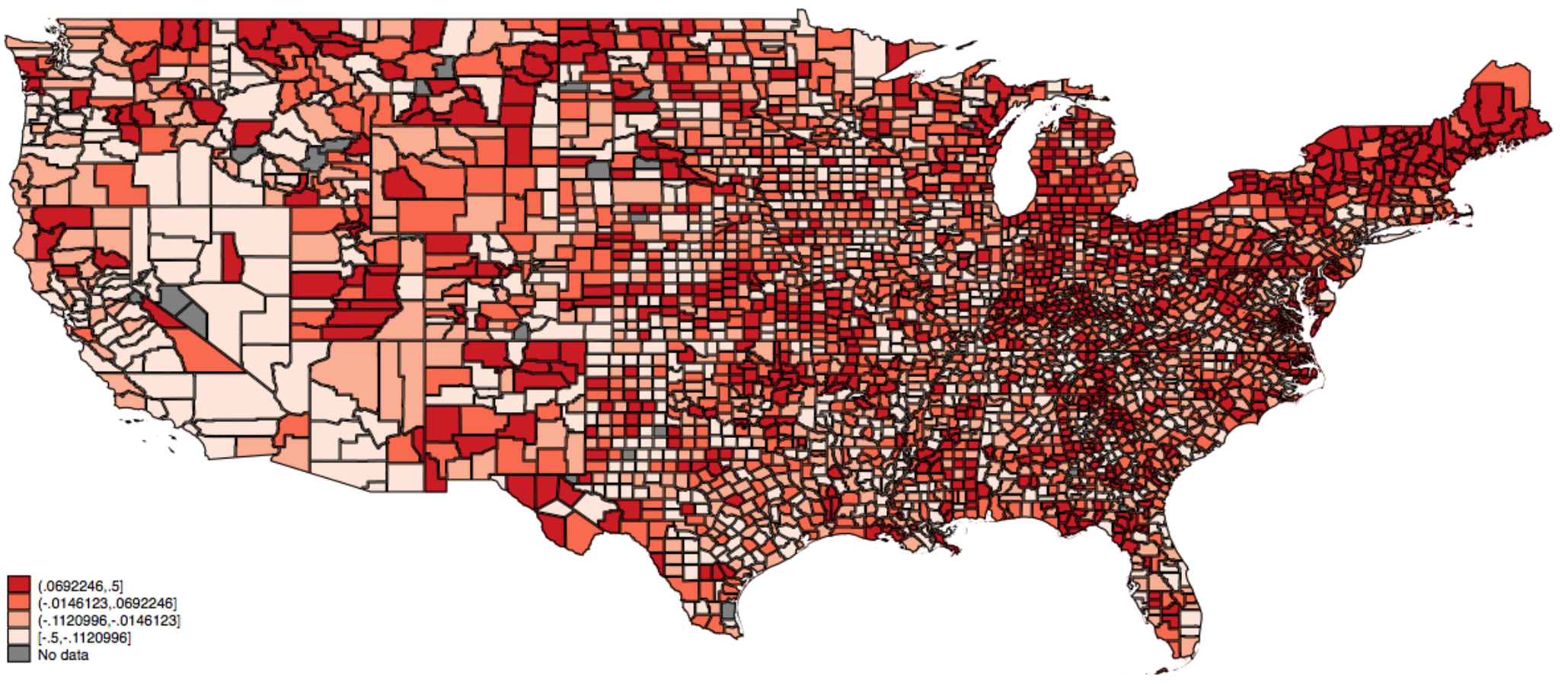




\section{Figure 5: State Exposure to PPPE and PPP per Establishment}

Figure 5 are scatterplots of the total PPP allocation per small business establishment in the state and the state exposure to the volume-based PPPE (Panel A) and fraction of small business establishments receiving a PPP loan and the state exposure to the PPPE based on the number of loans (Panel B). Data comes from SBA, Call Reports, Summary of Deposits, and County Business Patterns.

Panel A: State Exposure to Volume-Based PPPE and PPP Allocation per Small Business

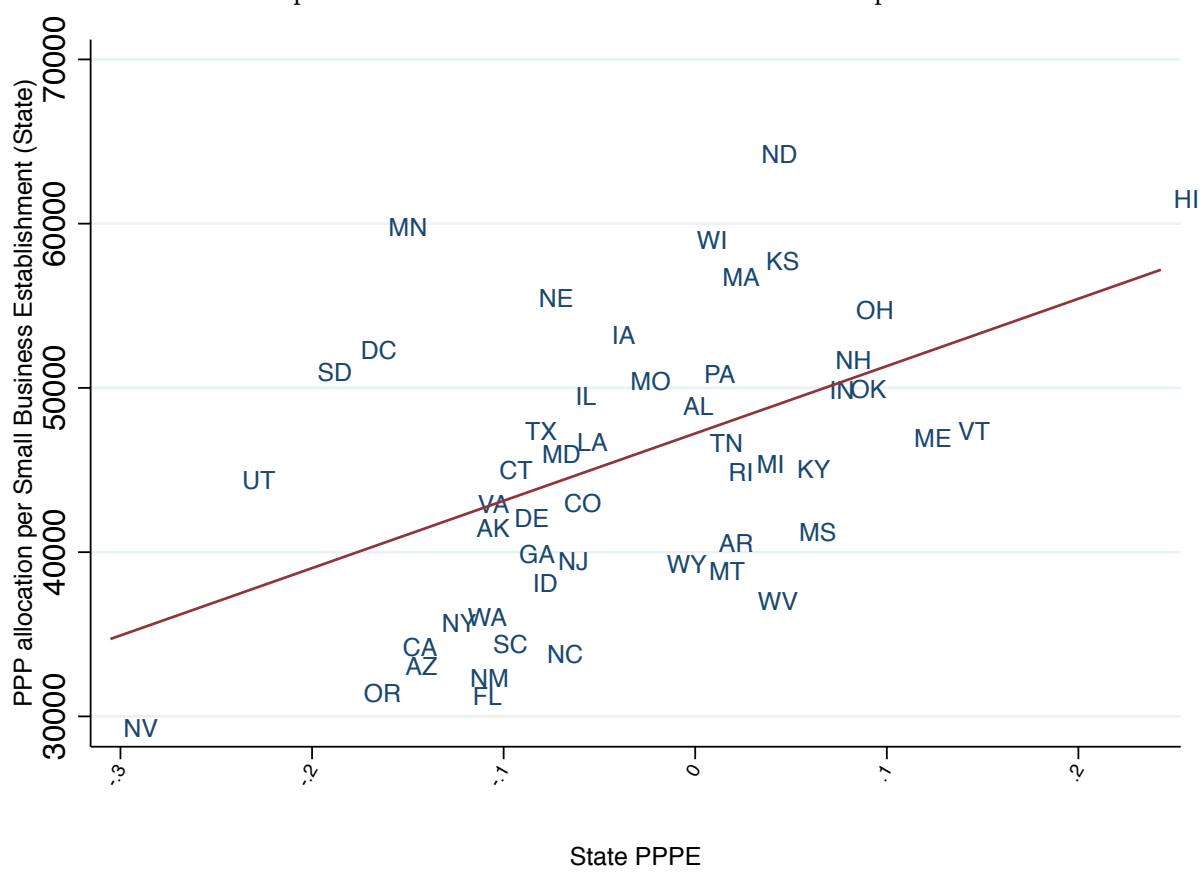

Panel B: State Exposure to Number-Based PPPE and Fraction of Small Businesses receiving PPP

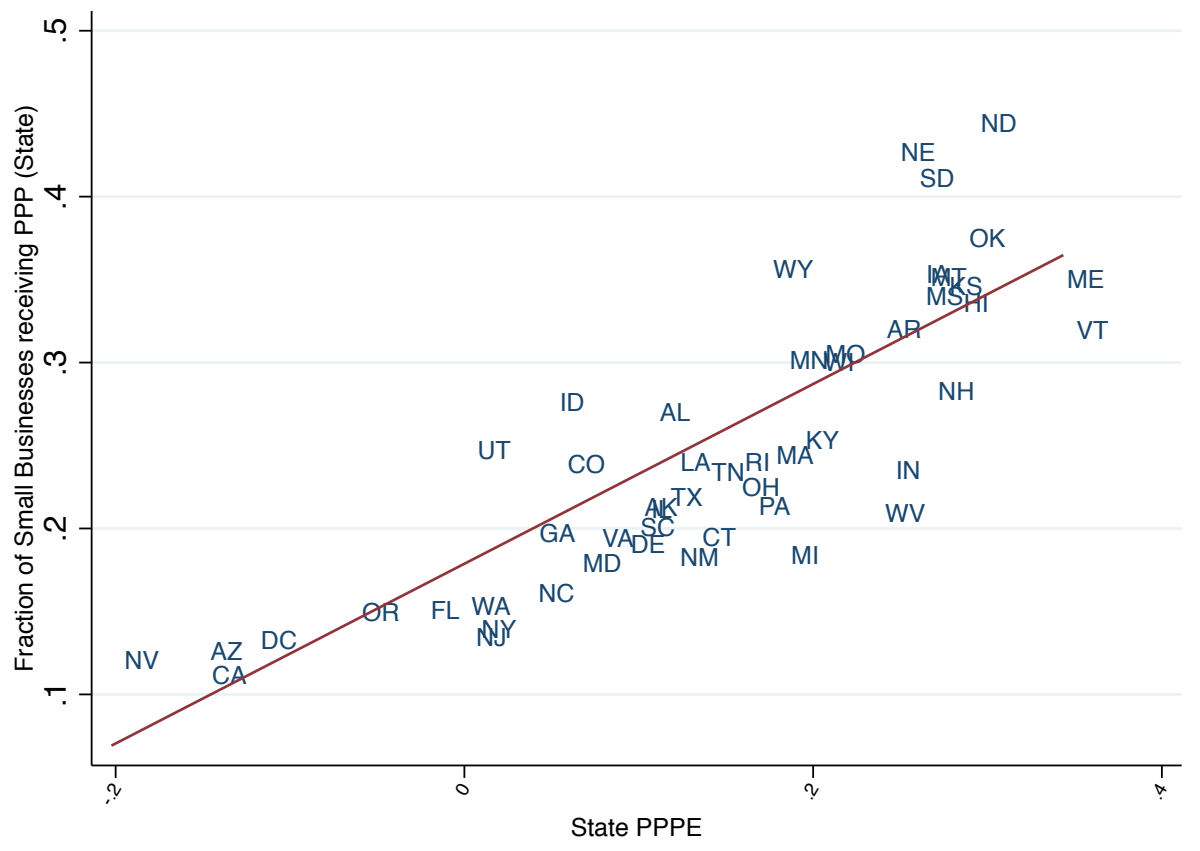




\section{Figure 6: State Exposure to PPPE and Unmet PPP Demand}

Figure 5 are scatterplots of the state exposure to the volume-based PPPE and the difference between percentage of businesses reporting having applied to PPP and percentage of business that received PPP in each state (Panel A) and the state exposure to the PPPE based on the number of loans and the difference between percentage of businesses reporting having applied to PPP and percentage of business that received PPP in each state (Panel B). Data comes from the Census Bureau, SBA, Call Reports, Summary of Deposits, and County Business Patterns.

Panel A: State Exposure to Volume-Based PPPE and Difference between \% Businesses Applying and Receiving PPP

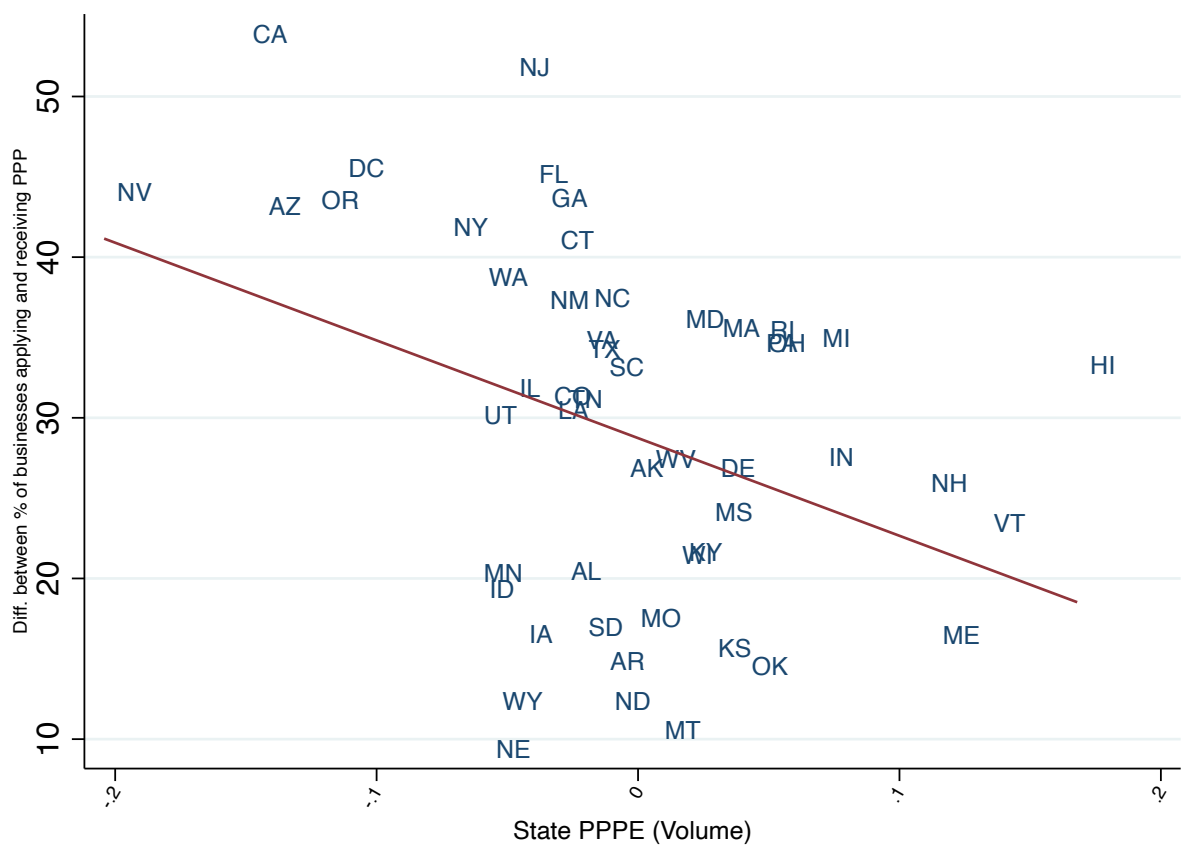

Panel B: State Exposure to Numer-Based PPPE and Difference between \% Businesses Applying and Receiving PPP

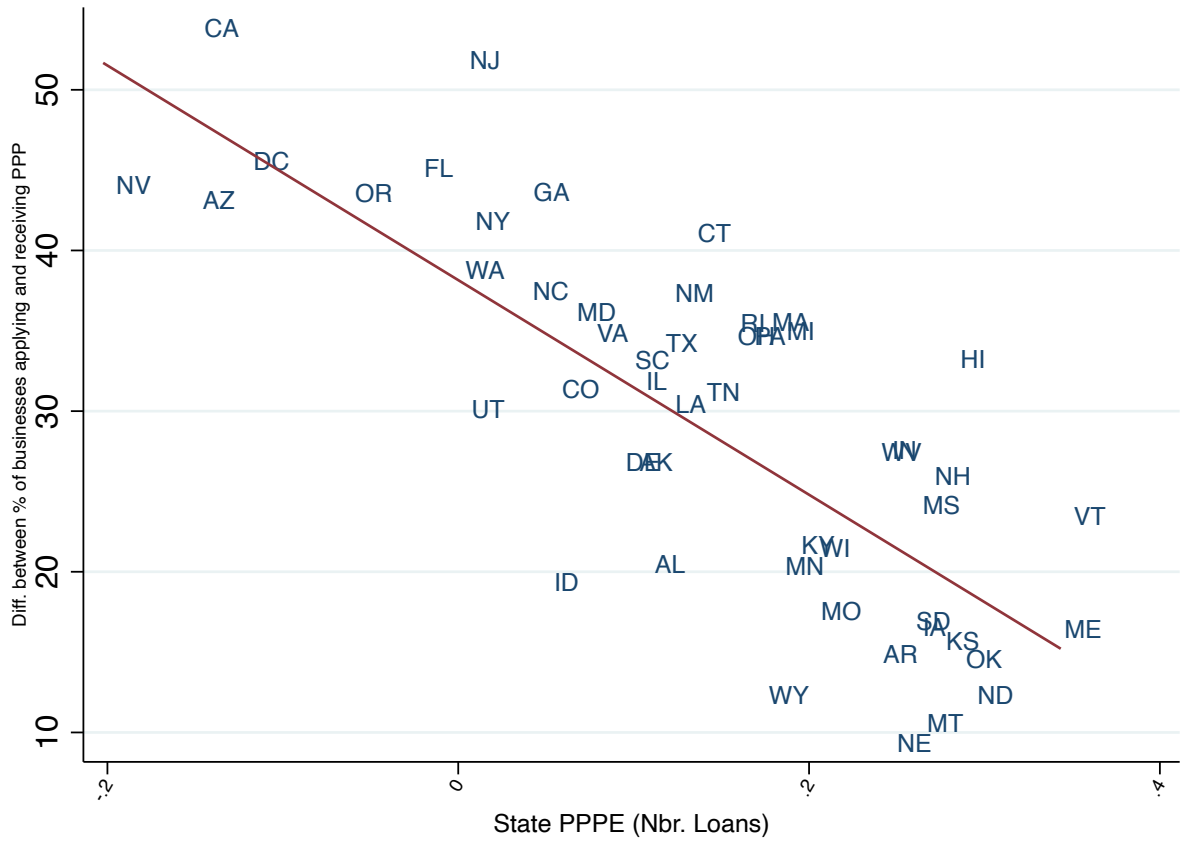




\section{Figure 7: Congressional District Exposure to PPPE and PPP per Establishment}

Figure 7 are scatterplots of the total PPP allocation per establishment in the congressional district and the congressional district exposure to the volume-based PPPE (Panel A) and fraction of establishments receiving a PPP loan and the congressional district exposure to the PPPE based on the number of loans (Panel B). Data comes from the SBA, Call Reports, Summary of Deposits, and County Business Patterns.

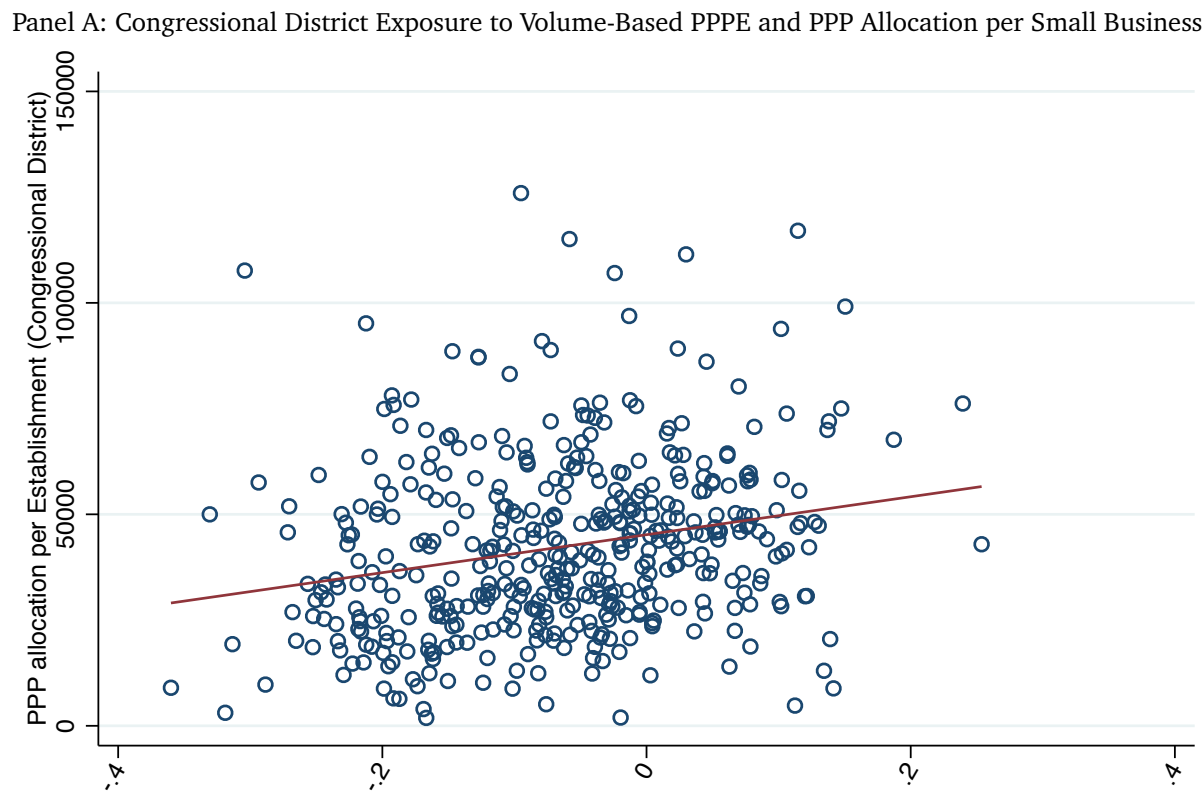

Congressional District PPPE

Panel B: Congressional District Exposure to Number-Based PPPE and Fraction of Small Businesses receiving PPP

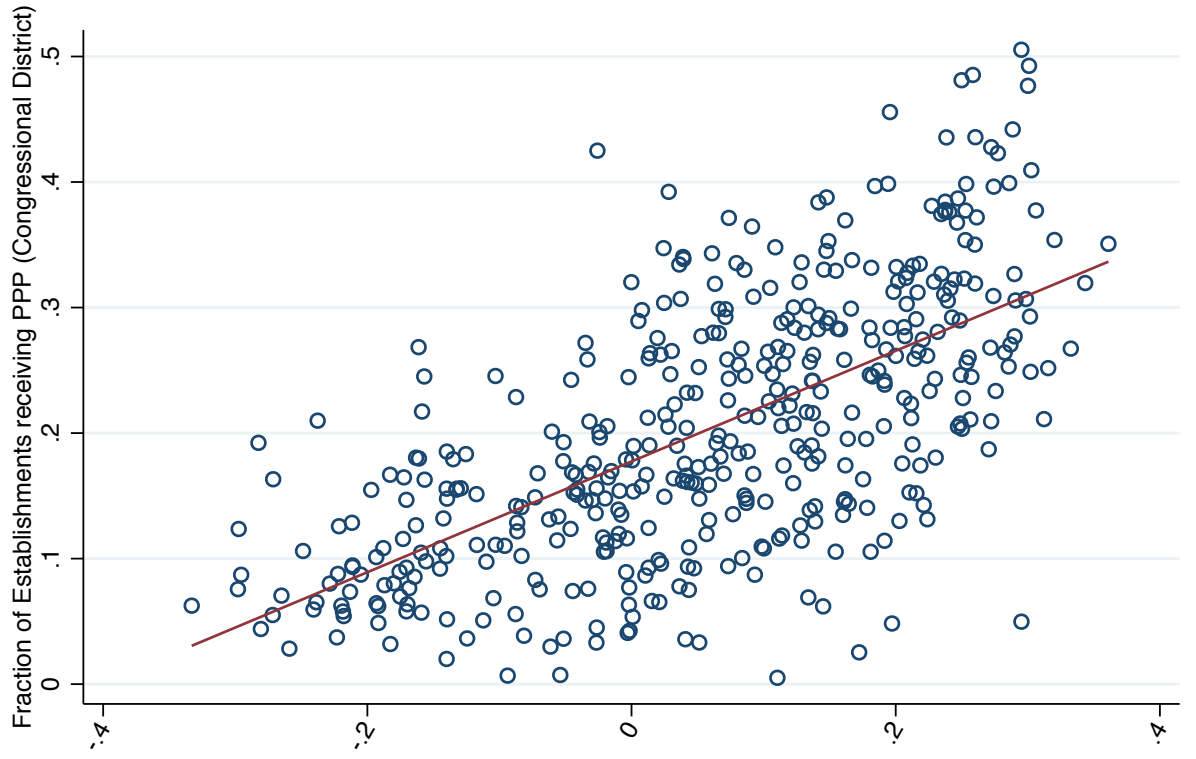

Congressional District PPPE 
Figure 8: Business Shutdowns and PPP Allocation by Congressional District

Figure 8 presents four scatterplots of the share of businesses in each state that shutdown that in the week of March 29th-April 4th and four alternative measures of allocation of PPP funds across states. The figure on the top left plots the amount of PPP loans received by small businesses in each state divided by the total number of small businesses in the state. The figure on the top right corner plots the fraction of small businesses in each state that received a PPP loan. The figure on the bottom left corner plots the fraction of small businesses in each state that received a PPP loan and the state exposure to the PPPE measured in terms of the total volume of loans. The figure on the bottom right corner plots the fraction of small businesses in each state that received a PPP loan and the state exposure to the PPPE measured in terms of the total number of loans.
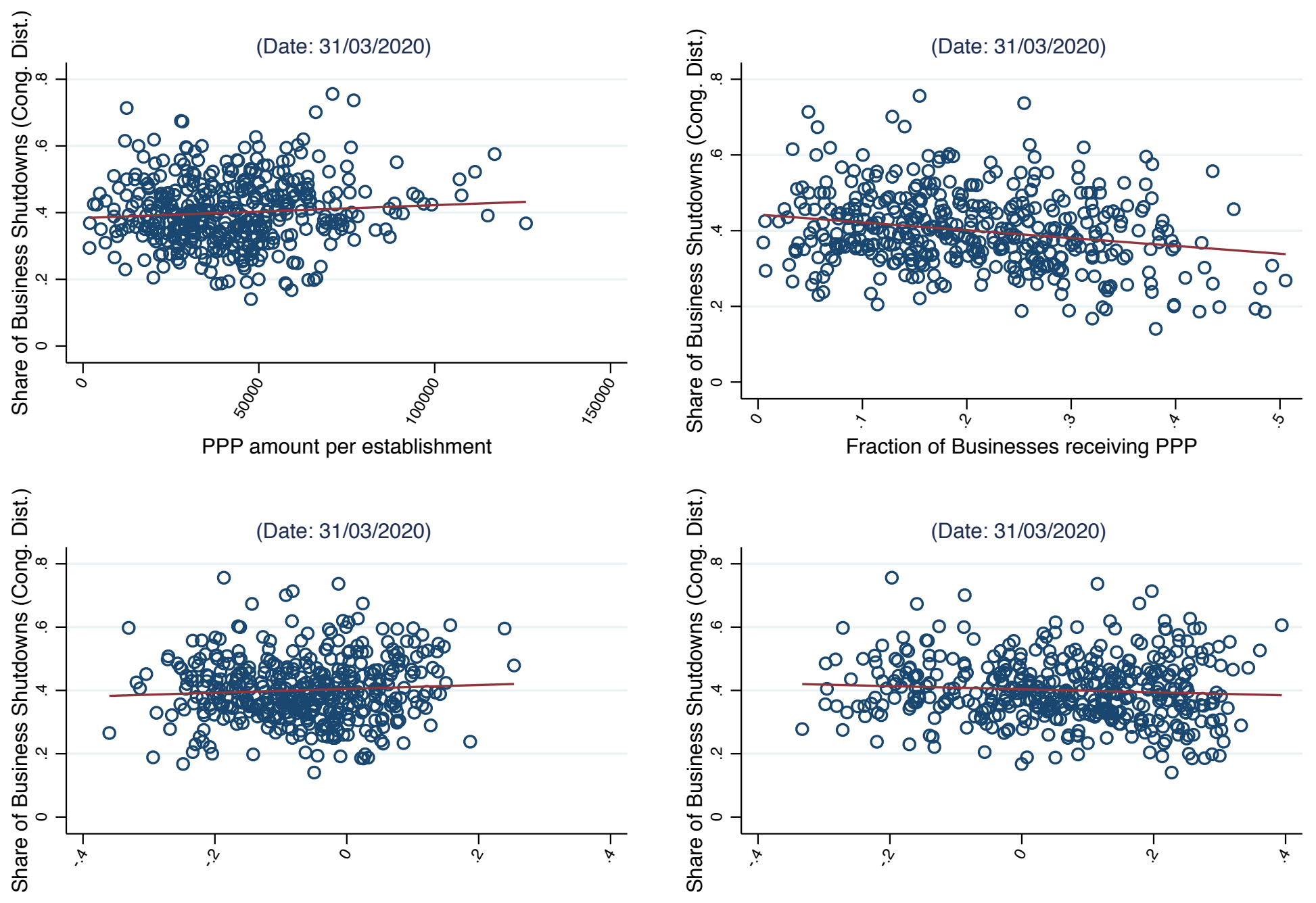

Congressional District PPPE (Volume)

Congressional District PPPE (Nbr. Loans) 
Figure 9: Decline in Hours Worked and PPP Allocation by Congressional District

Figure 9 presents four scatterplots of the decline in hours worked in each congressional district relative to a January baseline and four alternative measures of allocation of PPP funds across states. The figure on the top left plots the amount of PPP loans received by small businesses in each state divided by the total number of small businesses in the state. The figure on the top right corner plots the fraction of small businesses in each state that received a PPP loan. The figure on the bottom left corner plots the fraction of small businesses in each state that received a PPP loan and the state exposure to the PPPE measured in terms of the total volume of loans. The figure on the bottom right corner plots the fraction of small businesses in each state that received a PPP loan and the state exposure to the PPPE measured in terms of the total number of loans.

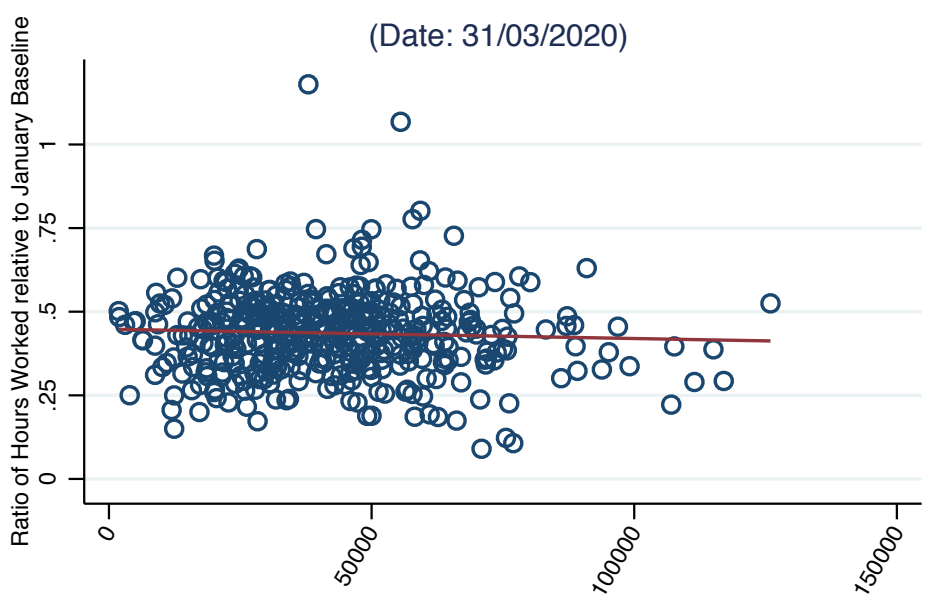

PPP amount per establishment

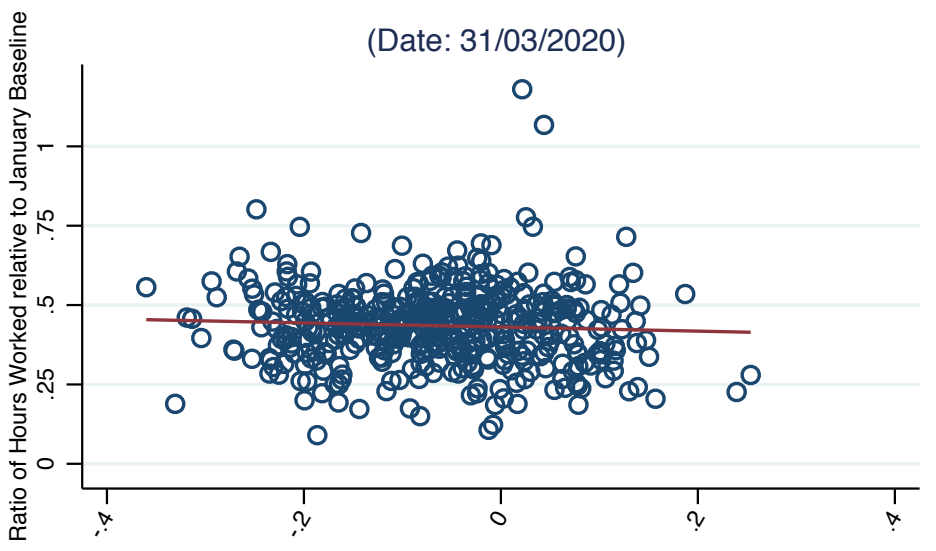

Congressional District PPPE (Volume)
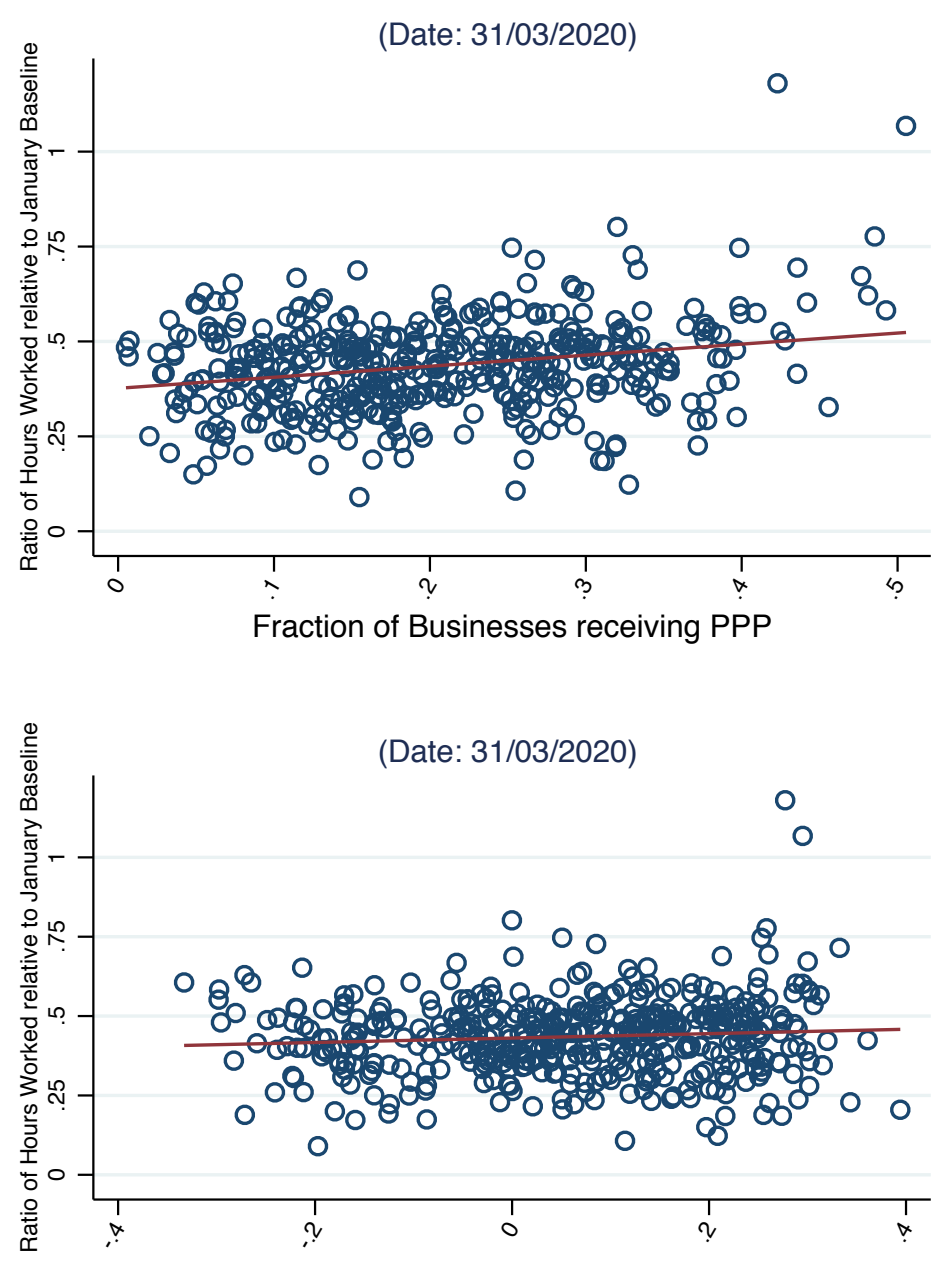

Congressional District PPPE (Nbr. Loans) 


\section{Figure 10: PPP Allocation by Employment Shock Bin}

Figure 10 stratifies congressional districts on 20 bins based on the share of Homebase businesses that shutdown in the week of March29thApril 4th (Panel A) and on their decline in hours worked relative to a January baseline. The y-axis represents the fraction of businesses receiving PPP funds in each bin computed as total number of PPP loans in that bin divided by total number of establishments of congressional districts in that bin. Data is from SBA, Homebase, and County Business Patterns.

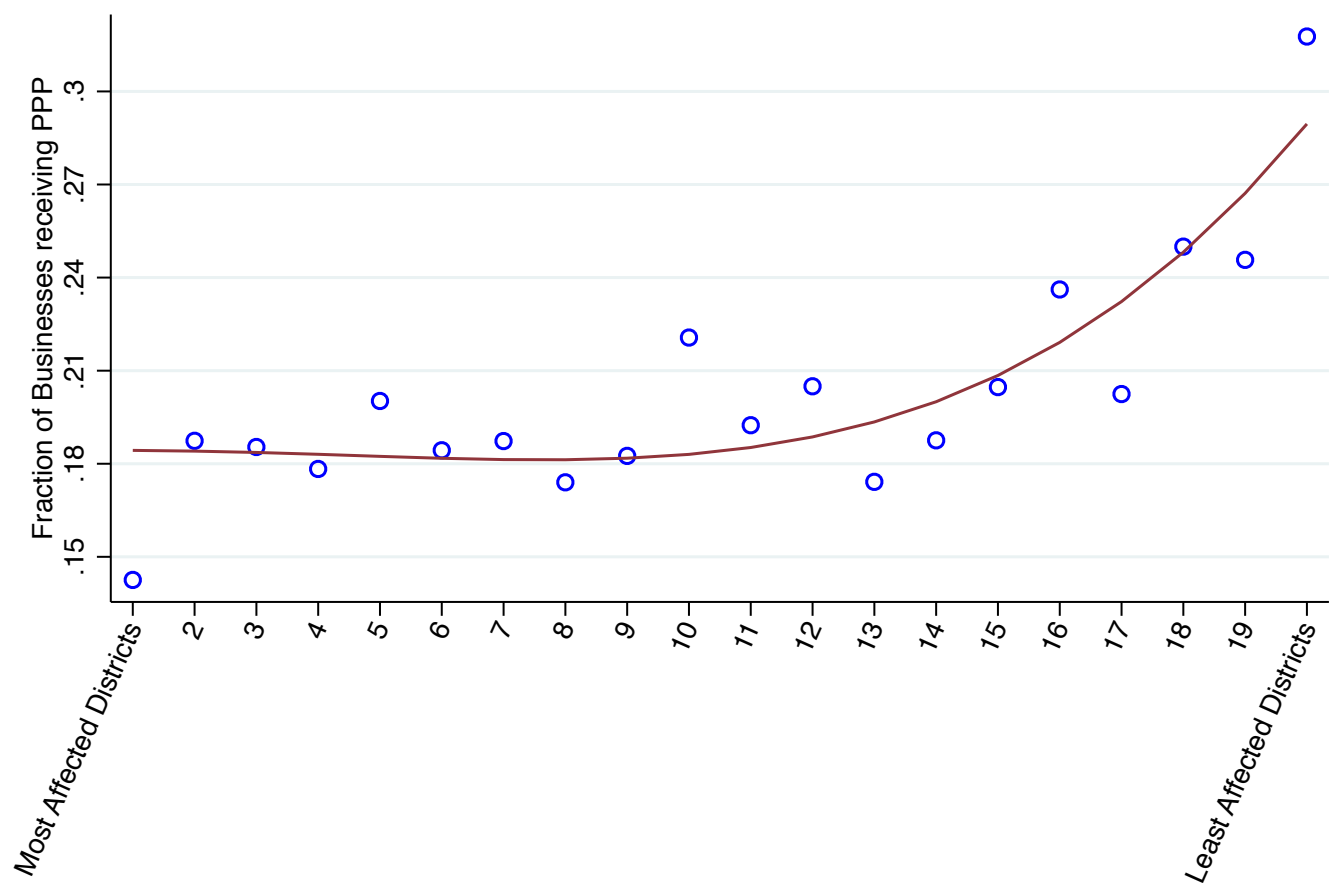

Business Shutdown Shock

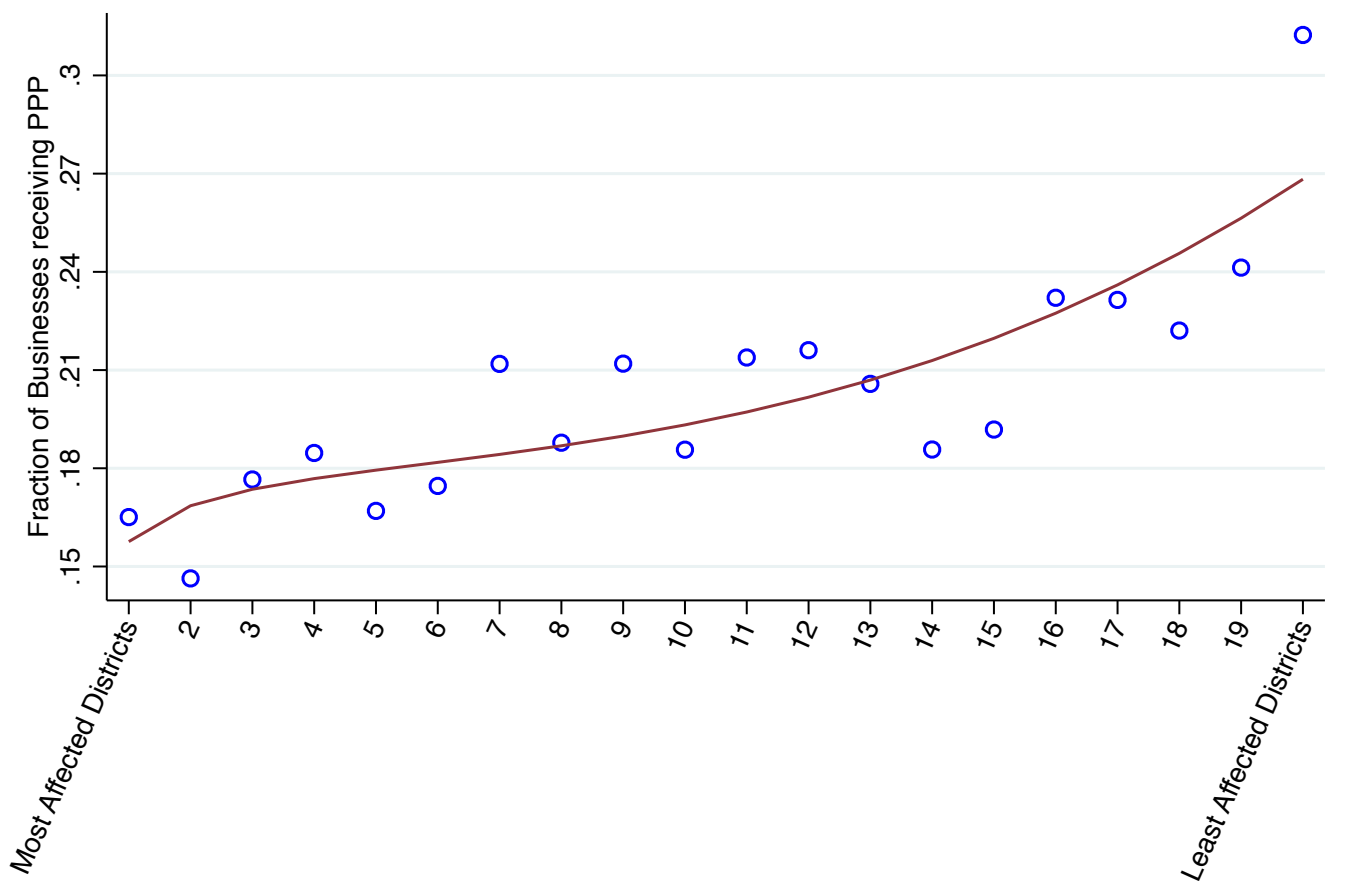

Decline in Hours Worked Shock 


\section{Figure 11: PPPE and Post-PPP Outcomes}

Figure 11 shows the ratio of hours worked over time, Data is from SBA, the percent of businesses shut down, initial unemployment filings and small business revenue by above and below PPPE exposure. Homebase, and County Business Patterns.
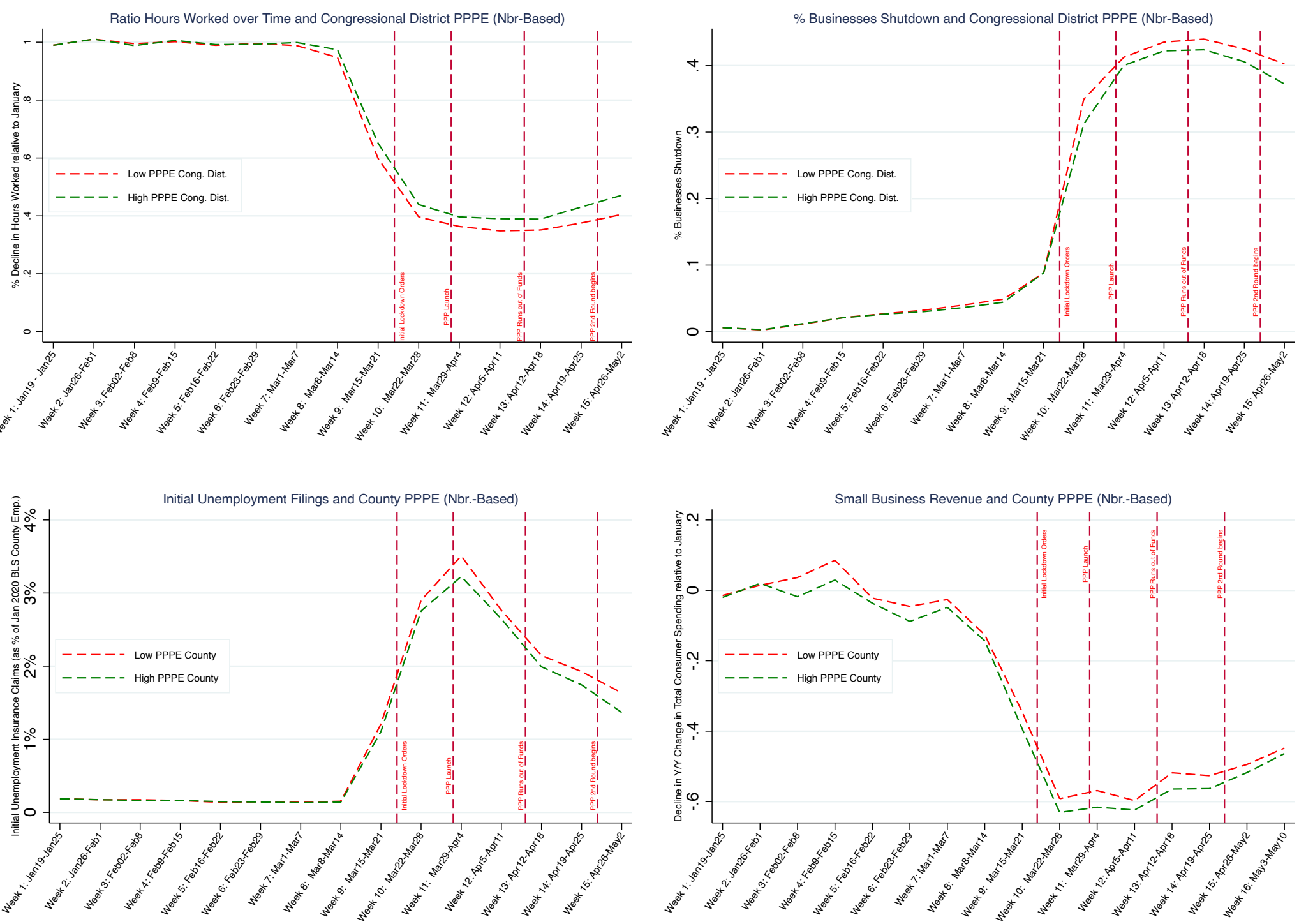
Figure 12: Weekly Elasticities of Employment and Firm Outcomes to PPPE

Figure 12 plots coefficients and respective standard errors of regression analyses investigating the week-by-week elasticities between employment and firm outcomes and exposure to PPPE. The top-left figure plots the coefficients and respective standard errors of an empirical specification that augments the specification of Panel A of Table 5 column (4) to include a full set of interactions between the Congressional District PPPE and week dummy variables. The top-left figure plots the coefficients and respective standard errors of an empirical specification that augments the specification of Panel B of Table 5 column (4) to include a full set of interactions between the Congressional District PPPE and week dummy variables. The bottom-left figure plots the coefficients and respective standard errors of an empirical specification that augments the specification of Table 6 column (4) to include a full set of interactions between the County PPPE and week dummy variables. The bottom-right figure plots the coefficients and respective standard errors of an empirical specification that augments the specification of Table 7 column (4) to include a full set of interactions between the County PPPE and week dummy variables.
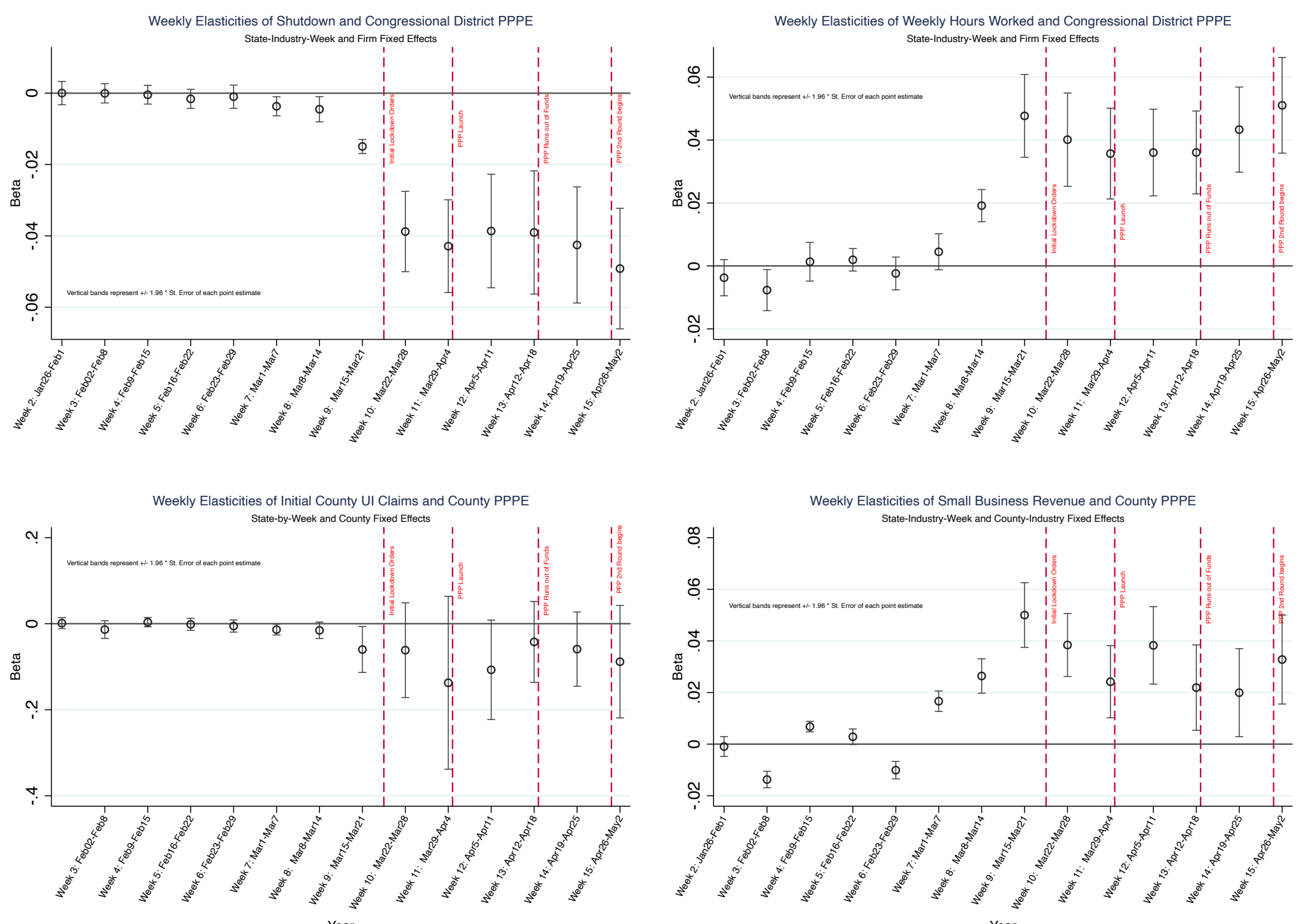


\section{Figure 13: \% Receiving PPP and State Exposure to PPPE (Industry $\times$ State Level)}

Figure 13 are scatterplots of the state exposure to the number-based PPPE and the percentage of businesses reporting receiving PPP at the state-by-industry level. The plots represent the evolution of the two variables for each survey week. Data comes from the Census Bureau, SBA, Call Reports, Summary of Deposits, and County Business Patterns.
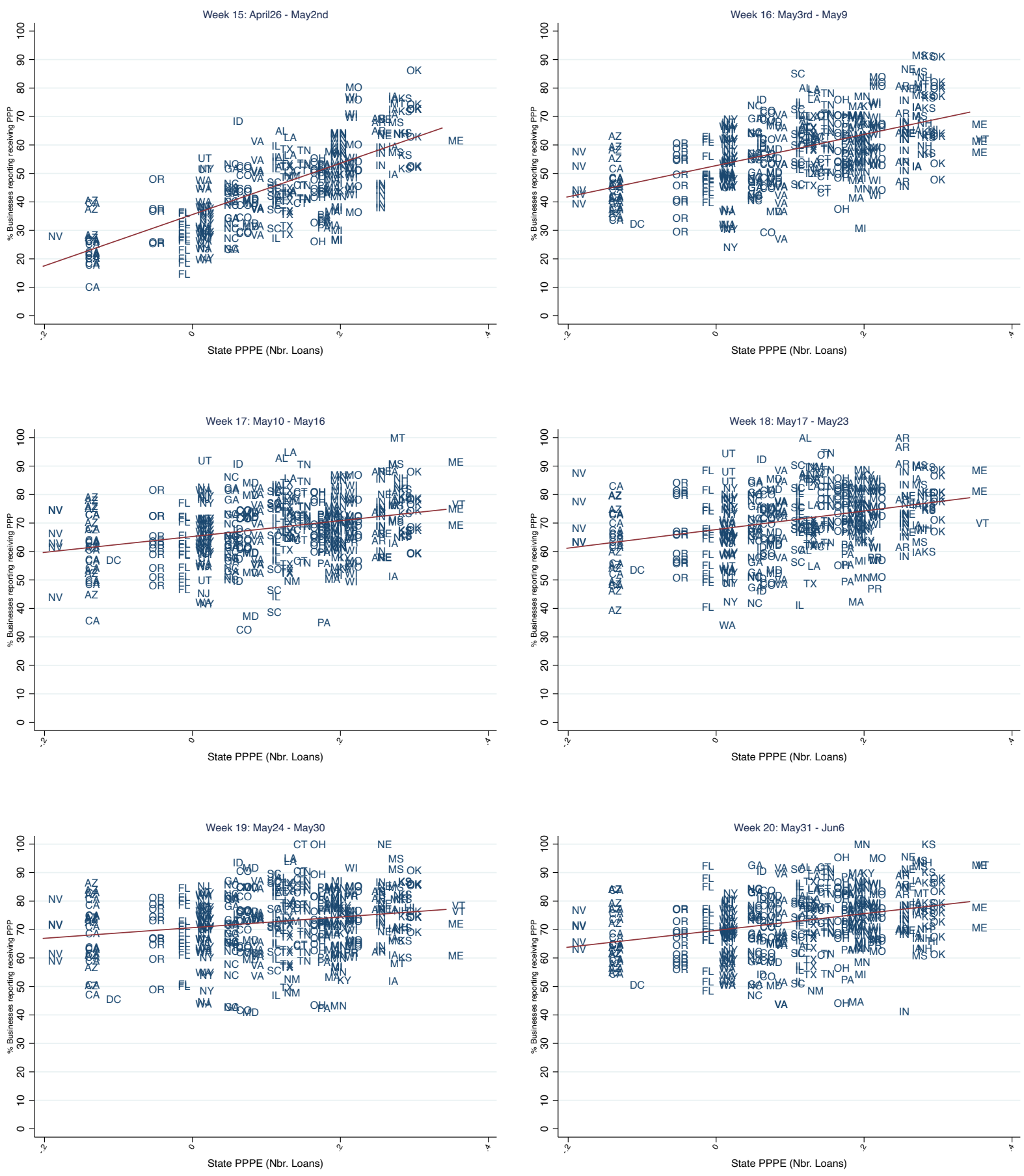


\section{Table 1: Top 20 Banks by Total Assets and PPPE}

Table 1 reports individual bank statistics and the PPPE index for the 20 largest financial institutions in the United States. Total Assets is computed using information from fourth quarter 2019 call reports. Share of total vol. PPP program is the total amount disbursed by each financial institution relative to the total amount disbursed under the first wave of the PPP. Share of SBL market is the share of the total outstanding amount of small business loans held by each financial institution relative to the total outstanding amount of small business loans as of 2019:Q4. PPPE (volume) is the volume-based bank PPP index. Total assets are in \$ millions. Share of loans in PPP program is the total number of loans processed by each financial institution relative to the total number of loans processed in the first wave of the PPP. Share of loans in SBL market is the share of the total number of outstanding small business loans held by each financial institution relative to the total outstanding number of small business loans as of 2019:Q4. PPPE (Nbr. Loans) is the number-based bank PPP index.

\begin{tabular}{|c|c|c|c|c|c|c|c|}
\hline Financial Institution Name & $\begin{array}{c}(1) \\
\text { Total } \\
\text { Assets }\end{array}$ & $\begin{array}{c}\text { (2) } \\
\text { Share } \\
\text { of total } \\
\text { vol. } \\
\text { PPP }\end{array}$ & $\begin{array}{c}\text { (3) } \\
\text { Share } \\
\text { of SBL } \\
\text { Market }\end{array}$ & $\begin{array}{c}\text { (4) } \\
\text { PPPE } \\
\text { (vol.) }\end{array}$ & $\begin{array}{c}\text { (5) } \\
\text { Share } \\
\text { of loans } \\
\text { in PPP }\end{array}$ & $\begin{array}{l}\text { (6) } \\
\text { Share } \\
\text { of loans } \\
\text { in SBL } \\
\text { Market }\end{array}$ & $\begin{array}{c}\text { (7) } \\
\text { PPPE } \\
\text { (Nbr. } \\
\text { Loans) }\end{array}$ \\
\hline JPMORGAN CHASE BANK, NATIONAL ASSOCIATION & $2,337,707$ & $3.892 \%$ & $6.547 \%$ & -0.127 & $1.432 \%$ & $10.47 \%$ & -0.380 \\
\hline BANK OF AMERICA, NATIONAL ASSOCIATION & $1,866,841$ & $1.199 \%$ & $9.510 \%$ & -0.388 & $.5565 \%$ & $11.86 \%$ & -0.455 \\
\hline WELLS FARGO BANK, NATIONAL ASSOCIATION & $1,736,928$ & $.0362 \%$ & $6.502 \%$ & -0.494 & $.0664 \%$ & $4.308 \%$ & -0.485 \\
\hline CITIBANK, N.A. & $1,453,998$ & $.3348 \%$ & $2.121 \%$ & -0.364 & $.4431 \%$ & $9.729 \%$ & -0.456 \\
\hline U.S. BANK NATIONAL ASSOCIATION & 486,004 & $.6953 \%$ & $3.327 \%$ & -0.327 & $1.120 \%$ & $5.643 \%$ & -0.334 \\
\hline TRUIST BANK & 461,256 & $3.160 \%$ & $2.011 \%$ & 0.111 & $2.078 \%$ & $1.732 \%$ & 0.045 \\
\hline CAPITAL ONE, NATIONAL ASSOCIATION & 453,626 & $.0212 \%$ & $2.822 \%$ & -0.493 & $.0134 \%$ & $10.38 \%$ & -0.499 \\
\hline PNC BANK, NATIONAL ASSOCIATION & 397,703 & $2.765 \%$ & $1.124 \%$ & 0.211 & $1.235 \%$ & $1.373 \%$ & -0.027 \\
\hline BANK OF NEW YORK MELLON, THE & 342,225 & $0 \%$ & $.0024 \%$ & -0.500 & $0 \%$ & $.0001 \%$ & -0.500 \\
\hline TD BANK, N.A. & 338,272 & $1.837 \%$ & $.6876 \%$ & 0.228 & $1.698 \%$ & $.5698 \%$ & 0.249 \\
\hline STATE STREET BANK AND TRUST COMPANY & 242,148 & $0 \%$ & $0 \%$ & 0.000 & $0 \%$ & $4.493 \%$ & -0.500 \\
\hline CHARLES SCHWAB BANK & 236,995 & $0 \%$ & $.0745 \%$ & -0.500 & $0 \%$ & $.0039 \%$ & -0.500 \\
\hline MORGAN STANLEY BANK, N.A. & 229,681 & $0 \%$ & $.1445 \%$ & -0.500 & $0 \%$ & $.0089 \%$ & -0.500 \\
\hline GOLDMAN SACHS BANK USA & 228,836 & $0 \%$ & $.0032 \%$ & -0.500 & $0 \%$ & $.0001 \%$ & -0.500 \\
\hline HSBC BANK USA, NATIONAL ASSOCIATION & 172,888 & $.1411 \%$ & $.0845 \%$ & 0.125 & $.0697 \%$ & $.0140 \%$ & 0.332 \\
\hline FIFTH THIRD BANK, NATIONAL ASSOCIATION & 167,845 & $.9991 \%$ & $.4589 \%$ & 0.185 & $.5948 \%$ & $.1920 \%$ & 0.256 \\
\hline ALLY BANK & 167,492 & $.2639 \%$ & $2.118 \%$ & -0.389 & $.0631 \%$ & $1.382 \%$ & -0.456 \\
\hline CITIZENS BANK, NATIONAL ASSOCIATION & 165,742 & $1.072 \%$ & $.8077 \%$ & 0.070 & $1.148 \%$ & $.5274 \%$ & 0.185 \\
\hline KEYBANK NATIONAL ASSOCIATION & 143,390 & $2.370 \%$ & $.7295 \%$ & 0.265 & $2.236 \%$ & $.2743 \%$ & 0.391 \\
\hline BMO HARRIS BANK NATIONAL ASSOCIATION & 137,588 & $1.385 \%$ & $1.959 \%$ & -0.086 & $.7133 \%$ & $.5413 \%$ & 0.069 \\
\hline ALL OTHER BANKS & $6,889,908$ & $79.82 \%$ & $58.96 \%$ & -0.048 & $86.52 \%$ & $40.97 \%$ & 0.218 \\
\hline
\end{tabular}




\section{Table 2: PPPE and PPP Allocation}

Table 2 reports the results of ordinary least squares (OLS) regressions examining the impact of the congressional district exposure to PPPE on the cross-sectional allocation of PPP funds to congressional districts. The dependent variable of the specifications, Ln(Total PPP Allocation per establishment), is the natural logarithm total amount of PPP funds disbursed to small businesses in each congressional district divided by the number of establishments in the congressional district. The dependent variable of the specifications in Panel B, Fraction of Establishments receiving $P P P$ is the total number of $P P P$ loans made to small businesses in each congressional district divided by the number of establishments in the congressional district. Cong. Dist. Exposure to PPPE ( Vol) is the congressional district average of the PPPE based on total amounts of outstanding PPP and small business loans, weighted by the share of deposits of each bank in each congressional district. Cong. Dist. Exposure to PPPE ( $\mathrm{Nbr}$.) is the congressional district average of the PPPE based on the number of outstanding loans, weighted by the share of deposits of each bank in each congressional district. Ln(Payroll) is the natural logarithm of the sum of payroll of all establishments in the congressional district. Ln(Employment) is the natural logarithm of total employment in the congressional district. Industry Shares are additional controls for the share of establishments in each two-digit NAICS code industry. The specification of column (4) includes state fixed effects. Standard errors are presented in parentheses, and are clustered at the level of the state. *****, and *, represent statistical significance at $1 \%, 5 \%$, and $10 \%$ levels, respectively.

Panel A: Total PPP Allocation per Establishment at the Congressional District

\begin{tabular}{lcccc}
\hline \hline & $(1)$ & $(2)$ & $(3)$ & $(4)$ \\
& \multicolumn{2}{c}{ Ln(Total PPP Allocation per Establishment) } \\
\hline Cong. Dist. PPPE (Vol) & $0.160^{* * *}$ & $0.174^{* * *}$ & $0.126^{* * *}$ & $0.148^{* *}$ \\
& $(0.023)$ & $(0.023)$ & $(0.038)$ & $(0.067)$ \\
Ln(Total Payroll) & & 0.290 & 0.279 & 0.191 \\
& & $(0.223)$ & $(0.233)$ & $(0.242)$ \\
Ln(Employment) & & -0.089 & -0.113 & 0.112 \\
& & $(0.397)$ & $(0.351)$ & $(0.376)$ \\
\hline Observations & 436 & 436 & 436 & 436 \\
Adjusted $R^{2}$ & 0.071 & 0.109 & 0.135 & 0.102 \\
Industry Shares & No & No & Yes & Yes \\
State Fixed Effects & No & No & No & Yes \\
\hline \hline
\end{tabular}

Panel B: Fraction of Establishment receiving PPP at the Congressional District

\begin{tabular}{|c|c|c|c|c|}
\hline & (1) & (2) & (3) & (4) \\
\hline & \multicolumn{4}{|c|}{ Fraction of Establishments receiving PPP } \\
\hline \multirow[t]{2}{*}{ Cong. Dist. PPPE (Nbr.) } & $0.068^{* * *}$ & $0.067^{* * *}$ & $0.056^{* * *}$ & $0.047^{* * *}$ \\
\hline & $(0.005)$ & $(0.005)$ & $(0.007)$ & $(0.009)$ \\
\hline \multirow[t]{2}{*}{ Ln(Total Payroll) } & & -0.017 & -0.045 & -0.029 \\
\hline & & $(0.038)$ & $(0.036)$ & $(0.037)$ \\
\hline \multirow[t]{2}{*}{ Ln(Employment) } & & 0.028 & 0.051 & 0.050 \\
\hline & & $(0.062)$ & $(0.059)$ & $(0.066)$ \\
\hline Observations & 436 & 436 & 436 & 436 \\
\hline Adjusted $R^{2}$ & 0.414 & 0.412 & 0.449 & 0.482 \\
\hline Industry Shares & No & No & Yes & Yes \\
\hline State Fixed Effects & No & No & No & Yes \\
\hline
\end{tabular}




\section{Table 3: Evolution of Homebase Employment Outcomes and Exposure to PPP}

Table 3 reports the results of ordinary least squares (OLS) regressions examining the relation between the geographic allocation of PPP funds during the first round and weekly firm employment outcomes measured using the Homebase data set between the second week of March until the last week of April. The dependent variable in Panel A, Bus. Shutdowns, is an indicator variable that takes the value of one if the business reported zero hours worked over the course of the week. The dependent variable in Panel B, Decline Hours Worked, is the decline in hours worked in each establishment relative to the average hours worked in the same establishment during the last two weeks of January. Pre-Covid is an indicator variable that takes the value of prior to the first week of March. This period represents the base period in the specifications that include firm fixed effects and as a result this variable is omitted in such specifications. Pre-Lockdown is an indicator variable that takes the value of one prior to the week of March 22nd - March 28th (exclusive) Post-Lockdown \& Pre-PPP is an indicator variable that takes the value of one during the weeks of March 22nd - March 28th and March 29th - April 4th. Post-PPP is an indicator variable that takes the value of one following the week of April 5th - April 12th (inclusive), Fraction receiving PPP is the percentage of businesses that received PPP loans during the first round in the congressional district where the firm is located. Congressional District PPPE (Nbr.) is the congressional district average of the PPPE based on the number of outstanding loans, weighted by the share of branches of each bank in each congressional district. Standard errors are presented in parentheses, and are double-clustered at the level of the state and week. ***,**, and *, represent statistical significance at $1 \%, 5 \%$, and $10 \%$ levels, respectively.

Panel A: Business Shutdowns

\begin{tabular}{|c|c|c|c|c|}
\hline & (1) & $(2)$ & (3) & (4) \\
\hline & \multicolumn{4}{|c|}{ Bus. Shutdown } \\
\hline Pre-Covid $\times$ Fraction receiving PPP & $\begin{array}{c}-0.005 \\
(0.004)\end{array}$ & & & \\
\hline Pre-Lockdown $\times$ Fraction receiving PPP & $\begin{array}{c}-0.032^{* * *} \\
(0.010)\end{array}$ & & $\begin{array}{c}-0.027^{* * *} \\
(0.002)\end{array}$ & \\
\hline Post-Lockdown \& Pre-PPP $\times$ Fraction receiving PPP & $\begin{array}{c}-0.104^{* *} \\
(0.042)\end{array}$ & & $\begin{array}{c}-0.098^{* *} \\
(0.043)\end{array}$ & \\
\hline Post-PPP $\times$ Fraction receiving PPP & $\begin{array}{l}-0.103^{*} \\
(0.049)\end{array}$ & & $\begin{array}{l}-0.097^{*} \\
(0.052)\end{array}$ & \\
\hline Pre-Lockdown $\times$ Congressional District PPPE (Nbr.) & & $\begin{array}{c}-0.008^{* *} \\
(0.003)\end{array}$ & & $\begin{array}{c}-0.007^{* * *} \\
(0.002)\end{array}$ \\
\hline Post-Lockdown \& Pre-PPP × Congressional District PPPE (Nbr.) & & $\begin{array}{c}-0.041^{* * *} \\
(0.007)\end{array}$ & & $\begin{array}{c}-0.040^{* * * *} \\
(0.007)\end{array}$ \\
\hline Post-PPP $\times$ Congressional District PPPE (Nbr.) & & $\begin{array}{c}-0.043^{* * *} \\
(0.009) \\
\end{array}$ & & $\begin{array}{c}-0.042^{* * *} \\
(0.010) \\
\end{array}$ \\
\hline Observations & 726868 & 726868 & 726868 & 726868 \\
\hline Adjusted $R^{2}$ & 0.261 & 0.262 & 0.522 & 0.522 \\
\hline P-Value Diff. in Coefficients & .8864 & .5061 & .9106 & 6163 \\
\hline Firm Fixed Effects & No & No & Yes & Yes \\
\hline State $\times$ Industry $\times$ Week Fixed Effects & Yes & Yes & Yes & Yes \\
\hline
\end{tabular}

Panel B: Decline in Hours Worked

\begin{tabular}{|c|c|c|c|c|}
\hline & (1) & $(2)$ & (3) & (4) \\
\hline & \multicolumn{4}{|c|}{ Decline Hours Worked } \\
\hline Pre-Covid $\times$ Fraction receiving PPP & $\begin{array}{c}-0.007 \\
(0.009)\end{array}$ & & & \\
\hline Pre-Lockdown $\times$ Fraction receiving PPP & $\begin{array}{l}0.062^{* *} \\
(0.025)\end{array}$ & & $\begin{array}{c}0.068^{* * *} \\
(0.024)\end{array}$ & \\
\hline Post-Lockdown \& Pre-PPP $\times$ Fraction receiving PPP & $\begin{array}{l}0.109^{* *} \\
(0.044)\end{array}$ & & $\begin{array}{l}0.113^{* *} \\
(0.047)\end{array}$ & \\
\hline Post-PPP $\times$ Fraction receiving $\mathrm{PPP}$ & $\begin{array}{l}0.112^{* *} \\
(0.046)\end{array}$ & & $\begin{array}{l}0.116^{* *} \\
(0.049)\end{array}$ & \\
\hline Pre-Covid $\times$ Congressional District PPPE (Nbr.) & & $\begin{array}{c}0.000 \\
(0.002)\end{array}$ & & \\
\hline Pre-Lockdown $\times$ Congressional District PPPE (Nbr.) & & $\begin{array}{c}0.026^{* * *} \\
(0.004)\end{array}$ & & $\begin{array}{c}0.026^{* * *} \\
(0.003)\end{array}$ \\
\hline Post-Lockdown \& Pre-PPP $\times$ Congressional District PPPE (Nbr.) & & $\begin{array}{c}0.040^{* * *} \\
(0.009)\end{array}$ & & $\begin{array}{c}0.040^{* * *} \\
(0.010)\end{array}$ \\
\hline Post-PPP $\times$ Congressional District PPPE (Nbr.) & & $\begin{array}{c}0.044^{* * *} \\
(0.009)\end{array}$ & & $\begin{array}{c}0.043^{* * *} \\
(0.009)\end{array}$ \\
\hline Observations & 726868 & 726868 & 726868 & 726868 \\
\hline Adjusted $R^{2}$ & 0.419 & 0.420 & 0.659 & 0.660 \\
\hline P-Value Diff. in Coefficients & .813 & .1661 & .7928 & .1718 \\
\hline Firm Fixed Effects & No & No & Yes & Yes \\
\hline State $\times$ Industry $\times$ Week Fixed Effects & Yes & Yes & Yes & Yes \\
\hline
\end{tabular}




\title{
Table 4: Evolution of County Unemployment Outcomes and Exposure to PPP
}

\begin{abstract}
Table 4 reports the results of ordinary least squares (OLS) regressions examining the relation between the geographic allocation of PPP funds during the first round and weekly initial unemployment insurance filings at the county level between the second week of March until the last week of April. The dependent variable, County Initial UI Filings Ratios, is the ratio between the weekly initial unemployment insurance filings hand-collected from several state labor departments and county employment measured using the Bureau of Labor and Statistics January County Employment data. Pre-Covid is an indicator variable that takes the value of prior to the first week of March. This period represents the base period in the specifications that include county fixed effects and as a result this variable is omitted in such specifications. Pre-Lockdown is an indicator variable that takes the value of one prior to the week of March 22nd - March 28th (exclusive) Post-Lockdown \& Pre-PPP is an indicator variable that takes the value of one during the weeks of March 22nd - March 28th and March 29th - April 4th. Post-PPP is an indicator variable that takes the value of one following the week of April 5th - April 12th (inclusive), County PPPE (Nbr.) is the county average of the PPPE based on the number of outstanding loans, weighted by the share of branches of each bank in each county. Weekly County Covid-19 Cases (per capita) are the weekly per capita number of reported Covid-19 cases. Weekly County Covid-19 Deaths (per capita) are the weekly per capita number of reported Covid-19 deaths. Social Distancing Index is the change in average distance travelled in the county using individuals' GPS signals. Standard errors are presented in parentheses, and are double-clustered at the level of the state and week. ***, **, and *, represent statistical significance at $1 \%, 5 \%$, and $10 \%$ levels, respectively.
\end{abstract}

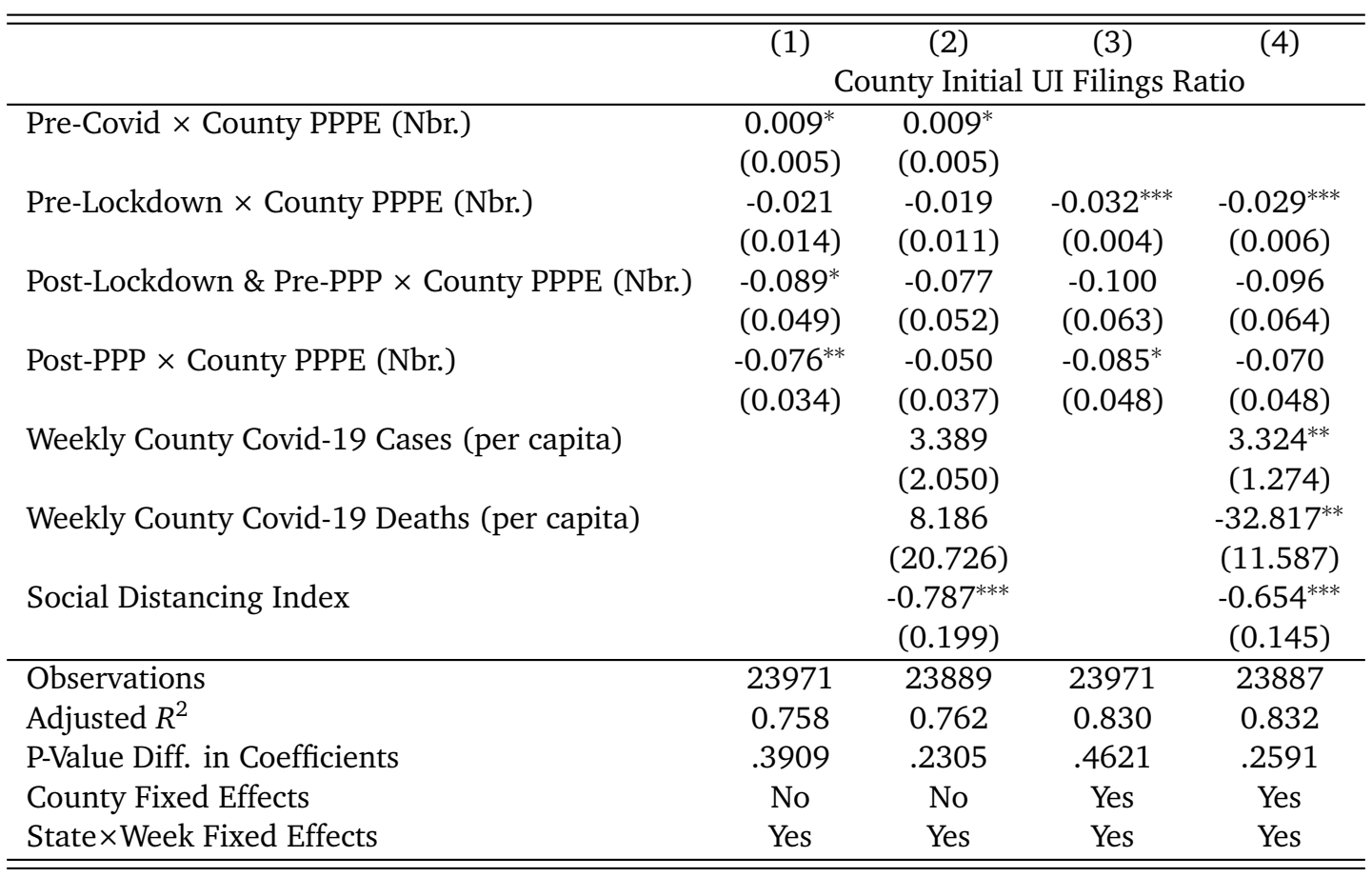




\title{
Table 5: Evolution of Small Business Revenues and Exposure to PPP
}

\begin{abstract}
Table 5 reports the results of ordinary least squares (OLS) regressions examining the relation between the geographic allocation of PPP funds during the first round and weekly small business revenues at the county $\times$ industry level between the second week of March until the last week of April collected from Womply, a company specializing in processing revenue for small businesses. The dependent variable, $Y / Y$ Change in Total Consumer Spending, is the average year-on-year change in small business revenues in a given county and industry. Pre-Covid is an indicator variable that takes the value of prior to the first week of March. This period represents the base period in the specifications that include county $\times$ industry fixed effects and as a result this variable is omitted in such specifications. Pre-Lockdown is an indicator variable that takes the value of one prior to the week of March 22nd - March 28th (exclusive) Post-Lockdown \& Pre-PPP is an indicator variable that takes the value of one during the weeks of March 22nd - March 28th and March 29th - April 4th. Post-PPP is an indicator variable that takes the value of one following the week of April 5th - April 12th (inclusive), County PPPE (Nbr.) is the county average of the PPPE based on the number of outstanding loans, weighted by the share of branches of each bank in each county. Weekly County Covid-19 Cases (per capita) are the weekly per capita number of reported Covid-19 cases. Weekly County Covid-19 Deaths (per capita) are the weekly per capita number of reported Covid-19 deaths. Social Distancing Index is the change in average distance travelled in the county using individuals' GPS signals. Standard errors are presented in parentheses, and are double-clustered at the level of the state and week. ***,**, and *, represent statistical significance at $1 \%, 5 \%$, and $10 \%$ levels, respectively.
\end{abstract}

\begin{tabular}{|c|c|c|c|c|}
\hline & (1) & (2) & (3) & (4) \\
\hline & \multicolumn{4}{|c|}{$\mathrm{Y} / \mathrm{Y}$ Change in Total Consumer Spending } \\
\hline Pre-Covid $\times$ County PPPE (Nbr.) & $\begin{array}{c}-0.068^{* * *} \\
(0.009)\end{array}$ & $\begin{array}{c}-0.075^{* * *} \\
(0.009)\end{array}$ & & \\
\hline Pre-Lockdown $\times$ County PPPE (Nbr.) & $\begin{array}{c}-0.032^{* *} \\
(0.012)\end{array}$ & $\begin{array}{c}-0.045^{* * *} \\
(0.011)\end{array}$ & $\begin{array}{c}0.033^{* * *} \\
(0.010)\end{array}$ & $\begin{array}{c}0.028^{* * *} \\
(0.009)\end{array}$ \\
\hline Post-Lockdown \& Pre-PPP $\times$ County PPPE (Nbr.) & $\begin{array}{c}-0.019^{* * *} \\
(0.006)\end{array}$ & $\begin{array}{c}-0.035^{* * *} \\
(0.007)\end{array}$ & $\begin{array}{c}0.042^{* * *} \\
(0.006)\end{array}$ & $\begin{array}{c}0.033^{* * *} \\
(0.007)\end{array}$ \\
\hline Post-PPP $\times$ County PPPE (Nbr.) & $\begin{array}{c}-0.014^{* *} \\
(0.005)\end{array}$ & $\begin{array}{c}-0.033^{* * *} \\
(0.008)\end{array}$ & $\begin{array}{c}0.046^{* * *} \\
(0.008)\end{array}$ & $\begin{array}{l}0.029^{* *} \\
(0.010)\end{array}$ \\
\hline Weekly County Covid-19 Cases (per capita) & & $\begin{array}{l}-0.017 \\
(0.306)\end{array}$ & & $\begin{array}{c}0.163 \\
(0.349)\end{array}$ \\
\hline Weekly County Covid-19 Deaths (per capita) & & $\begin{array}{c}4.020 \\
(3.781)\end{array}$ & & $\begin{array}{c}-7.032 \\
(8.209)\end{array}$ \\
\hline Social Distancing Index & & $\begin{array}{c}0.255^{* * *} \\
(0.071) \\
\end{array}$ & & $\begin{array}{c}0.288^{* * *} \\
(0.063) \\
\end{array}$ \\
\hline Observations & 210076 & 193328 & 209950 & 193216 \\
\hline Adjusted $R^{2}$ & 0.362 & 0.361 & 0.665 & 0.668 \\
\hline P-Value Diff. in Coefficients & 1093 & .6282 & .3683 & .3787 \\
\hline County×Industry Fixed Effects & No & No & Yes & Yes \\
\hline State $\times$ Industry $\times$ Week Fixed Effects & Yes & Yes & Yes & Yes \\
\hline
\end{tabular}




\section{Table 6: \% Receiving PPP and Exposure to State PPPE}

Table 6 reports the results of ordinary least squares (OLS) regressions examining the relation between the geographic allocation of PPP funds during the first round and the percentage of firms reporting having received PPP funds at the state-by-industry level in each week of the survey collected from the Census Small Business Pulse Survey. The dependent variable is the percentage of businesses that received PPP funds in a state-by-industry group during each week of the survey. State PPPE (Nbr.) is the state average of the PPPE based on the number of outstanding loans. Standard errors are presented in parentheses, and are double-clustered at the level of the state and week. ***, **, and *, represent statistical significance at $1 \%, 5 \%$, and $10 \%$ levels, respectively.

\begin{tabular}{|c|c|c|c|c|c|c|c|}
\hline & (1) & (2) & (3) & $\begin{array}{c}\text { (4) } \\
\text { \% PPP Receive }\end{array}$ & (5) & (6) & (7) \\
\hline State PPPE (Nbr.) & $\begin{array}{c}35.865^{* * *} \\
(3.201)\end{array}$ & $\begin{array}{c}89.549^{* * *} \\
(8.169)\end{array}$ & $\begin{array}{c}51.603^{* * *} \\
(4.298)\end{array}$ & $\begin{array}{c}23.899^{* * *} \\
(3.594)\end{array}$ & $\begin{array}{c}28.381^{* * *} \\
(5.024)\end{array}$ & $\begin{array}{c}17.061^{* * *} \\
(3.610)\end{array}$ & $\begin{array}{c}24.315^{* * *} \\
(3.879)\end{array}$ \\
\hline Observations & 2230 & 277 & 386 & 390 & 390 & 393 & 394 \\
\hline Adjusted $R^{2}$ & 0.653 & 0.629 & 0.529 & 0.397 & 0.416 & 0.387 & 0.516 \\
\hline Industry Fixed Effects & No & Yes & Yes & Yes & Yes & Yes & Yes \\
\hline Industry $\times$ Week Fixed Effects & Yes & No & No & No & No & No & No \\
\hline Week: & Full Sample & Apr26-May2 & Мay3-May9 & May10-May16 & May17-May23 & May24-May30 & May31-Jun6 \\
\hline
\end{tabular}




\section{Table 7: \% Receiving PPP and Missed Loans Payments}

Table 7 reports the results of ordinary least squares (OLS) and instrumental variables (IV) regressions examining the relation between the geographic allocation of PPP funds during the first round and the percentage of firms reporting missing payments at the state-by-industry level collected from the Census Small Business Pulse Survey. The dependent variable is the percentage of firms reporting a missed scheduled loan payment. \% PPP Received is the percentage of businesses reporting having received PPP funds in a state-by-industry group. State PPPE (Nbr.) is the state average of the PPPE based on the number of outstanding loans. Pre-PPP Decline Hours Worked is the average decline in hours worked in each state between January and the last week of March. Pre-PPP State Covid-19 Cases (per capita) are per capita number of reported Covid-19 cases in the state. Pre-PPP State Covid-19 Deaths (per capita) are the weekly per capita number of reported Covid-19 deaths in the state. Pre-PPP State Social Distancing Index is the change in average distance travelled in the state until the end of March using individuals' GPS signals. All specifications include industry $\times$ week fixed-effects. Standard errors are presented in parentheses, and are clustered at the level of the state. ***,**, and *, represent statistical significance at $1 \%$, $5 \%$, and $10 \%$ levels, respectively.

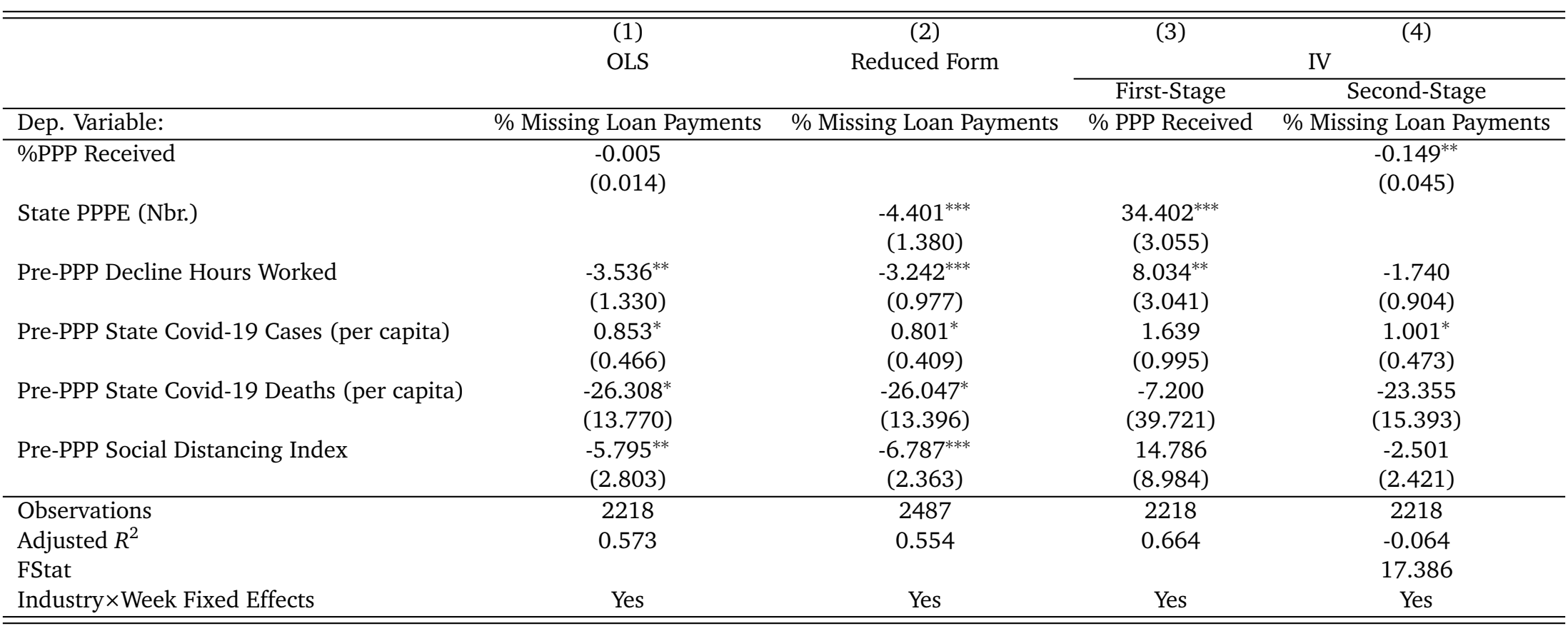


Table 8: \% Receiving PPP and Missed Other Scheduled Payments

Table 8 reports the results of ordinary least squares (OLS) and instrumental variables (IV) regressions examining the relation between the geographic allocation of PPP funds during the first round and the percentage of firms reporting missing payments at the state-by-industry level collected from the Census Small Business Pulse Survey. The dependent variable is the percentage of firms reporting a missed other scheduled payment such as rent, utilities, and payroll. \% PPP Received is the percentage of businesses reporting having received PPP funds in a state-by-industry group. State PPPE (Nbr.) is the state average of the PPPE based on the number of outstanding loans. Pre-PPP Decline Hours Worked is the average decline in hours worked in each state between January and the last week of March. Pre-PPP State Covid-19 Cases (per capita) are per capita number of reported Covid-19 cases in the state. Pre-PPP State Covid-19 Deaths (per capita) are the weekly per capita number of reported Covid-19 deaths in the state. Pre-PPP State Social Distancing Index is the change in average distance travelled in the state until the end of March using individuals' GPS signals. All specifications include industry $\times$ week fixed-effects. Standard errors are presented in parentheses, and are clustered at the level of the state. ***, **, and *, represent statistica significance at $1 \%, 5 \%$, and $10 \%$ levels, respectively.

\begin{tabular}{|c|c|c|c|c|}
\hline & \multirow[t]{2}{*}{$\begin{array}{l}1) \\
\text { OLS }\end{array}$} & \multirow[t]{2}{*}{$\begin{array}{c}\text { (2) } \\
\text { Reduced Form }\end{array}$} & \multicolumn{2}{|r|}{ (4) } \\
\hline & & & \multicolumn{2}{|r|}{ IV } \\
\hline Dep. Variable: & \% Missing Schd. Payments & \% Missing Schd. Payments & \% PPP Received & \% Missing Schd. Payments \\
\hline \%PPP Received & $-0.091^{* * *}$ & & & $-0.435^{* * *}$ \\
\hline & $(0.022)$ & & & $(0.067)$ \\
\hline State PPPE (Nbr.) & & $\begin{array}{c}-14.807^{* * *} \\
(2.651)\end{array}$ & $\begin{array}{c}34.662^{* * *} \\
(3.053)\end{array}$ & \\
\hline Pre-PPP Decline Hours Worked & $\begin{array}{c}-12.380^{* * *} \\
(3.587)\end{array}$ & $\begin{array}{c}-12.176^{* * *} \\
(4.094)\end{array}$ & $\begin{array}{l}7.824^{* *} \\
(3.097)\end{array}$ & $\begin{array}{l}-8.192^{*} \\
(4.094)\end{array}$ \\
\hline Pre-PPP State Covid-19 Cases (per capita) & $\begin{array}{c}4.390^{* * *} \\
(0.736)\end{array}$ & $\begin{array}{c}4.189^{* * *} \\
(0.577)\end{array}$ & $\begin{array}{c}1.674^{*} \\
(0.988)\end{array}$ & $\begin{array}{c}4.754^{* * *} \\
(0.462)\end{array}$ \\
\hline Pre-PPP State Covid-19 Deaths (per capita) & $\begin{array}{c}-107.446^{* * *} \\
(25.205)\end{array}$ & $\begin{array}{c}-101.315^{* * *} \\
(20.723)\end{array}$ & $\begin{array}{c}-8.416 \\
(39.435)\end{array}$ & $\begin{array}{c}-100.872^{* * *} \\
(17.170)\end{array}$ \\
\hline Pre-PPP Social Distancing Index & $\begin{array}{c}-15.797^{* *} \\
(6.450)\end{array}$ & $\begin{array}{c}-13.084^{* *} \\
(6.317)\end{array}$ & $\begin{array}{l}14.833 \\
(9.059)\end{array}$ & $\begin{array}{l}-7.857 \\
(5.592)\end{array}$ \\
\hline Observations & 2206 & 2448 & 2206 & 2206 \\
\hline Adjusted $R^{2}$ & 0.708 & 0.698 & 0.663 & -0.028 \\
\hline FStat & & & & 128.871 \\
\hline Industry $\times$ Week Fixed Effects & Yes & Yes & Yes & Yes \\
\hline
\end{tabular}




\section{Table 9: \% Receiving PPP and Cash-on-Hand}

Table 9 reports the results of ordinary least squares (OLS) and instrumental variables (IV) regressions examining the relation between the geographic allocation of PPP funds during the first round and the percentage of businesses at the state-by-industry level reporting at least two months of cash on hand to sustain operations as collected from the Census Small Business Pulse Survey. The dependent variable is the fraction of businesses with cash on hand to sustain operations for two months or more. \% PPP Received is the percentage of businesses reporting having received PPP funds in a state-by-industry group. State PPPE (Nbr.) is the state average of the PPPE based on the number of outstanding loans. Pre-PPP Decline Hours Worked is the average decline in hours worked in each state between January and the last week of March. Pre-PPP State Covid-19 Cases (per capita) are per capita number of reported Covid-19 cases in the state. Pre-PPP State Covid-19 Deaths (per capita) are the weekly per capita number of reported Covid-19 deaths in the state. Pre-PPP State Social Distancing Index is the change in average distance travelled in the state until the end of March using individuals' GPS signals. All specifications include industry $\times$ week fixed-effects. Standard errors are presented in parentheses, and are clustered at the level of the state. ***, **, and *, represent statistical significance at 1\%,5\%, and $10 \%$ levels, respectively.

\begin{tabular}{|c|c|c|c|c|}
\hline & \multirow{2}{*}{$\begin{array}{l}\text { (1) } \\
\text { OLS }\end{array}$} & \multirow{2}{*}{$\begin{array}{c}(2) \\
\text { Reduced Form }\end{array}$} & & (4) \\
\hline & & & First-Stage & Second-Stage \\
\hline Dep. Variable: & \% Cash 3 months & \% Cash 3 months & \% PPP Received & \% Cash 3 months \\
\hline \%PPP Received & $\begin{array}{l}-0.000 \\
(0.035)\end{array}$ & & & $\begin{array}{c}0.270^{*} \\
(0.125)\end{array}$ \\
\hline State PPPE (Nbr.) & & $\begin{array}{l}8.920^{* *} \\
(3.768)\end{array}$ & $\begin{array}{c}32.502^{* * *} \\
(3.116)\end{array}$ & \\
\hline Pre-PPP Decline Hours Worked & $\begin{array}{l}11.966^{*} \\
(6.170)\end{array}$ & $\begin{array}{c}15.861^{* * *} \\
(5.378)\end{array}$ & $\begin{array}{c}4.354 \\
(5.855)\end{array}$ & $\begin{array}{l}11.007^{*} \\
(4.844)\end{array}$ \\
\hline Pre-PPP State Covid-19 Cases (per capita) & $\begin{array}{l}-1.979^{* *} \\
(0.733)\end{array}$ & $\begin{array}{c}-2.003^{* *} \\
(0.818)\end{array}$ & $\begin{array}{l}2.095^{* *} \\
(0.937)\end{array}$ & $\begin{array}{l}-2.476^{* *} \\
(0.726)\end{array}$ \\
\hline Pre-PPP State Covid-19 Deaths (per capita) & $\begin{array}{l}75.244^{* *} \\
(28.941)\end{array}$ & $\begin{array}{l}76.722^{* *} \\
(31.278)\end{array}$ & $\begin{array}{l}-26.761 \\
(44.659)\end{array}$ & $\begin{array}{l}76.491^{*} \\
(35.062)\end{array}$ \\
\hline Pre-PPP Social Distancing Index & $\begin{array}{l}-6.850 \\
(9.277)\end{array}$ & $\begin{array}{l}-12.334 \\
(11.326)\end{array}$ & $\begin{array}{c}13.236 \\
(11.661)\end{array}$ & $\begin{array}{l}-12.138 \\
(9.223)\end{array}$ \\
\hline Observations & 903 & 918 & 903 & 903 \\
\hline Adjusted $R^{2}$ & 0.629 & 0.640 & 0.797 & -0.089 \\
\hline FStat & & & & 19.527 \\
\hline Industry $\times$ Week Fixed Effects & Yes & Yes & Yes & Yes \\
\hline
\end{tabular}




\section{A Case Study: Wells Fargo}

This section explores a case study, illlustrating the importance of financial intermediation in allocating PPP funds. Figure A.1 and Table A.1 present a case study of a particular bank with a very low share of PPP loans relative to overall market share-Wells Fargo. Wells Fargo was severely constrained from expanding its balance sheet as a result of an asset cap imposed by the Fed in the aftermath of the fake accounts scandal. This asset cap was only lifted on April 10, when the Fed excluded PPP loans from the formula it uses to restrict Wells Fargo's growth. The asset cap limited Wells Fargo's ability to lend under the PPP in the early days for the first phase of the program. Table 1 shows that Wells Fargo, the third largest bank in the nation by total assets, held a $6.5 \%$ share of the total outstanding small business loans but processed only $0.04 \%$ of the total volume of loans in the PPP program until April 15. Figure A.1 shows PPP allocations by the market share of Wells Fargo. The top panel shows volume, while the bottom panel shows the number of loans. Both figures show a similar pattern-firms located in areas with higher Wells Fargo market share see lower PPP allocations, both in terms of overall aggregate loan volume per business and in the fraction of businesses receiving PPP loans.

Table A.1 presents similar information, regressing the log total volume and number of loans on the share of Wells Fargo branches in congressional districts. The relationship between PPP allocations and Wells Fargo branches echoes the results seen in Table 2. Areas with higher Wells Fargo exposure (and lower PPPE exposure) see lower PPP allocations. The effect is statistically significant at the 5 percent level or higher in columns (1) through (3), but loses significance when state fixed effects are included. More broadly, Figure A.1 and Table A.1 illustrate an example of the variation underlying overall PPPE exposure. 


\section{Figure A.1: Wells Fargo Exposure and PPP per Establishment}

Figure A.1 are scatterplots of the total PPP allocation per establishment in the congressional district and the share of branches of Wells Fargo in the Congressional District (Panel A) and fraction of establishments receiving a PPP loan and the share of Branches of Wells Fargo in the Congressional District (Panel B). Data comes from the SBA, Summary of Deposits, and County Business Patterns.
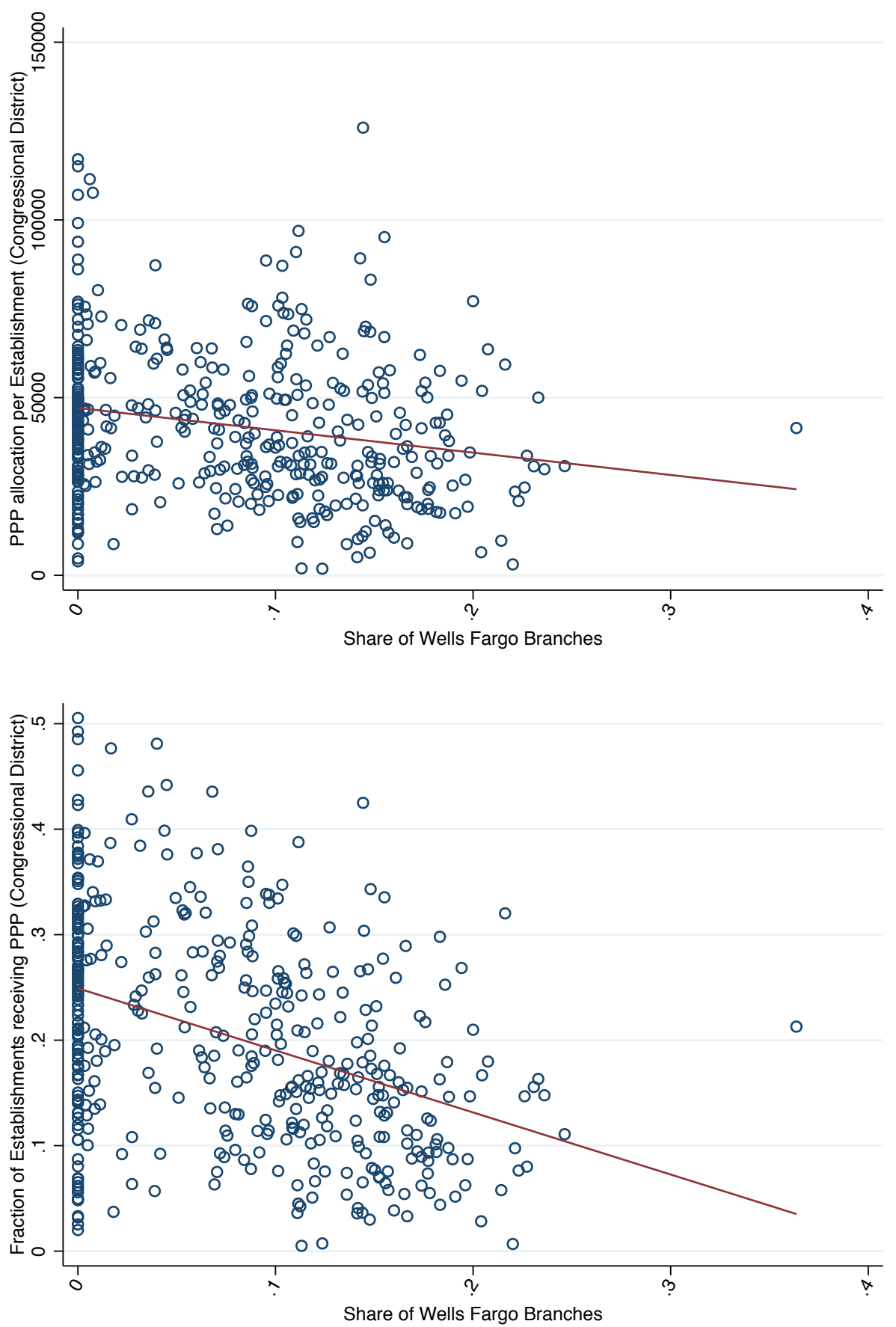


\section{Figure A.2: Decline in Hours Worked and PPP Allocation by State}

Figure A.3 presents four scatterplots of the decline in hours worked relative to a January baseline and four alternative measures of allocation of PPP funds across states. The figure on the top left plots the amount of PPP loans received by small businesses in each state divided by the total number of small businesses in the state. The figure on the top right corner plots the fraction of small businesses in each state that received a PPP loan. The figure on the bottom left corner plots the fraction of small businesses in each state that received a PPP loan and the state exposure to the PPPE measured in terms of the total volume of loans. The figure on the bottom right corner plots the fraction of small businesses in each state that received a PPP loan and the state exposure to the PPPE measured in terms of the total number of loans.
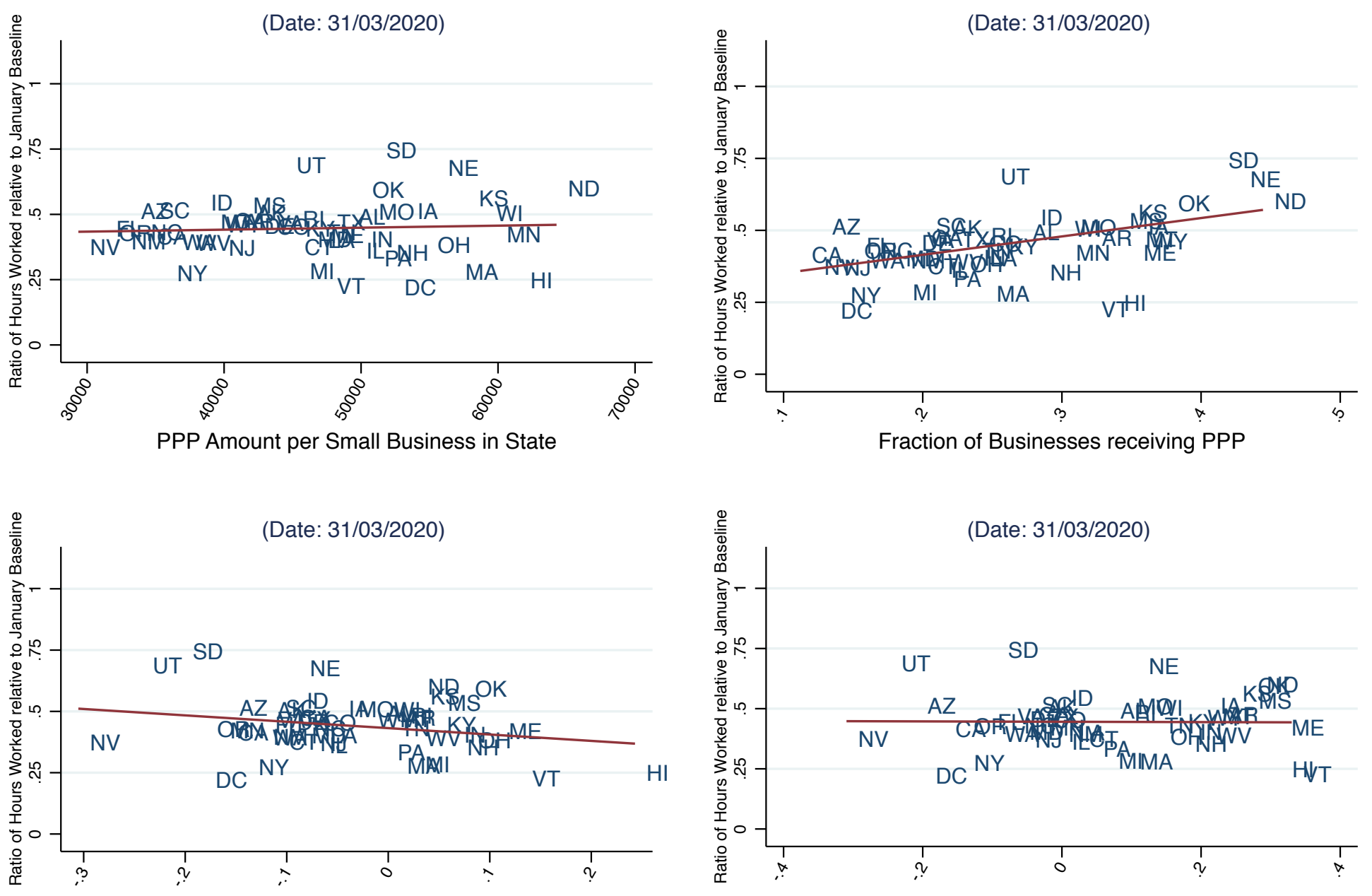
Figure A.3: Business Shutdowns and PPP Allocation by State

Figure A.3 presents four scatterplots of the share of businesses in each state that shutdown that in the week of March29th-April 4th and four alternative measures of allocation of PPP funds across states. The figure on the top left plots the amount of PPP loans received by small businesses in each state divided by the total number of small businesses in the state. The figure on the top right corner plots the fraction of small businesses in each state that received a PPP loan. The figure on the bottom left corner plots the fraction of small businesses in each state that received a PPP loan and the state exposure to the PPPE measured in terms of the total volume of loans. The figure on the bottom right corner plots the fraction of small businesses in each state that received a PPP loan and the state exposure to the PPPE measured in terms of the total number of loans.

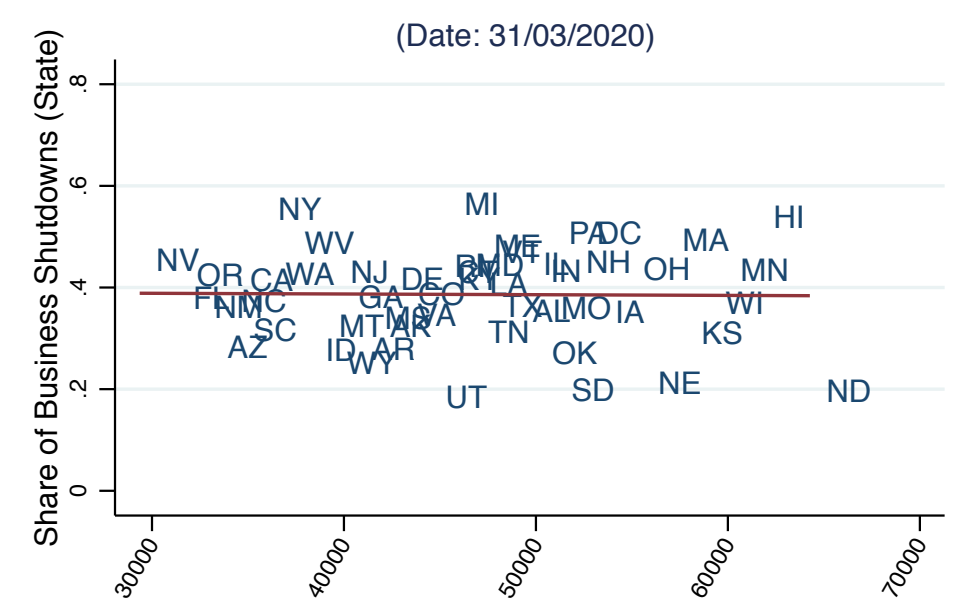

PPP Amount per Small Business in State

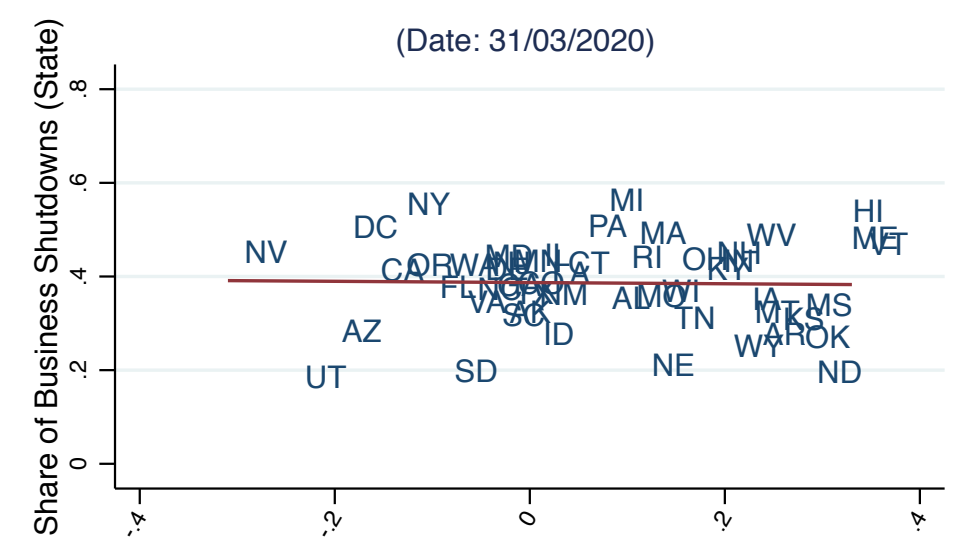

State PPPE (Nbr. Loans)
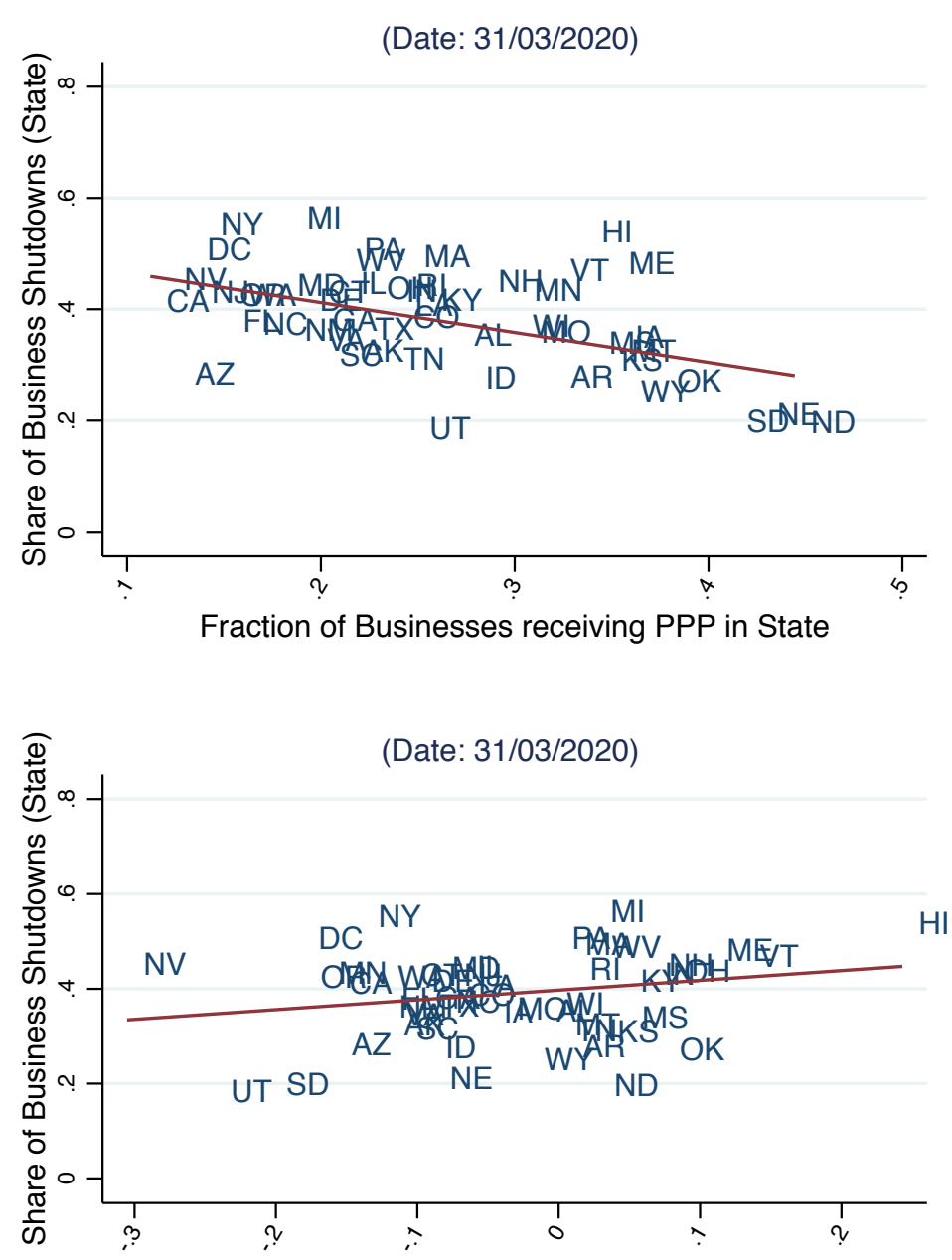

State PPPE (Volume) 
Figure A.4: COVID-19 Cases and PPP Allocation by State

Figure A.4 presents four scatterplots of the number of confirmed COVID-19 cases per thousand as of April, 3rd 2020 and four alternative measures of allocation of PPP funds across states. The figure on the top left plots the amount of PPP loans received by small businesses in each state divided by the total number of small businesses in the state. The figure on the top right corner plots the fraction of small businesses in each state that received a PPP loan. The figure on the bottom left corner plots the fraction of small businesses in each state that received a PPP loan and the state exposure to the PPPE measured in terms of the total volume of loans. The figure on the bottom right corner plots the fraction of small businesses in each state that received a PPP loan and the state exposure to the PPPE measured in terms of the total number of loans. Data comes from the Center for Disease Control, SBA, Call Reports, and FDIC Summary of Deposits.

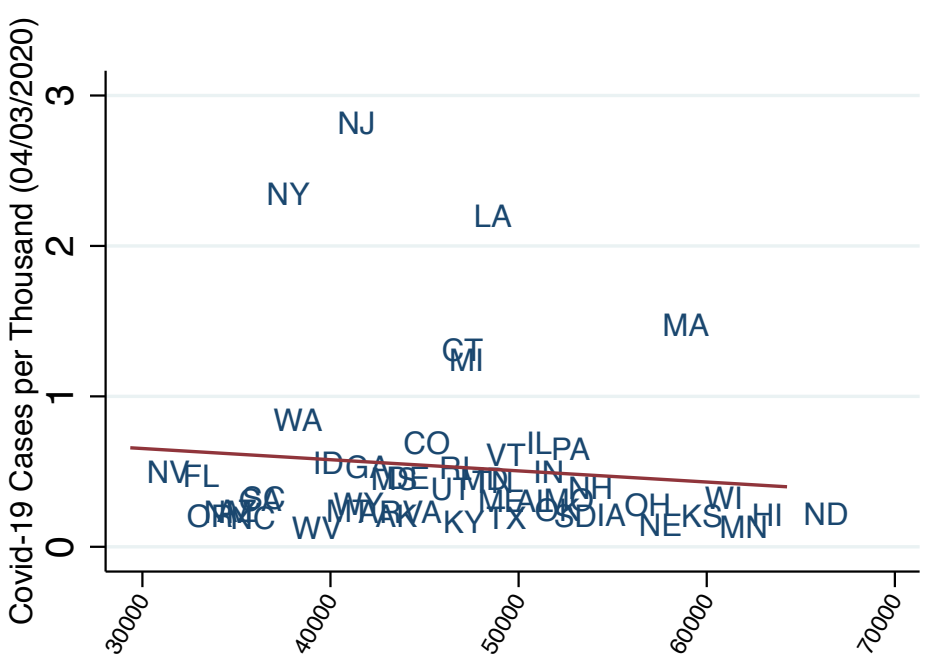

PPP volume per Small Business Establishment

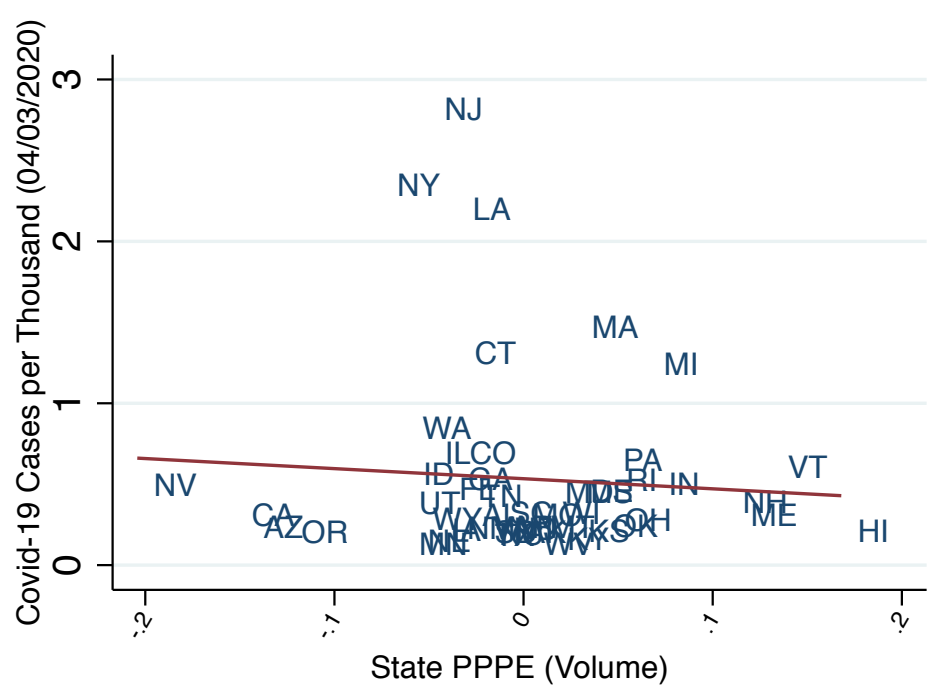

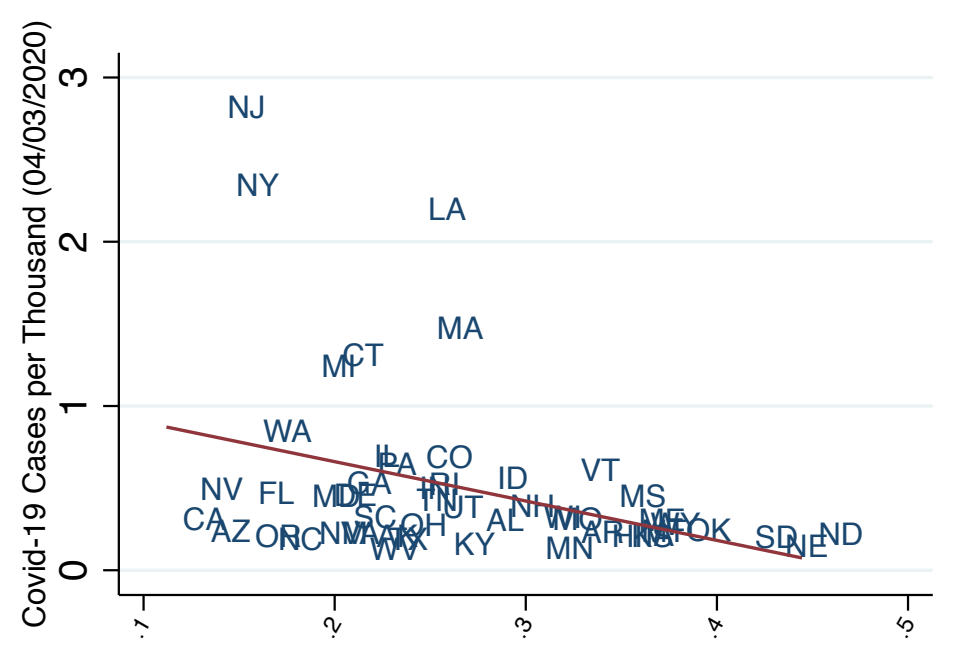

Fraction of Small Businesses Receiving PPP loan

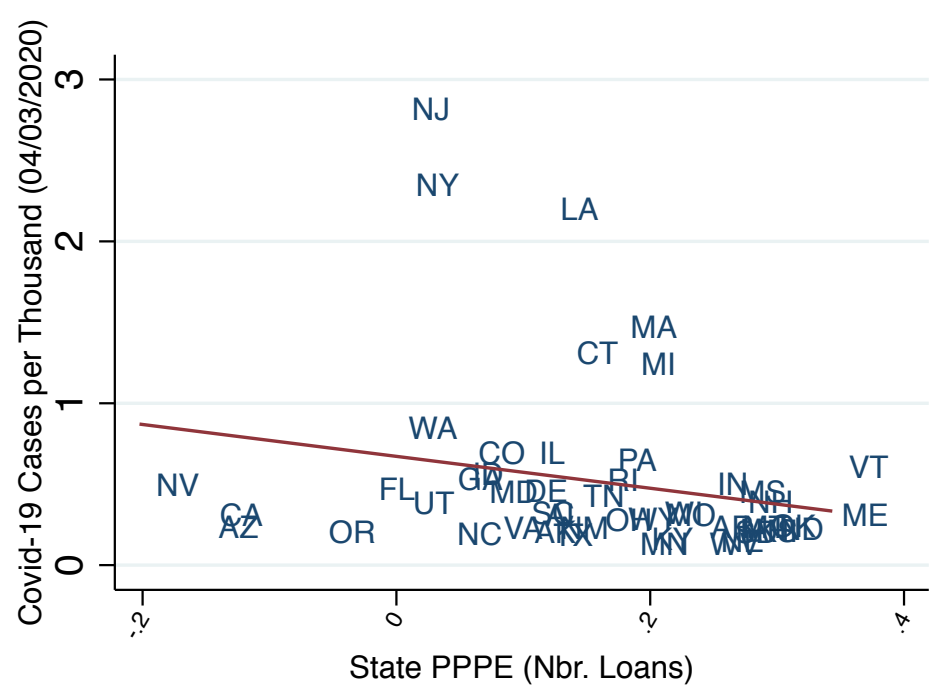




\section{Figure A.5: COVID-19 Deaths and PPP Allocation by State}

Figure A.5 presents four scatterplots of the number of COVID-19 deaths per thousand as of April, 3rd 2020 and four alternative measures of allocation of PPP funds across states. The figure on the top left plots the amount of PPP loans received by small businesses in each state divided by the total number of small businesses in the state. The figure on the top right corner plots the fraction of small businesses in each state that received a PPP loan. The figure on the bottom left corner plots the fraction of small businesses in each state that received a PPP loan and the state exposure to the PPPE measured in terms of the total volume of loans. The figure on the bottom right corner plots the fraction of small businesses in each state that received a PPP loan and the state exposure to the PPPE measured in terms of the total number of loans. Data comes from the Center for Disease Control, SBA, Call Reports, and FDIC Summary of Deposits.

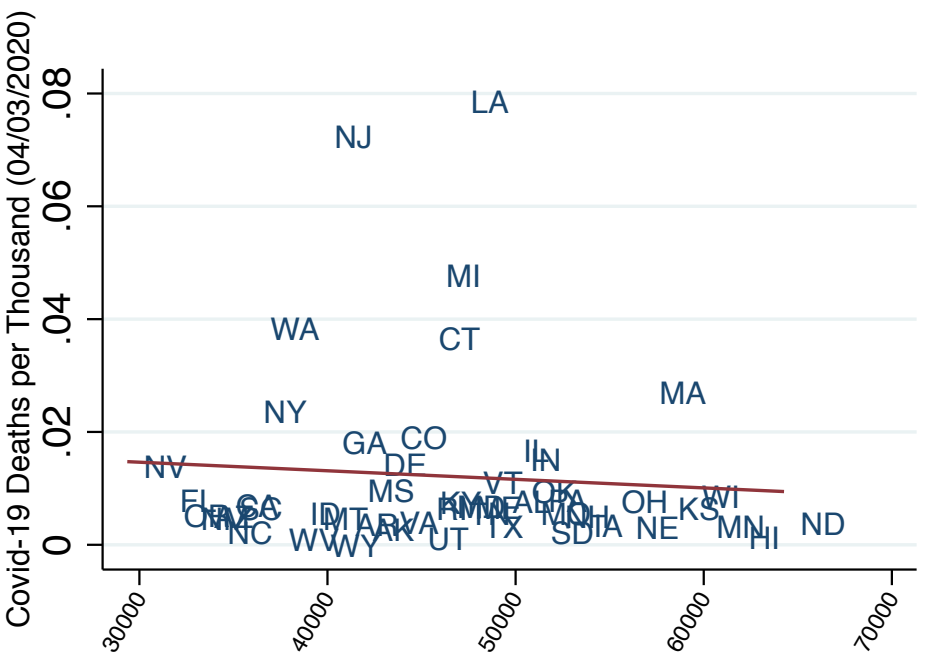

PPP volume per Small Business Establishment

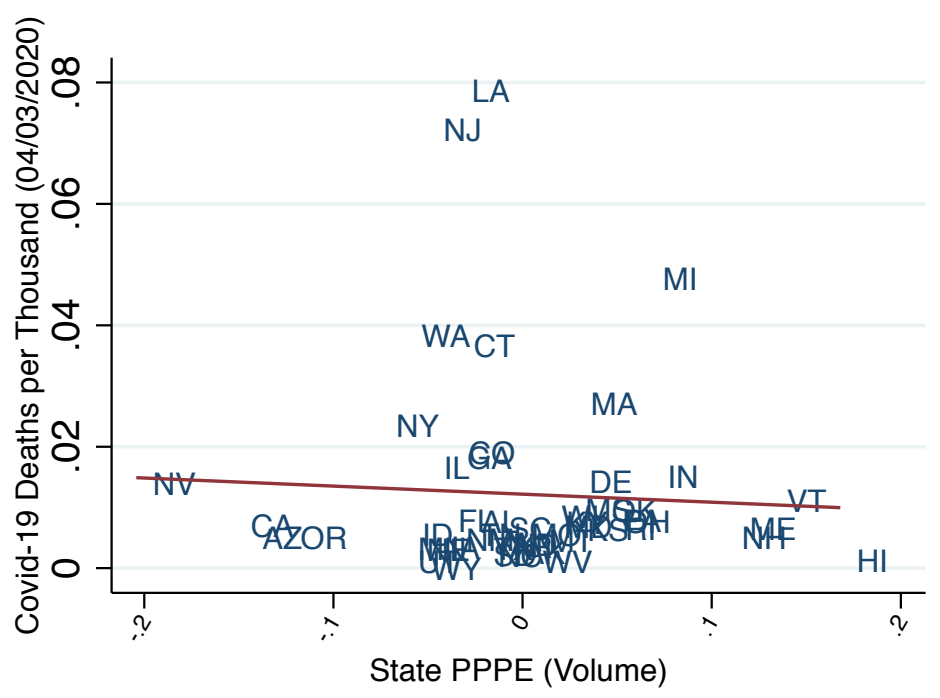

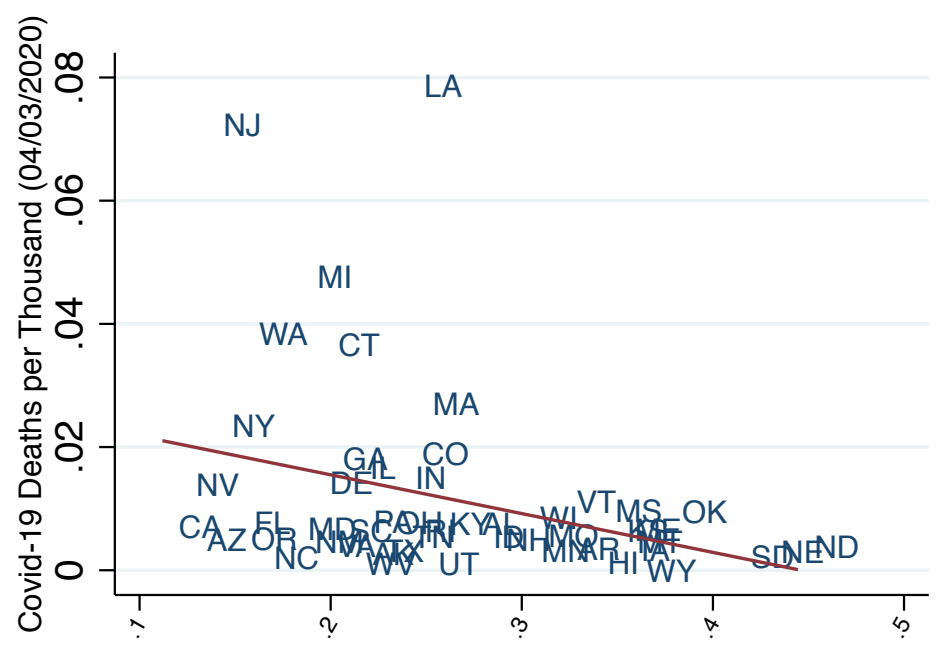

Fraction of Small Businesses Receiving PPP loan

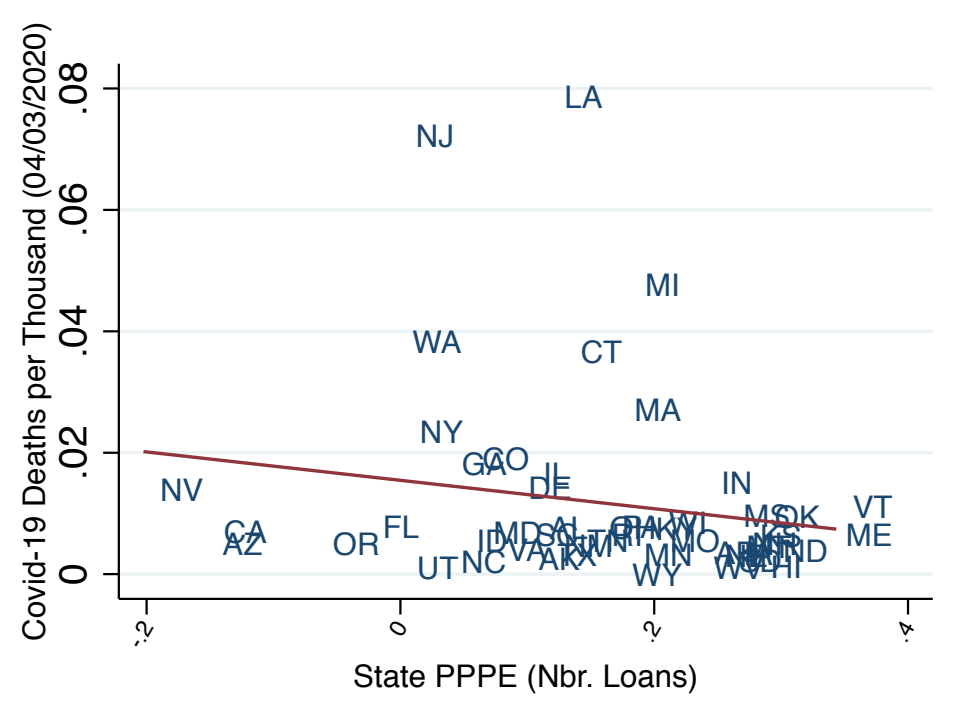




\section{Figure A.6: Shelter-in-Place Orders and PPP Allocation by State}

Figure A.6 presents four scatterplots of the timing of statewide shelter-in-place orders and four alternative measures of allocation of PPP funds across states. The figure on the top left plots the amount of PPP loans received by small businesses in each state divided by the total number of small businesses in the state. The figure on the top right corner plots the fraction of small businesses in each state that received a PPP loan. The figure on the bottom left corner plots the fraction of small businesses in each state that received a PPP loan and the state exposure to the PPPE measured in terms of the total volume of loans. The figure on the bottom right corner plots the fraction of small businesses in each state that received a PPP loan and the state exposure to the PPPE measured in terms of the total number of loans. Data comes from the New York Times, SBA, Call Reports, and FDIC Summary of Deposits.

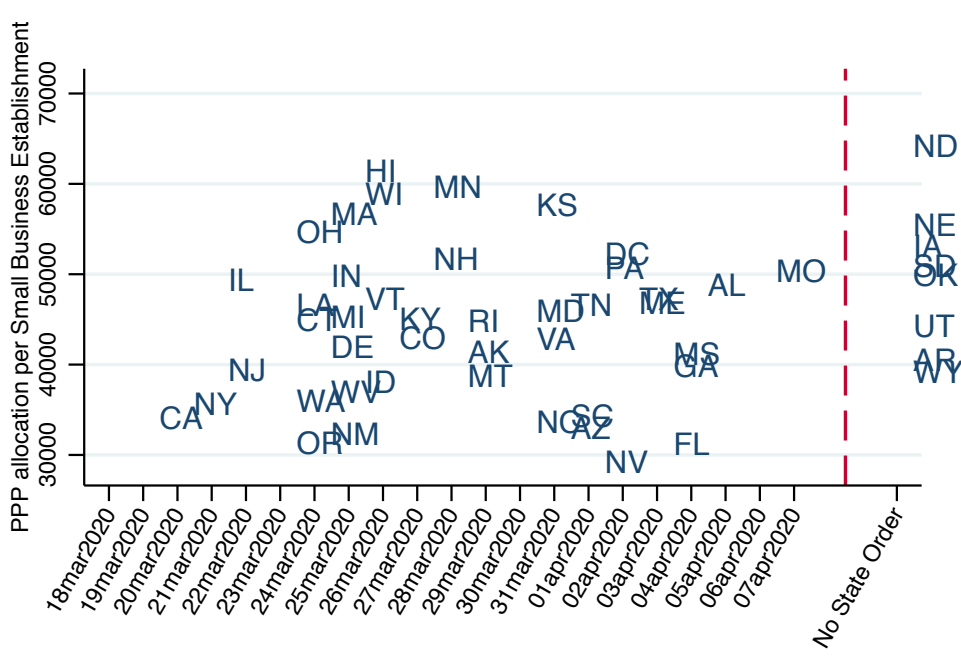

Date Shelter Order

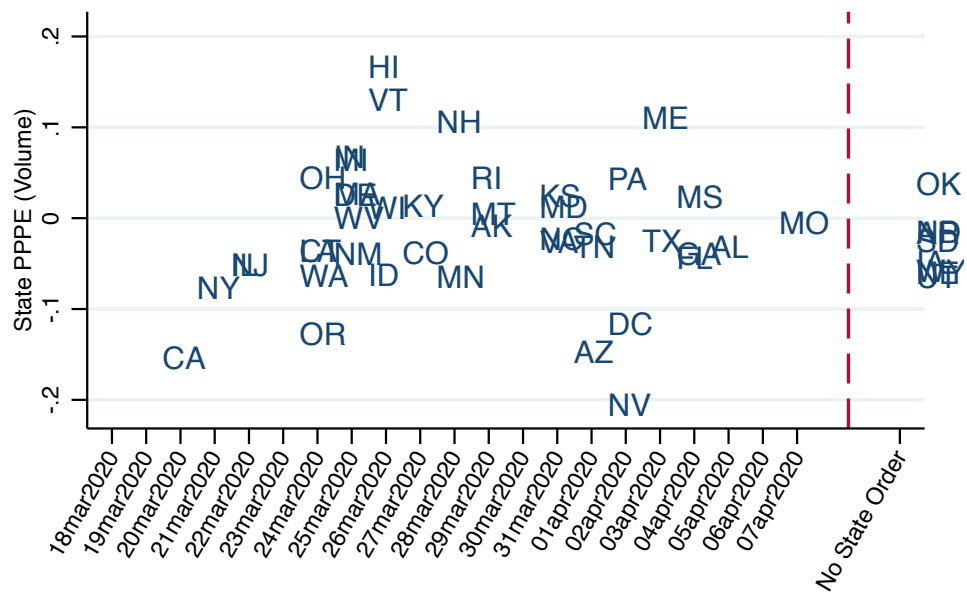

Date Shelter Order

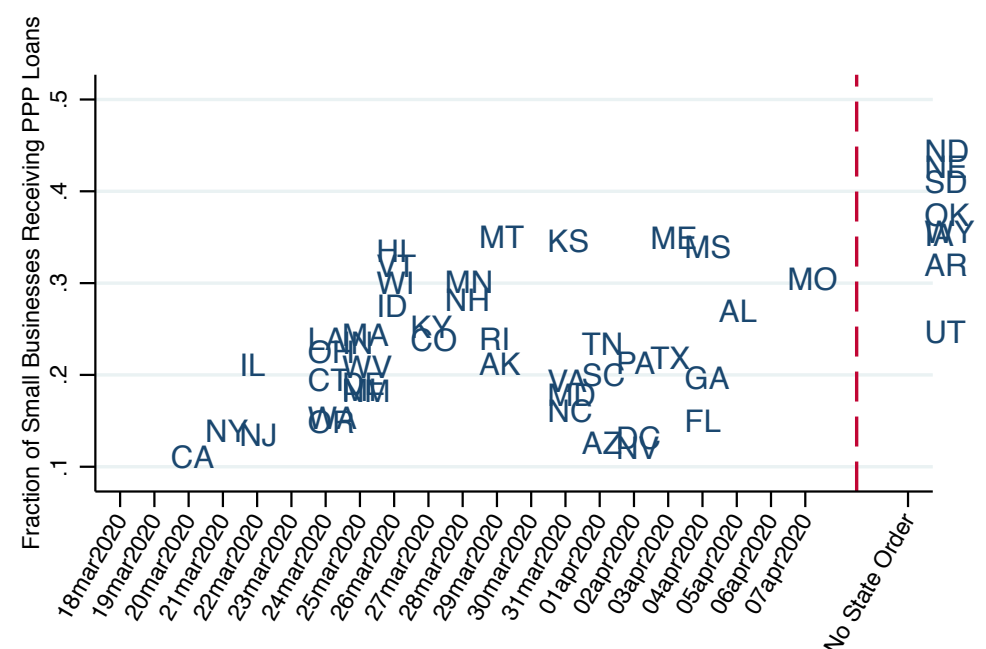

Date Shelter Order

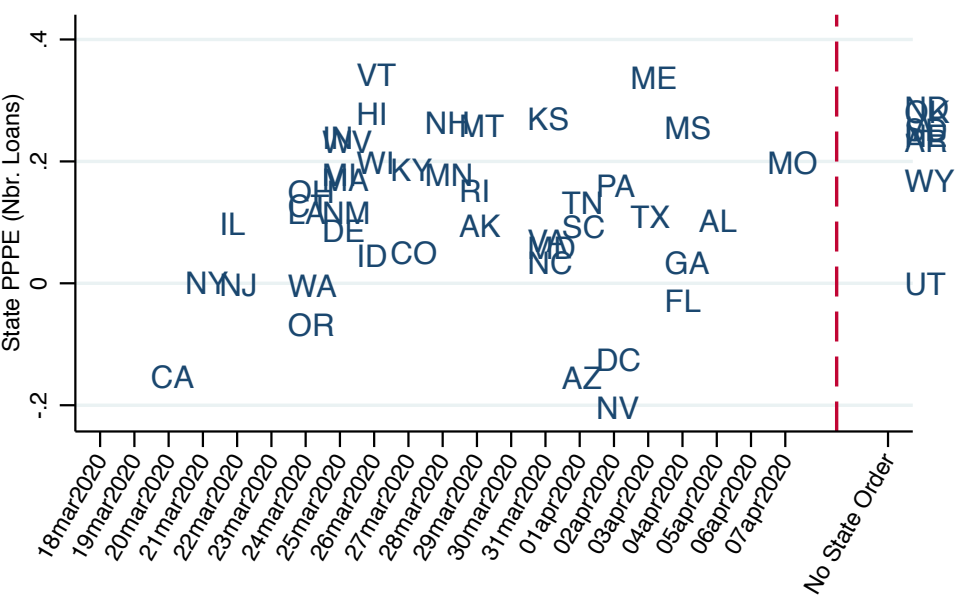

Date Shelter Order 


\section{Figure A.7: Social Distancing Index and PPP Allocation by State}

Figure A.7 presents four scatterplots of and four alternative measures of allocation of PPP funds across states. The figure on the top left plots the amount of PPP loans received by small businesses in each state divided by the total number of small businesses in the state. The figure on the top right corner plots the fraction of small businesses in each state that received a PPP loan. The figure on the bottom left corner plots the fraction of small businesses in each state that received a PPP loan and the state exposure to the PPPE measured in terms of the total volume of loans. The figure on the bottom right corner plots the fraction of small businesses in each state that received a PPP loan and the state exposure to the PPPE measured in terms of the total number of loans. Data comes from the SBA, Call Reports, and FDIC Summary of Deposits.

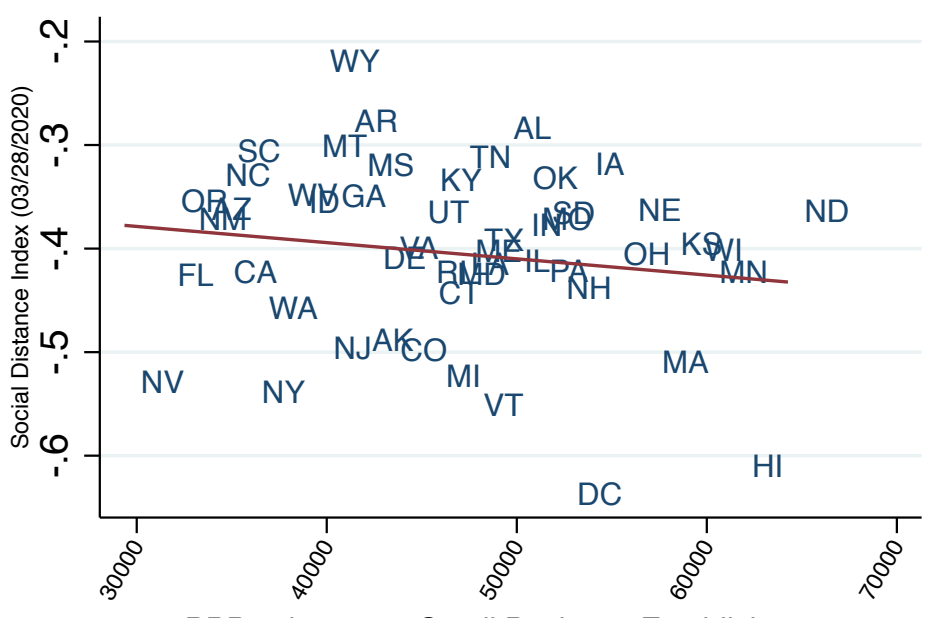

PPP volume per Small Business Establishment

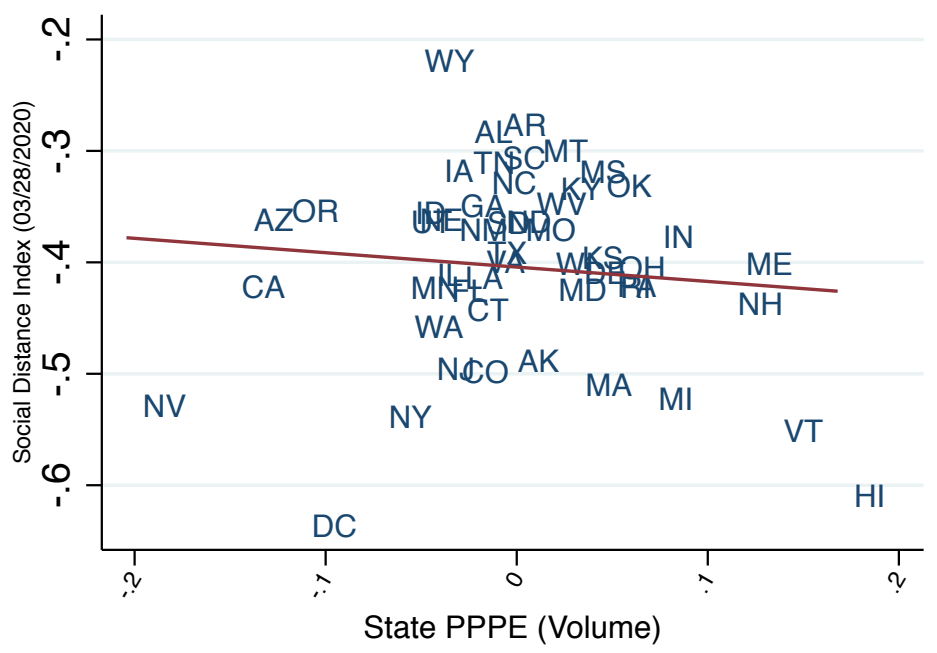

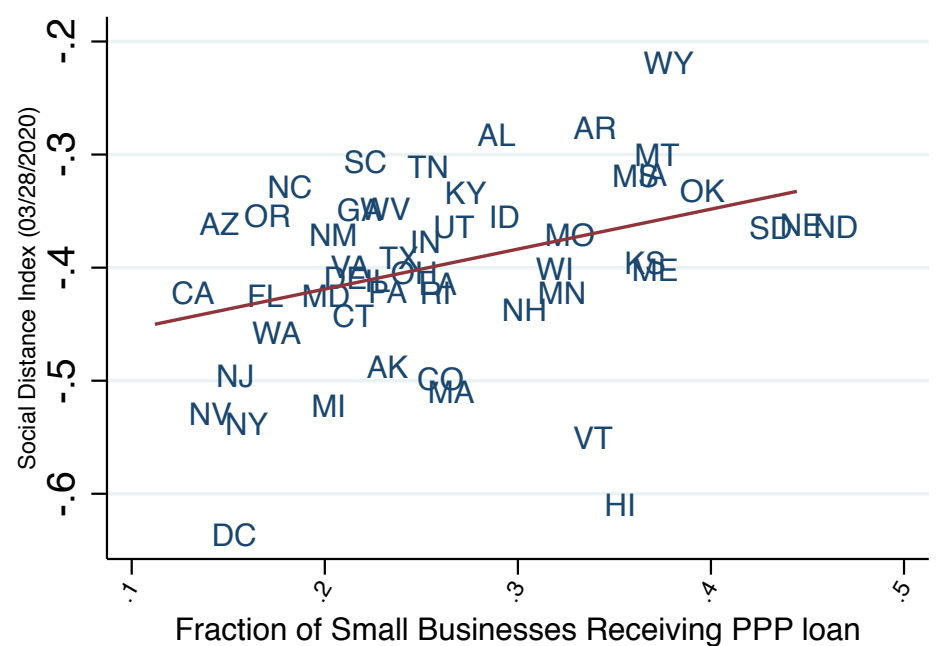

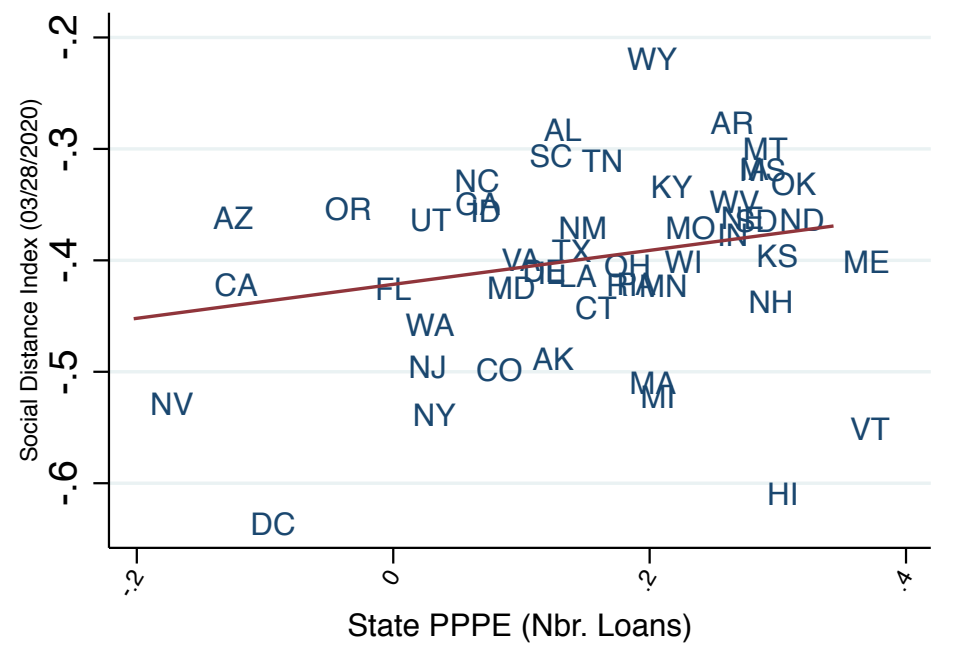




\section{Figure A.8: State Unemployment Insurance and PPP Allocation by State}

Figure A.8 presents four scatterplots of the ratio of state unemployment insurance claims to employment covered by unemployment insurance and four alternative measures of allocation of PPP funds across states. State unemployment insurance claims are the sum of filed claim in the weeks ended March 21st, March 28th, and April 4th, 2020. The figure on the top left plots the amount of PPP loans received by small businesses in each state divided by the total number of small businesses in the state. The figure on the top right corner plots the fraction of small businesses in each state that received a PPP loan. The figure on the bottom left corner plots the fraction of small businesses in each state that received a PPP loan and the state exposure to the PPPE measured in terms of the total volume of loans. The figure on the bottom right corner plots the fraction of small businesses in each state that received a PPP loan and the state exposure to the PPPE measured in terms of the total number of loans. Data comes from the Department of Labor, SBA, Call Reports, and FDIC Summary of Deposits.

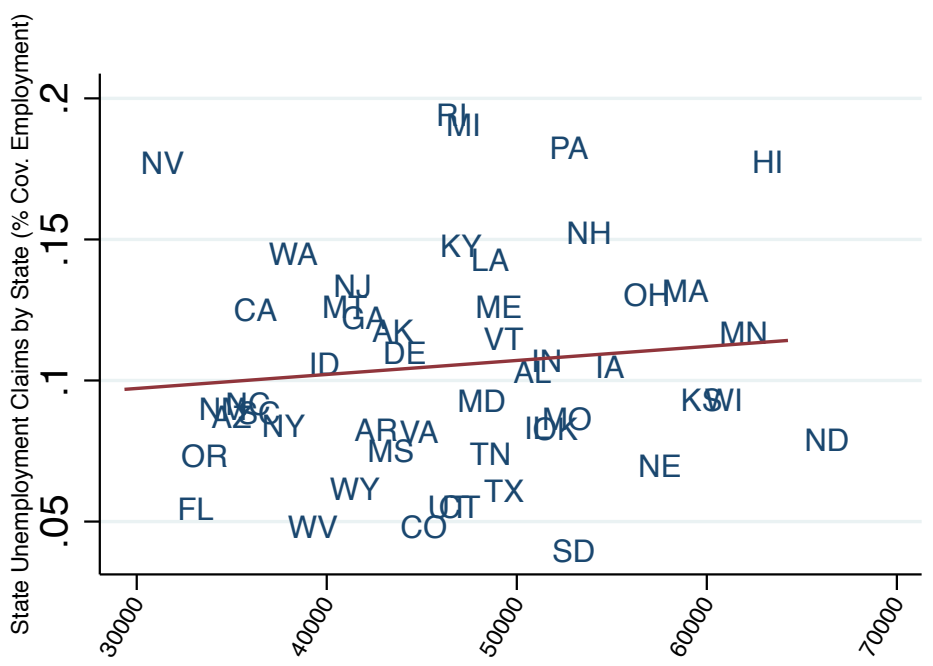

PPP volume per Small Business Establishment

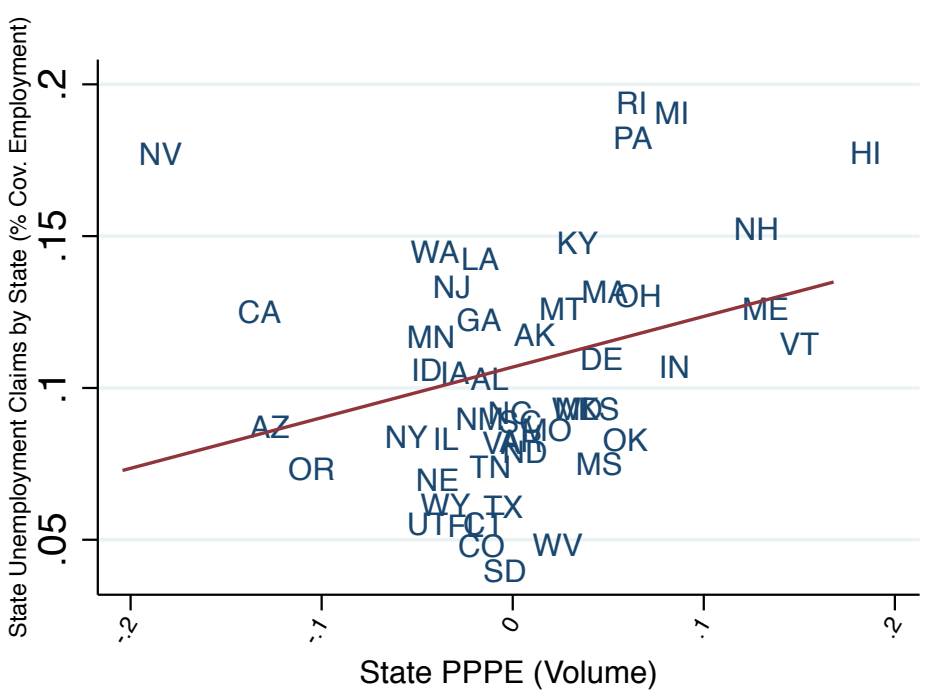

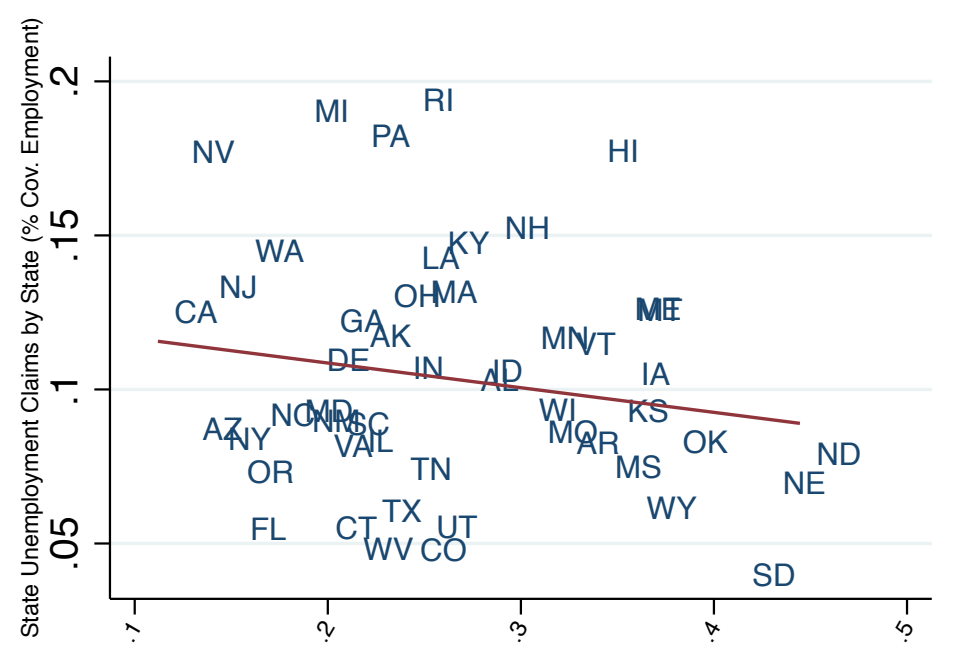

Fraction of Small Businesses Receiving PPP loan

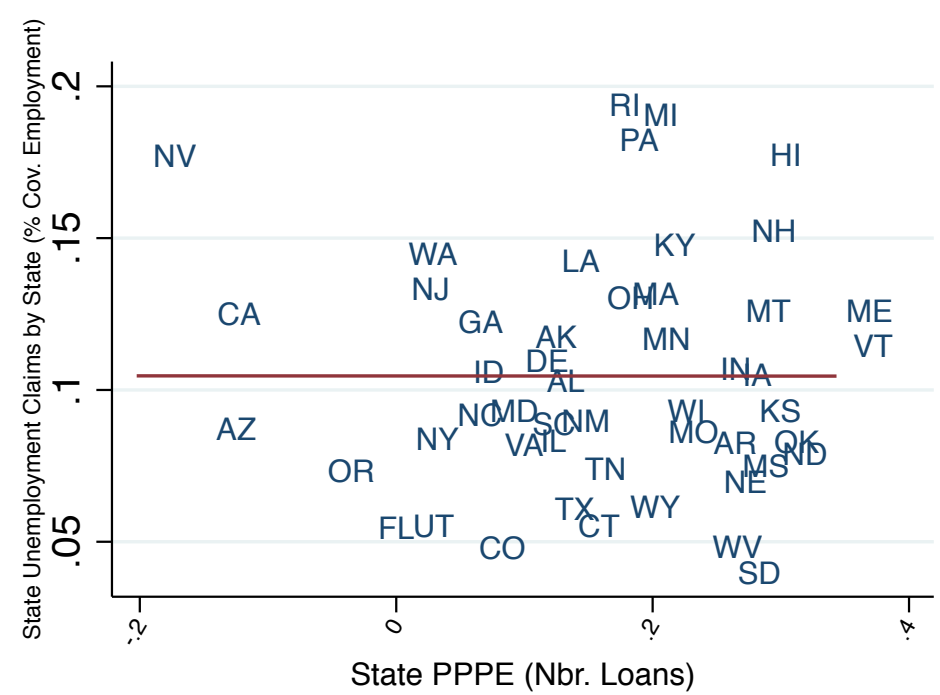




\section{Figure A.9: Weekly Elasticities of Employment Outcomes to \% Businesses Receiving PPP}

Figure A.9 plots coefficients and respective standard errors of regression analyses investigating the week-by-week elasticities between employment and firm outcomes and exposure to PPPE. The left figure plots the coefficients and respective standard errors of an empirical specification that augments the specification of Panel A of Table 5 column ( 3 ) to include a full set of interactions between the fraction of businesses receiving PPP in the Congressional District during the first round and week dummy variables. The figure on the right plots the coefficients and respective standard errors of an empirical specification that augments the specification of Panel B of Table 5 column (3) to include a full set of interactions between the Congressional District PPPE and week dummy variables.
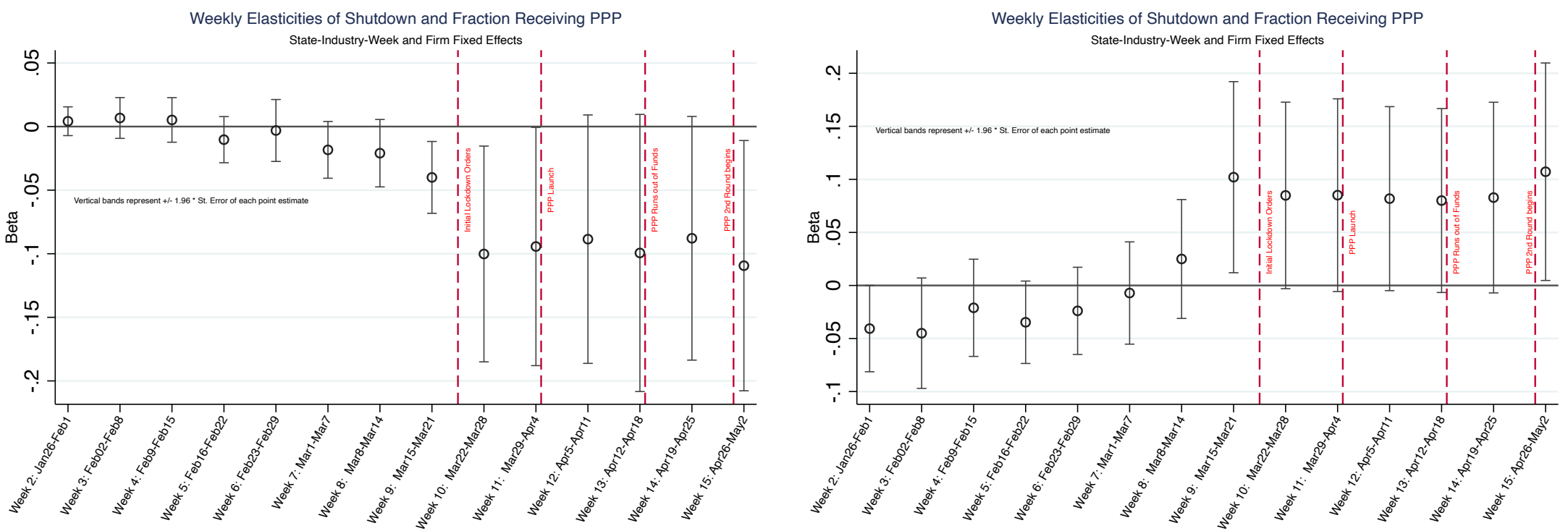


\section{Figure A.10: Unmet PPP Demand and Exposure to State PPPE (Industry $\times$ State)}

Figure A.10 are scatterplots of the state exposure to the number-based PPPE and the percentage of businesses in each industry within a state that applied but did not receive PPP. The plots represent the evolution of the two variables for each survey week. Data comes from the Census Bureau, SBA, Call Reports, Summary of Deposits, and County Business Patterns.
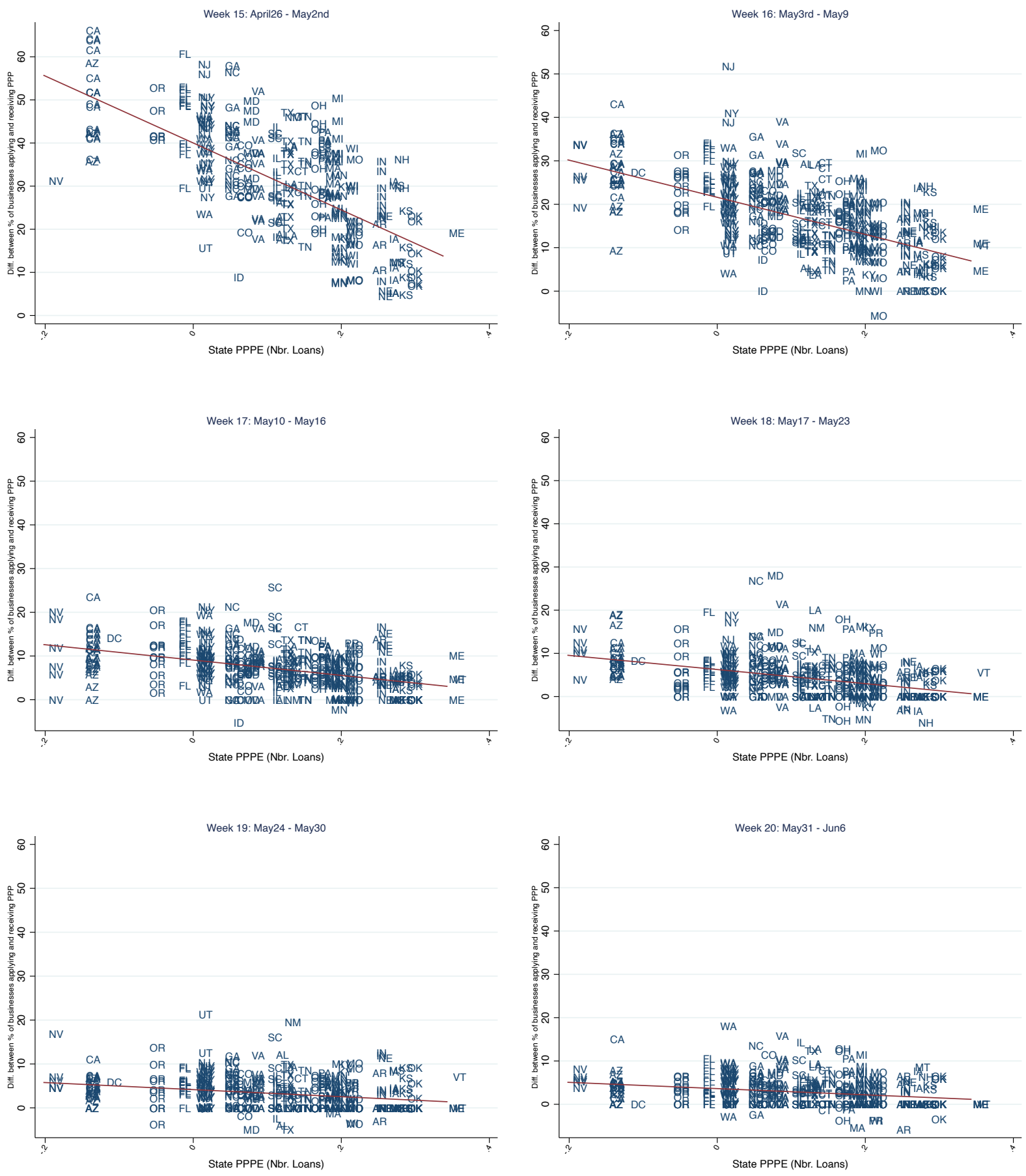


\section{Figure A.11: \% Receiving PPP and Exposure to MSA PPPE}

Figure A.11 are scatterplots of the MSA exposure to the number-based PPPE and the percentage of businesses in each MSA that applied but did not receive PPP in each week. The plots represent the evolution of the two variables for each survey week. Data comes from the Census Bureau, SBA, Call Reports, Summary of Deposits, and County Business Patterns.
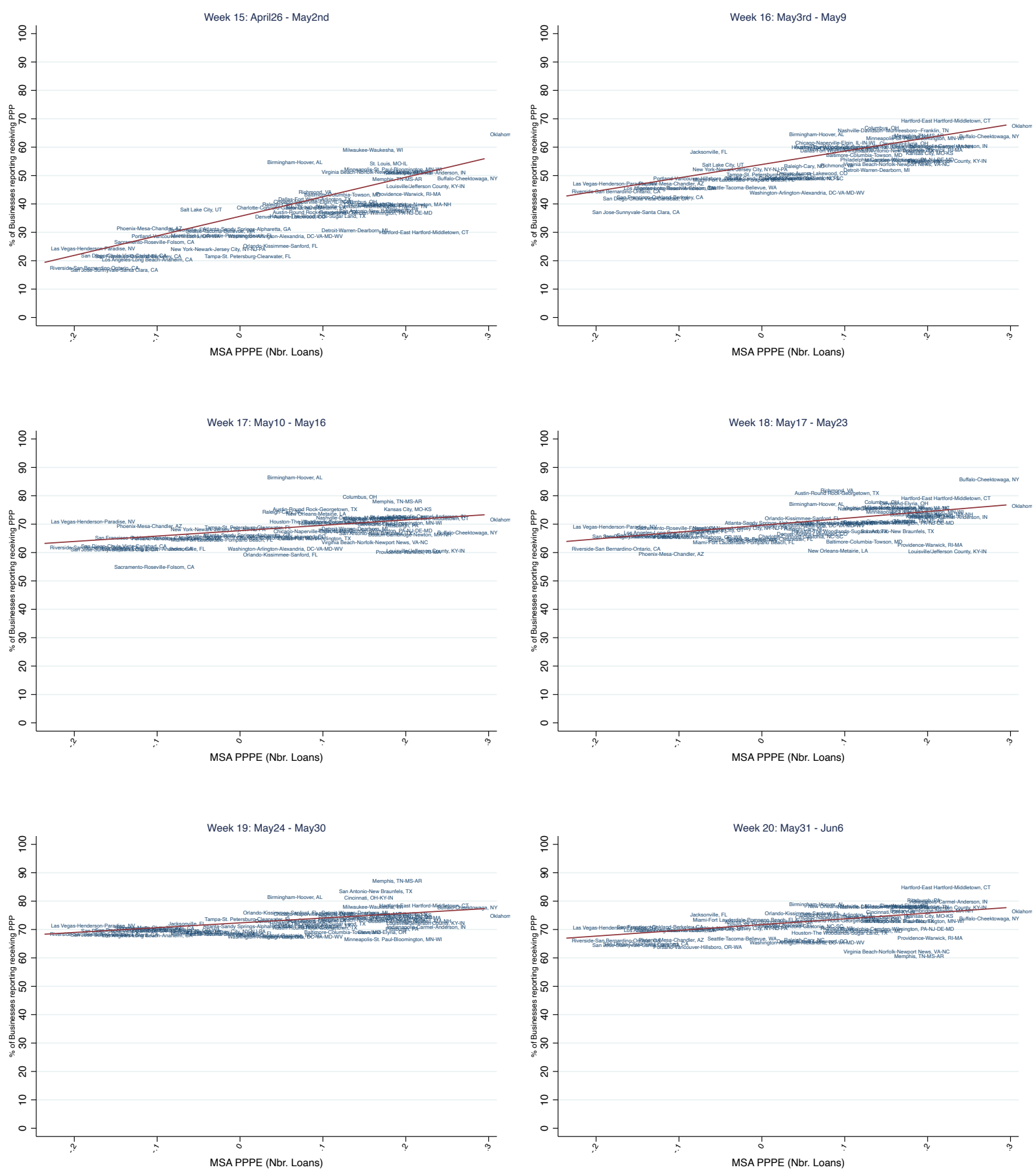


\section{Figure A.12: Unmet PPP Demand and Exposure to MSA PPPE}

Figure A.12 are scatterplots of the MSA exposure to the number-based PPPE and the percentage of businesses in each MSA that applied but did not receive PPP in each week. The plots represent the evolution of the two variables for each survey week. Data comes from the Census Bureau, SBA, Call Reports, Summary of Deposits, and County Business Patterns.
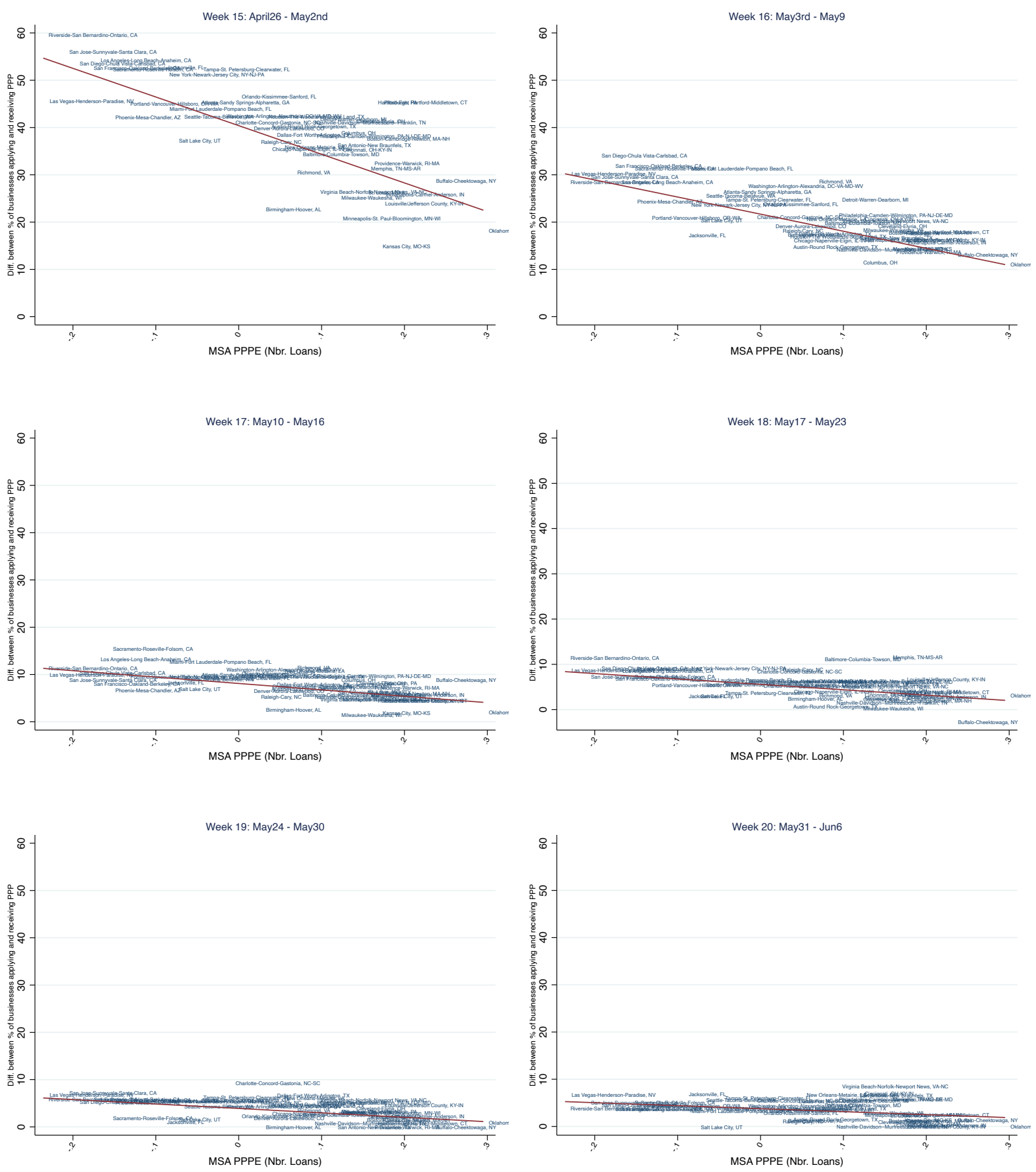


\section{Table A.1: Wells Fargo and PPP Allocation}

Table A.1 reports the results of ordinary least squares (OLS) regressions examining the impact of the exposure of the Congressional District to Wells Fargo on the allocation of PPP funds. The dependent variable of the specifications, Ln(Total PPP Allocation per establishment), is the natural logarithm total amount of PPP funds disbursed to small businesses in each congressional district divided by the number of establishments in the congressional district. The dependent variable of the specifications in Panel B, Ln(Total PPP Allocation per establishment) is the total number of PPP loans made to small businesses in each congressional district divided by the number of establishments in the congressional district. Share of Wells in the Congressional District is share of branches owned by Wells Fargo in the Congressional District. Ln(Payroll) is the natural logarithm of the sum of payroll of all establishments in the congressional district Ln(Employment) is the natural logarithm of total employment in the congressional district Industry Shares are additional controls for the share of establishments in each two-digit NAICS code industry. The specification of column (4) includes state fixed effects Standard errors are presented in parentheses, and are clustered at the level of the state. ${ }^{* *},{ }^{* *}$, and *, represent statistical significance at $1 \%, 5 \%$, and $10 \%$ levels, respectively.

Panel A: Total PPP Allocation per Establishment at the Congressional District

\begin{tabular}{lcccc}
\hline \hline & $(1)$ & $(2)$ & $(3)$ & $(4)$ \\
& Ln(Total & PPP Allocation & per Establishment) \\
\hline Share of Wells Branches in Cong Dist. & $-1.871^{* * * *}$ & $-1.977^{* * * *}$ & $-1.277^{* *}$ & -2.317 \\
& $(0.526)$ & $(0.594)$ & $(0.629)$ & $(1.721)$ \\
Ln(Total Payroll) & & 0.078 & 0.116 & 0.127 \\
& & $(0.299)$ & $(0.253)$ & $(0.251)$ \\
Ln(Employment) & & 0.259 & 0.105 & 0.183 \\
& & $(0.521)$ & $(0.354)$ & $(0.367)$ \\
\hline Observations & 436 & 436 & 436 & 436 \\
Adjusted $R^{2}$ & 0.047 & 0.088 & 0.125 & 0.097 \\
Industry Shares & No & No & Yes & Yes \\
State Fixed Effects & No & No & No & Yes \\
\hline \hline
\end{tabular}

Panel B: Fraction of Establishment receiving PPP at the Congressional District

\begin{tabular}{|c|c|c|c|c|}
\hline & (1) & (2) & (3) & (4) \\
\hline & \multicolumn{4}{|c|}{ Fraction of Establishments receiving PPP } \\
\hline Share of Wells Branches in Cong Dist. & $\begin{array}{c}-0.588^{* * *} \\
(0.148)\end{array}$ & $\begin{array}{c}-0.492^{* * *} \\
(0.137)\end{array}$ & $\begin{array}{c}-0.272^{* *} \\
(0.108)\end{array}$ & $\begin{array}{l}-0.287 \\
(0.276)\end{array}$ \\
\hline Ln(Total Payroll) & & $\begin{array}{c}-0.162^{* * * *} \\
(0.061)\end{array}$ & $\begin{array}{c}-0.119^{* * * *} \\
(0.043)\end{array}$ & $\begin{array}{l}-0.071^{*} \\
(0.041)\end{array}$ \\
\hline Ln(Employment) & & $\begin{array}{l}0.233^{* *} \\
(0.098)\end{array}$ & $\begin{array}{c}0.172^{\text {**** }} \\
(0.062)\end{array}$ & $\begin{array}{c}0.099 \\
(0.070)\end{array}$ \\
\hline Observations & 436 & 436 & 436 & 436 \\
\hline Adjusted $R^{2}$ & 0.151 & 0.210 & 0.376 & 0.455 \\
\hline Industry Shares & No & No & Yes & Yes \\
\hline State Fixed Effects & No & No & No & Yes \\
\hline
\end{tabular}




\section{Table A.2: Business Shutdowns and PPP Allocation}

Table A.2 reports the results of ordinary least squares (OLS) regressions examining the relation between the allocation of PPP funds and the share of businesses that shutdown operations in the last week of March. The dependent variable, Share of Firms Shutdown (March 31st, 2020), is the share of businesses in the congressional district that did not operate in the week of March29th-April 4th. Ln(Total PPP Allocation per establishment) is the natural logarithm total amount of PPP funds disbursed to small businesses in each congressional district divided by the number of establishments in the congressional district. Fraction of Establishments receiving PPP is the total number of PPP loans made to small businesses in each congressional district divided by the number of establishments in the congressional district. Congressional District PPPE (Vol) is the congressional district average of the PPPE based on total amounts of outstanding PPP and small business loans, weighted by the share of deposits of each bank in each congressional district. Congressional District PPPE (Nbr.) is the congressional district average of the PPPE based on the number of outstanding loans, weighted by the share of deposits of each bank in each congressional district. Ln(Payroll) is the natural logarithm of the sum of payroll of all establishments in the congressional district Ln(Employment) is the natural logarithm of total employment in the congressional district Industry Shares are additional controls for the share of establishments in each two-digit NAICS code industry. Standard errors are presented in parentheses, and are clustered at the level of the state. $* * *, * *$, and *, represent statistical significance at $1 \%, 5 \%$, and $10 \%$ levels, respectively.

\begin{tabular}{|c|c|c|c|c|c|c|c|c|}
\hline & (1) & (2) & (3) & (4) & (5) & (6) & (7) & (8) \\
\hline & \multicolumn{8}{|c|}{ Share of Firms Shutdown (March 31st, 2020) } \\
\hline Fraction receiving PPP & $\begin{array}{c}-0.078 \\
(0.049)\end{array}$ & $\begin{array}{c}-0.025 \\
(0.045)\end{array}$ & & & & & & \\
\hline Ln(PPP loan per establishment) & & & $\begin{array}{c}0.008 \\
(0.007)\end{array}$ & $\begin{array}{c}0.008 \\
(0.006)\end{array}$ & & & & \\
\hline Congressional District PPPE (Vol) & & & & & $\begin{array}{c}0.020^{*} \\
(0.010)\end{array}$ & $\begin{array}{c}-0.008 \\
(0.008)\end{array}$ & & \\
\hline Congressional District PPPE (Nbr.) & & & & & & & $\begin{array}{c}0.019 \\
(0.012)\end{array}$ & $\begin{array}{c}-0.015 \\
(0.011)\end{array}$ \\
\hline Ln(Total Payroll) & $\begin{array}{c}0.062 \\
(0.039)\end{array}$ & $\begin{array}{c}0.011 \\
(0.022)\end{array}$ & $\begin{array}{c}0.071^{*} \\
(0.041)\end{array}$ & $\begin{array}{c}0.014 \\
(0.021)\end{array}$ & $\begin{array}{l}0.096^{* *} \\
(0.044)\end{array}$ & $\begin{array}{c}0.006 \\
(0.025)\end{array}$ & $\begin{array}{l}0.095^{* *} \\
(0.044)\end{array}$ & $\begin{array}{c}-0.004 \\
(0.030)\end{array}$ \\
\hline Ln(Employment) & $\begin{array}{c}0.023 \\
(0.050)\end{array}$ & $\begin{array}{c}0.010 \\
(0.043)\end{array}$ & $\begin{array}{c}-0.000 \\
(0.053)\end{array}$ & $\begin{array}{c}-0.001 \\
(0.040)\end{array}$ & $\begin{array}{c}-0.038 \\
(0.064)\end{array}$ & $\begin{array}{c}0.016 \\
(0.046)\end{array}$ & $\begin{array}{c}-0.038 \\
(0.066)\end{array}$ & $\begin{array}{c}0.028 \\
(0.051)\end{array}$ \\
\hline Observations & 436 & 436 & 436 & 436 & 436 & 436 & 436 & 436 \\
\hline Adjusted $R^{2}$ & 0.317 & 0.583 & 0.315 & 0.584 & 0.335 & 0.584 & 0.325 & 0.586 \\
\hline Industry Shares & Yes & Yes & Yes & Yes & Yes & Yes & Yes & Yes \\
\hline State Fixed Effects & No & Yes & No & Yes & No & Yes & No & Yes \\
\hline
\end{tabular}




\section{Table A.3: Decline in Hours Worked and PPP Allocation}

Table A.3 reports the results of ordinary least squares (OLS) regressions examining the relation between the allocation of PPP funds and the share of businesses that shutdown operations in the last week of March. The dependent variable, Decline in Hours Worked (March 31st, 2020), is the decline in hours worked at establishments located in the congressional district related to the average hours worked in the same weekdays of the last two weeks of January at the same congressional district. Ln(Total PPP Allocation per establishment) is the natural logarithm total amount of PPP funds disbursed to small businesses in each congressional district divided by the number of establishments in the congressional district. Fraction of Establishments receiving PPP is the total number of PPP loans made to small businesses in each congressional district divided by the number of establishments in the congressional district. Congressional District PPPE (Vol) is the congressional district average of the PPPE based on total amounts of outstanding PPP and small business loans, weighted by the share of deposits of each bank in each congressional district. Congressional District PPPE (Nbr.) is the congressional district average of the PPPE based on the number of outstanding loans, weighted by the share of branches of each bank in each congressional district. Ln(Payroll) is the natural logarithm of the sum of payroll of all establishments in the congressional district Ln(Employment) is the natural logarithm of total employment in the congressional district Industry Shares are additional controls for the share of establishments in each two-digit NAICS code industry. Standard errors are presented in parentheses, and are clustered at the level of the state. ***,

**, and *, represent statistical significance at $1 \%, 5 \%$, and $10 \%$ levels, respectively.

\begin{tabular}{|c|c|c|c|c|c|c|c|c|}
\hline & (1) & (2) & (3) & (4) & (5) & (6) & (7) & (8) \\
\hline & \multicolumn{8}{|c|}{ Decline in Hours Worked (March 31st, 2020) } \\
\hline Fraction receiving PPP & $\begin{array}{l}0.121^{*} \\
(0.067)\end{array}$ & $\begin{array}{c}0.051 \\
(0.068)\end{array}$ & & & & & & \\
\hline Ln(PPP loan per establishment) & & & $\begin{array}{l}-0.005 \\
(0.007)\end{array}$ & $\begin{array}{c}-0.005 \\
(0.007)\end{array}$ & & & & \\
\hline Congressional District PPPE (Vol) & & & & & $\begin{array}{c}-0.022^{* *} \\
(0.010)\end{array}$ & $\begin{array}{c}-0.001 \\
(0.011)\end{array}$ & & \\
\hline Congressional District PPPE (Nbr.) & & & & & & & $\begin{array}{l}-0.024^{*} \\
(0.014)\end{array}$ & $\begin{array}{l}-0.002 \\
(0.017)\end{array}$ \\
\hline Ln(Total Payroll) & $\begin{array}{c}-0.073^{* *} \\
(0.032)\end{array}$ & $\begin{array}{c}0.014 \\
(0.043)\end{array}$ & $\begin{array}{c}-0.087^{* *} \\
(0.034)\end{array}$ & $\begin{array}{c}0.009 \\
(0.041)\end{array}$ & $\begin{array}{c}-0.114^{* * *} \\
(0.038)\end{array}$ & $\begin{array}{c}0.008 \\
(0.047)\end{array}$ & $\begin{array}{c}-0.117^{* * *} \\
(0.038)\end{array}$ & $\begin{array}{c}0.007 \\
(0.052)\end{array}$ \\
\hline Ln(Employment) & $\begin{array}{l}-0.011 \\
(0.043)\end{array}$ & $\begin{array}{l}-0.065 \\
(0.069)\end{array}$ & $\begin{array}{c}0.017 \\
(0.046)\end{array}$ & $\begin{array}{c}-0.054 \\
(0.068)\end{array}$ & $\begin{array}{c}0.063 \\
(0.059)\end{array}$ & $\begin{array}{c}-0.058 \\
(0.076)\end{array}$ & $\begin{array}{c}0.069 \\
(0.063)\end{array}$ & $\begin{array}{c}-0.056 \\
(0.083)\end{array}$ \\
\hline Observations & 436 & 436 & 436 & 436 & 436 & 436 & 436 & 436 \\
\hline Adjusted $R^{2}$ & 0.274 & 0.462 & 0.267 & 0.461 & 0.286 & 0.461 & 0.280 & 0.461 \\
\hline Industry Shares & Yes & Yes & Yes & Yes & Yes & Yes & Yes & Yes \\
\hline State Fixed Effects & No & Yes & No & Yes & No & Yes & No & Yes \\
\hline
\end{tabular}




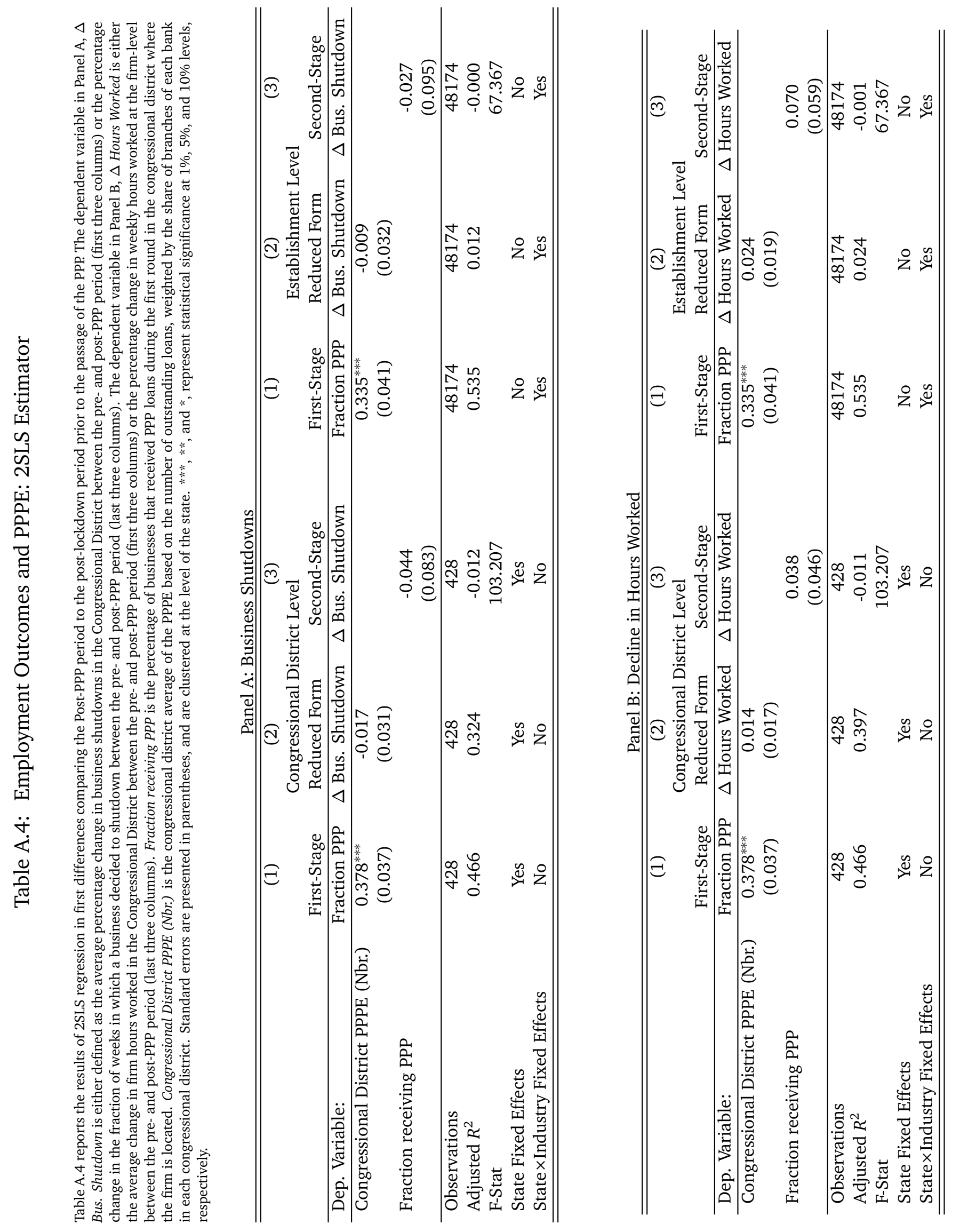




\section{Table A.5: Unmet Demand for Loans and Exposure to PPP}

Table A.5 reports the results of ordinary least squares (OLS) regressions examining the relation between the geographic allocation of PPP funds during the first round and the percentage of businesses reporting applying but not receiving PPP funds at the state-by-industry level. The dependent variable is the difference between the percentage of businesses that applied for PPP funds and the percentage of businesses that received PPP funds at the state-by-industry level. State PPPE ( $\mathrm{Nbr}$.) is the state average of the PPPE based on the number of outstanding loans. All specifications include industry $\times$ week fixed-effects. Standard errors are presented in parentheses, and are clustered at the level of the state. $* * *$, **, and *, represent statistical significance at $1 \%, 5 \%$, and $10 \%$ levels, respectively.

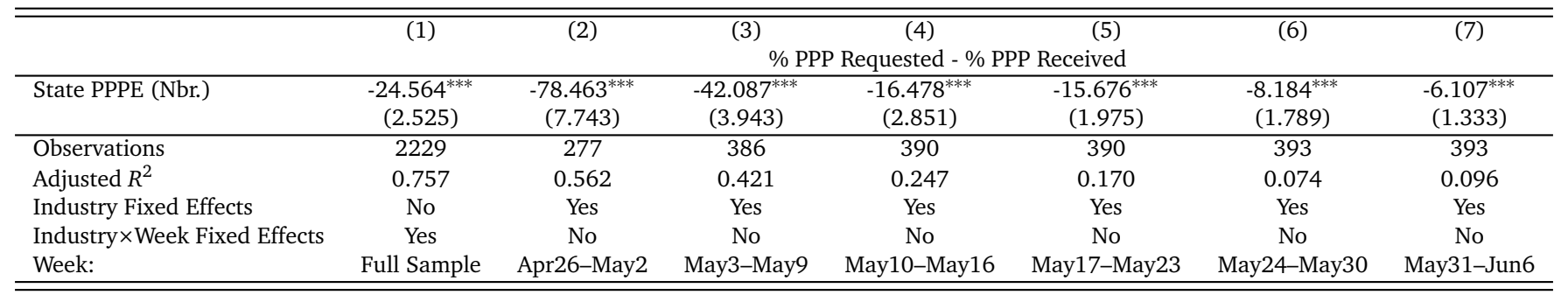




\section{Table A.6: Unmet Demand for PPP and Missed Loan Payments}

Table A.6 reports the results of ordinary least squares (OLS) and instrumental variables (IV) regressions examining the relation between the geographic allocation of PPP funds during the first round and the percentage of businesses reporting missing scheduled payments at the state-by-industry level. The dependent variable is the percentage of firms reporting a missed scheduled loan payment. \% PPP Requested - \% PPP Received is the difference between the percentage of businesses that applied for PPP funds and the percentage of businesses that received PPP funds at a state-by-industry level. State PPPE (Nbr.) is the state average of the PPPE based on the number of outstanding loans. Pre-PPP Decline Hours Worked is the average decline in hours worked in each state between January and the last week of March. Pre-PPP State Covid-19 Cases (per capita) are per capita number of reported Covid-19 cases in the state. Pre-PPP State Covid-19 Deaths (per capita) are the weekly per capita number of reported Covid-19 deaths in the state. Pre-PPP State Social Distancing Index is the change in average distance travelled in the state until the end of March using individuals' GPS signals. All specifications include industry $\times$ week fixed-effects. Standard errors are presented in parentheses, and are clustered at the level of the state. *** **, and

$*$, represent statistical significance at $1 \%, 5 \%$, and $10 \%$ levels, respectively.

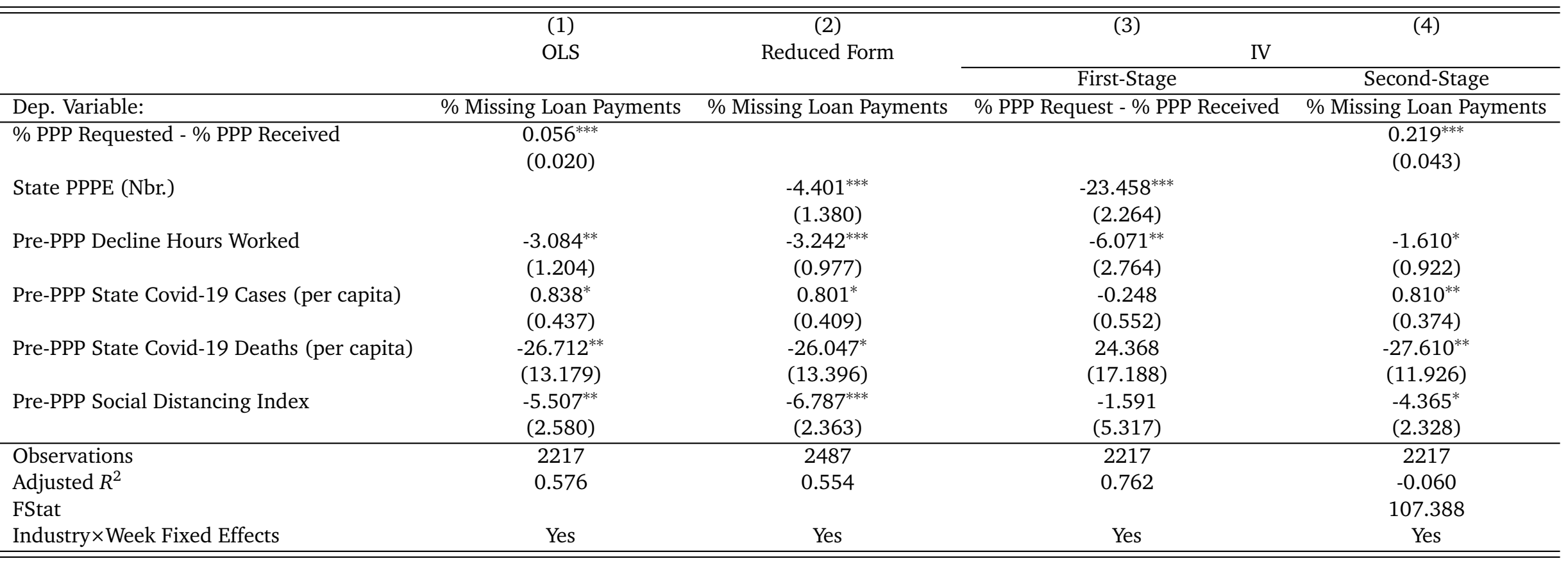




\section{Table A.7: Unmet Demand for PPP and Missed Non-Loan Payments}

Table A.7 reports the results of ordinary least squares (OLS) and instrumental variables (IV) regressions examining the relation between the geographic allocation of PPP funds during the first round and the percentage of businesses reporting missing scheduled payments at the state-by-industry level. The dependent variable is the percentage of firms reporting a missed other scheduled payment such as rent, utilities, and payroll. \% PPP Requested - \% PPP Received is the difference between the percentage of businesses that applied for PPP funds and the percentage of businesses that received PPP funds at a state-by-industry level. State PPPE (Nbr.) is the state average of the PPPE based on the number of outstanding loans. Pre-PPP Decline Hours Worked is the average decline in hours worked in each state between January and the last week of March. Pre-PPP State Covid-19 Cases (per capita) are per capita number of reported Covid-19 cases in the state. Pre-PPP State Covid-19 Deaths (per capita) are the weekly per capita number of reported Covid-19 deaths in the state. Pre-PPP State Social Distancing Index is the change in average distance travelled in the state until the end of March using individuals' GPS signals. All specifications include industry $\times$ week fixed-effects. Standard errors are presented in parentheses, and are clustered at the level of the state. ***,**, and *, represent statistical significance at $1 \%, 5 \%$, and $10 \%$ levels, respectively.

\begin{tabular}{|c|c|c|c|c|}
\hline & (1) & $(2)$ & (3) & (4) \\
\hline & OLS & Reduced Form & \multicolumn{2}{|l|}{ IV } \\
\hline & & & First-Stage & Second-Stage \\
\hline Dep. Variable: & \% Missing Schd. Payments & \% Missing Schd. Payments & \% PPP Request - \% PPP Received & \% Missing Schd. Payments \\
\hline \% PPP Requested - \% PPP Received & $\begin{array}{c}0.229^{* * *} \\
(0.029)\end{array}$ & & & $\begin{array}{c}0.639^{* * *} \\
(0.068)\end{array}$ \\
\hline State PPPE (Nbr.) & & $\begin{array}{c}-14.807^{* * *} \\
(2.651)\end{array}$ & $\begin{array}{c}-23.577^{* * *} \\
(2.211)\end{array}$ & \\
\hline Pre-PPP Decline Hours Worked & $\begin{array}{c}-11.404^{* * *} \\
(3.328)\end{array}$ & $\begin{array}{l}-12.176^{* * *} \\
(4.094)\end{array}$ & $\begin{array}{l}-6.119^{* *} \\
(2.770)\end{array}$ & $\begin{array}{l}-7.682^{* *} \\
(3.127)\end{array}$ \\
\hline Pre-PPP State Covid-19 Cases (per capita) & $\begin{array}{c}4.261^{* * *} \\
(0.666)\end{array}$ & $\begin{array}{c}4.189^{* * *} \\
(0.577)\end{array}$ & $\begin{array}{l}-0.270 \\
(0.556)\end{array}$ & $\begin{array}{c}4.199^{* * *} \\
(0.361)\end{array}$ \\
\hline Pre-PPP State Covid-19 Deaths (per capita) & $\begin{array}{c}-110.471^{* * *} \\
(25.156)\end{array}$ & $\begin{array}{c}-101.315^{* * *} \\
(20.723)\end{array}$ & $\begin{array}{c}24.296 \\
(17.605)\end{array}$ & $\begin{array}{c}-112.755^{* * *} \\
(18.614)\end{array}$ \\
\hline Pre-PPP Social Distancing Index & $\begin{array}{c}-16.215^{* * *} \\
(5.683)\end{array}$ & $\begin{array}{c}-13.084^{* *} \\
(6.317)\end{array}$ & $\begin{array}{l}-1.645 \\
(5.344)\end{array}$ & $\begin{array}{c}-13.250^{* * *} \\
(4.319)\end{array}$ \\
\hline Observations & 2205 & 2448 & 2205 & 2205 \\
\hline Adjusted $R^{2}$ & 0.718 & 0.698 & 0.762 & 0.086 \\
\hline FStat & & & & 113.656 \\
\hline Industry $\times$ Week Fixed Effects & Yes & Yes & Yes & Yes \\
\hline
\end{tabular}




\section{Table A.8: Unmet Demand for Loans and Cash-on-Hand}

Table A.8 reports the results of ordinary least squares (OLS) and instrumental variables (IV) regressions examining the relation between the geographic allocation of PPP funds during the first round and the percentage of businesses reporting at two months or more of cash-on-hand at the state-by-industry level. The dependent variable is the fraction of businesses with cash on hand to sustain operations for two months or more. \% PPP Requested - \% PPP Received is the difference between the percentage of businesses that applied for PPP funds and the percentage of businesses that received PPP funds at a state-by-industry level. State PPPE (Nbr.) is the state average of the PPPE based on the number of outstanding loans. Pre-PPP Decline Hours Worked is the average decline in hours worked in each state between January and the last week of March. Pre-PPP State Covid-19 Cases (per capita) are per capita number of reported Covid-19 cases in the state. Pre-PPP State Covid-19 Deaths (per capita) are the weekly per capita number of reported Covid-19 deaths in the state. Pre-PPP State Social Distancing Index is the change in average distance travelled in the state until the end of March using individuals' GPS signals. All specifications include industryx week fixed-effects. Standard errors are presented in parentheses, and are clustered at the level of the state. $* * * * *$, and $*$, represent statistical significance at $1 \%, 5 \%$, and $10 \%$ levels, respectively.

\begin{tabular}{|c|c|c|c|c|}
\hline & (1) & $\begin{array}{c}(2) \\
\text { (2) }\end{array}$ & (3) & (4) \\
\hline & & & First-Stage & Second-Stage \\
\hline Dep. Variable: & \% Cash 3 months & $\%$ Cash 3 months & \% PPP Request - \% PPP Received & $\%$ Cash 3 months \\
\hline \% PPP Requested - \% PPP Received & $\begin{array}{c}-0.172^{* * *} \\
(0.047)\end{array}$ & & & $\begin{array}{c}-0.411^{* *} \\
(0.152)\end{array}$ \\
\hline State PPPE (Nbr.) & & $\begin{array}{l}8.920^{* *} \\
(3.768)\end{array}$ & $\begin{array}{c}-21.380^{* * *} \\
(2.019)\end{array}$ & \\
\hline Pre-PPP Decline Hours Worked & $\begin{array}{l}10.973^{*} \\
(5.868)\end{array}$ & $\begin{array}{c}15.861^{* * *} \\
(5.378)\end{array}$ & $\begin{array}{c}-6.302 \\
(4.006)\end{array}$ & $\begin{array}{c}9.596 \\
(5.830)\end{array}$ \\
\hline Pre-PPP State Covid-19 Cases (per capita) & $\begin{array}{c}-1.912^{* *} \\
(0.743)\end{array}$ & $\begin{array}{c}-2.003^{* *} \\
(0.818)\end{array}$ & $\begin{array}{c}0.219 \\
(0.381)\end{array}$ & $\begin{array}{c}-1.820^{* *} \\
(0.756)\end{array}$ \\
\hline Pre-PPP State Covid-19 Deaths (per capita) & $\begin{array}{l}75.800^{* *} \\
(29.392)\end{array}$ & $\begin{array}{l}76.722^{\text {** }} \\
(31.278)\end{array}$ & $\begin{array}{c}17.796 \\
(17.170)\end{array}$ & $\begin{array}{l}76.570^{* *} \\
(31.054)\end{array}$ \\
\hline Pre-PPP Social Distancing Index & $\begin{array}{c}-6.618 \\
(9.077)\end{array}$ & $\begin{array}{c}-12.334 \\
(11.326)\end{array}$ & $\begin{array}{c}5.529 \\
(5.524)\end{array}$ & $\begin{array}{c}-6.293 \\
(9.132)\end{array}$ \\
\hline Observations & 903 & 918 & 903 & 903 \\
\hline Adjusted $R^{2}$ & 0.637 & 0.640 & 0.846 & -0.077 \\
\hline FStat & & & & 112.191 \\
\hline Industry $\times$ Week Fixed Effects & Yes & Yes & Yes & Yes \\
\hline
\end{tabular}


Table A.9: \% Receiving PPP and \% Missing Payments: Week-by-Week

Table A.9 reports the results of instrumental variables (IV) regressions split week by week examining the relation between the geographic allocation of PPP funds during the first round and the percentage of businesses reporting missing scheduled payments at the state-by-industry level. In the top panel, the dependent variable is the percentage of firms reporting a missed scheduled loan payment. In the bottom panel, the dependent variable is the percentage of firms reporting a missed other scheduled payment such as rent, utilities, and payroll. \% PPP Received is the percentage of businesses reporting having received PPP funds in a state-by-industry group. State PPPE (Nbr.) is the state average of the PPPE based on the number of outstanding loans. All specifications include industry $\times$ week fixed-effects. Standard errors are presented in parentheses, and are clustered at the level of the state. ***,**, and *, represent statistical significance at $1 \%, 5 \%$, and $10 \%$ levels, respectively.

Panel A: Missing Loan Payments

\begin{tabular}{|c|c|c|c|c|c|c|c|}
\hline & (1) & (2) & (3) & (4) & $(5)$ & (6) & (7) \\
\hline & \multicolumn{7}{|c|}{ \% Missing Loan Payments } \\
\hline \multirow[t]{2}{*}{ \%PPP Received } & $-0.173^{* * *}$ & $-0.068^{*}$ & $-0.148^{* * *}$ & $-0.278^{* * *}$ & $-0.210^{* * *}$ & $-0.349^{* * *}$ & $-0.208^{* *}$ \\
\hline & $(0.041)$ & $(0.034)$ & $(0.048)$ & $(0.097)$ & $(0.075)$ & $(0.122)$ & $(0.091)$ \\
\hline Observations & 2229 & 277 & 386 & 390 & 389 & 393 & 394 \\
\hline Adjusted $R^{2}$ & -0.154 & -0.021 & -0.076 & -0.370 & -0.336 & -0.665 & -0.185 \\
\hline FStat & 126.358 & 120.162 & 144.125 & 44.222 & 30.384 & 22.335 & 39.285 \\
\hline Industry Fixed Effects & No & Yes & Yes & Yes & Yes & Yes & Yes \\
\hline Industry $\times$ Week Fixed Effects & Yes & No & No & No & No & No & No \\
\hline Week: & Full Sample & Apr26-May2 & May3-May9 & May10-May16 & May17-May23 & May24-May30 & May31-Jun6 \\
\hline
\end{tabular}

Panel B: Missing Other Scheduled Payments (Rent, Utilities, Payroll)

\begin{tabular}{|c|c|c|c|c|c|c|c|}
\hline & (1) & (2) & (3) & (4) & $(5)$ & (6) & (7) \\
\hline & \multicolumn{7}{|c|}{ \% Missing Schd. Payments } \\
\hline \%PPP Received & $\begin{array}{c}-0.555^{* * *} \\
(0.110)\end{array}$ & $\begin{array}{c}-0.282^{* * *} \\
(0.060)\end{array}$ & $\begin{array}{c}-0.468^{* * *} \\
(0.092) \\
\end{array}$ & $\begin{array}{c}-0.880^{* * *} \\
(0.187)\end{array}$ & $\begin{array}{c}-0.651^{* * *} \\
(0.226)\end{array}$ & $\begin{array}{c}-0.998^{* * *} \\
(0.291)\end{array}$ & $\begin{array}{c}-0.630^{* * *} \\
(0.218)\end{array}$ \\
\hline Observations & 2216 & 277 & 385 & 387 & 388 & 389 & 390 \\
\hline Adjusted $R^{2}$ & -0.346 & 0.153 & -0.067 & -1.089 & -0.687 & -1.932 & -0.403 \\
\hline FStat & 131.427 & 120.162 & 144.126 & 44.423 & 29.598 & 25.182 & 39.759 \\
\hline Industry Fixed Effects & No & Yes & Yes & Yes & Yes & Yes & Yes \\
\hline Industry $\times$ Week Fixed Effects & Yes & No & No & No & No & No & No \\
\hline Week: & Full Sample & Apr26-May2 & May3-May9 & May10-May16 & May17-May23 & May24-May30 & May31-Jun6 \\
\hline
\end{tabular}


Table A.10: \% Receiving PPP and Cash-on-Hand: Week-by-Week

Table A.10 reports the results of instrumental variables (IV) regressions split week-by-week examining the relation between the geographic allocation of PPP funds during the first round and the percentage of businesses reporting at least two months or more of cash-on-hand at the state-by-industry level. The dependent variable is the difference between the percentage of businesses that applied for PPP fundings, minus the percentage of businesses that received PPP funds. \% PPP Received is the percentage of businesses reporting having received PPP funds in a state-by-industry group. State PPPE (Nbr.) is the state average of the PPPE based on the number of outstanding loans. All specifications include industry $\times$ week fixed-effects. Standard errors are presented in parentheses, and are clustered at the level of the state. ***,**, and *, represent statistical significance at $1 \%, 5 \%$, and $10 \%$ levels, respectively.

\begin{tabular}{|c|c|c|c|c|c|c|c|}
\hline & (1) & (2) & (3) & $\begin{array}{c}\text { (4) } \\
\% \text { Cash } 3 \text { mon }\end{array}$ & (5) & (6) & (7) \\
\hline \%PPP Received & $\begin{array}{l}0.283^{* *} \\
(0.121)\end{array}$ & $\begin{array}{c}0.091 \\
(0.079)\end{array}$ & $\begin{array}{c}0.153 \\
(0.105)\end{array}$ & $\begin{array}{c}0.327^{*} \\
(0.188)\end{array}$ & $\begin{array}{c}0.285 \\
(0.310)\end{array}$ & $\begin{array}{l}0.619^{* *} \\
(0.279)\end{array}$ & $\begin{array}{c}0.555 \\
(0.348)\end{array}$ \\
\hline Observations & 903 & 95 & 141 & 136 & 177 & 180 & 174 \\
\hline Adjusted $R^{2}$ & -0.247 & -0.079 & -0.166 & -0.291 & -0.280 & -0.678 & -0.480 \\
\hline FStat & 144.087 & 50.909 & 84.021 & 49.197 & 16.342 & 32.496 & \\
\hline Industry Fixed Effects & No & Yes & Yes & Yes & Yes & Yes & Yes \\
\hline Industry $\times$ Week Fixed Effects & Yes & No & No & No & No & No & No \\
\hline Week: & Full Sample & Apr26-May2 & May3-May9 & May10-May16 & May17-May23 & May24-May30 & May31-Jun6 \\
\hline
\end{tabular}


Table A.11: \% Receiving PPP and Exposure to PPP: MSA Level

Table A.11 reports the results of ordinary least squares (OLS) regressions examining the relation between the geographic allocation of PPP funds during the first round and the percentage of businesses reporting applying but not receiving PPP funds at the MSA level. The dependent variable is the difference between the percentage of businesses that applied for PPP funds and the percentage of businesses that received PPP funds at the MSA level. MSA PPPE (Nbr.) is the MSA average of the PPPE based on the number of outstanding loans. Standard errors are presented in parentheses, and are clustered at the level of the MSA. ***,**, and *, represent statistical significance at $1 \%, 5 \%$, and $10 \%$ levels, respectively.

\begin{tabular}{lccccccc}
\hline \hline & $(1)$ & $(2)$ & $(3)$ & $\begin{array}{c}(4) \\
\text { PPP Received }\end{array}$ & $(5)$ & $(6)$ & $(7)$ \\
& & \multicolumn{7}{c}{$\begin{array}{c}\text { PP) } \\
\text { MSA PPPE (Nbr.) }\end{array}$} & $32.714^{* * *}$ & $68.793^{* * *}$ & $47.107^{* * *}$ & $19.004^{* * *}$ & $24.207^{* * *}$ & $16.938^{* * *}$ & $20.232^{* * *}$ \\
& $(6.579)$ & $(6.202)$ & $(4.106)$ & $(5.071)$ & $(4.977)$ & $(3.356)$ & $(4.363)$ \\
\hline Observations & 300 & 50 & 50 & 50 & 50 & 50 & 50 \\
Adjusted $R^{2}$ & 0.083 & 0.656 & 0.657 & 0.171 & 0.284 & 0.242 & 0.241 \\
Week Fixed Effects & Yes & No & No & No & No & No & No \\
Week: & Full Sample & Apr26-May2 & May3-May9 & May10-May16 & May17-May23 & May24-May30 May31-Jun6 \\
\hline \hline
\end{tabular}


Table A.12: \% Receiving PPP and Missed Payments: MSA-Level

Table A.12 reports the results of ordinary least squares (OLS) and instrumental variables (IV) regressions examining the relation between the geographic allocation of PPP funds during the first round and the percentage of firms reporting missing payments at the MSA level collected from the Census Small Business Pulse Survey. In the top panel, the dependent variable is the percentage of firms at the MSA reporting a missed scheduled loan payment. In the bottom panel, the dependent variable is the percentage of firms reporting a missed other scheduled payment such as rent, utilities, and payroll. \% PPP Received is the percentage of businesses reporting having received PPP funds in a state-by-industry group. MSA PPPE (Nbr.) is the MSA average of the PPPE based on the number of outstanding loans. All specifications include week fixed-effects. Robust standard errors are presented in parentheses. ***, **, and *, represent statistical significance at $1 \%, 5 \%$, and $10 \%$ levels, respectively.

Panel A: Missing Loan Payments

\begin{tabular}{|c|c|c|c|c|}
\hline & \multirow{3}{*}{$\begin{array}{l}\text { (1) } \\
\text { OLS }\end{array}$} & \multirow{3}{*}{$\begin{array}{c}(2) \\
\text { Reduced Form }\end{array}$} & \multicolumn{2}{|r|}{ (4) } \\
\hline & & & & IV \\
\hline & & & First-Stage & Second-Stage \\
\hline Dep. Variable: & \% Missing Loan Payments & \% Missing Loan Payments & \% PPP Received & \% Missing Loan Payments \\
\hline \% PPP Received & $\begin{array}{c}-0.154^{* * *} \\
(0.013)\end{array}$ & & & $\begin{array}{c}-0.181^{* * *} \\
(0.042)\end{array}$ \\
\hline MSA PPPE (Nbr.) & & $\begin{array}{c}-5.902^{* * *} \\
(1.583) \\
\end{array}$ & $\begin{array}{c}32.652^{* * *} \\
(6.579)\end{array}$ & \\
\hline Observations & 298 & 298 & 298 & 298 \\
\hline Adjusted $R^{2}$ & 0.357 & 0.039 & 0.083 & 0.347 \\
\hline FStat & & & & 24.635 \\
\hline Week Fixed Effects & Yes & Yes & Yes & Yes \\
\hline
\end{tabular}

Panel B: Missing Other Scheduled Payments (Rent, Utilities, Payroll)

\begin{tabular}{|c|c|c|c|c|}
\hline & \multirow{3}{*}{ OLS } & \multirow{3}{*}{$\begin{array}{c}\text { (2) } \\
\text { Reduced Form }\end{array}$} & \multirow{2}{*}{\multicolumn{2}{|c|}{ (4) }} \\
\hline & & & & \\
\hline & & & First-Stage & Second-Stage \\
\hline \% PPP Received & $\begin{array}{c}-0.235^{* * *} \\
(0.019)\end{array}$ & & & $\begin{array}{c}-0.451^{* * *} \\
(0.085)\end{array}$ \\
\hline MSA PPPE (Nbr.) & & $\begin{array}{l}-14.753^{* * *} \\
(2.438)\end{array}$ & $\begin{array}{c}32.714^{* * *} \\
(6.579)\end{array}$ & \\
\hline Adjusted $R^{2}$ & 0.320 & 0.099 & 0.083 & 0.046 \\
\hline FStat & & & & 24.728 \\
\hline Week Fixed Effects & Yes & Yes & Yes & Yes \\
\hline
\end{tabular}


Table A.13: \% Receiving PPP and Cash-on-Hand: MSA-Level

Table A.13 reports the results of ordinary least squares (OLS) and instrumental variables (IV) regressions examining the relation between the geographic allocation of PPP funds during the first round and the percentage of businesses at the MSA level reporting at least two months of cash on hand to sustain operations as collected from the Census Small Business Pulse Survey. The dependent variable is the fraction of businesses in the MSA reporting cash on hand to sustain operations for two months or more. \% PPP Received is the percentage of businesses reporting having received PPP funds at the MSA level. MSA PPPE ( $\mathrm{Nbr}$.) is the MSA average of the PPPE based on the number of outstanding loans. All specifications include week fixed-effects. Robust standard errors are presented in parentheses. ***,**, and *, represent statistical significance at $1 \%, 5 \%$, and $10 \%$ levels, respectively.

\begin{tabular}{lcccc}
\hline \hline & OLS & Reduced Form & (3) & (4) \\
\cline { 4 - 5 } & & & First-Stage & Second-Stage \\
\hline Dep. Variable: & \% Cash 3 months & \% Cash 3 months & \% PPP Received & \% Cash 3 months \\
\hline \% PPP Received & $0.172^{* * *}$ & & & $-0.172^{*}$ \\
MSA PPPE (Nbr.) & $(0.018)$ & & & $(0.097)$ \\
& & $-5.628^{* *}$ & $32.714^{* * *}$ & \\
\hline Observations & 300 & $(2.468)$ & $(6.579)$ & 300 \\
Adjusted $R^{2}$ & 0.194 & 300 & 300 & -0.595 \\
FStat & & 0.014 & 0.083 & 24.728 \\
Week Fixed Effects & Yes & & & Yes \\
\hline \hline
\end{tabular}


Table A.14: Unmet Demand and Exposure to PPP: MSA Level

Table A.14 reports the results of ordinary least squares (OLS) regressions examining the relation between the geographic allocation of PPP funds during the first round and the percentage of businesses reporting applying but not receiving PPP funds at the MSA level. The dependent variable is the difference between the percentage of businesses that applied for PPP funds and the percentage of businesses that received PPP funds at the MSA level. MSA PPPE (Nbr) is the MSA average of the PPPE based on the number of outstanding loans. Robust standard errors are presented in parentheses. ${ }^{* * *}, * *$, and *, represent statistical significance at $1 \%, 5 \%$, and $10 \%$ levels, respectively.

\begin{tabular}{|c|c|c|c|c|c|c|c|}
\hline & (1) & (2) & (3) & (4) & (5) & (6) & (7) \\
\hline & \multicolumn{7}{|c|}{ \% PPP Requested - \% PPP Received } \\
\hline MSA PPPE (Nbr.) & $\begin{array}{c}-22.987^{* * *} \\
(6.526)\end{array}$ & $\begin{array}{c}-60.564^{* * *} \\
(7.053)\end{array}$ & $\begin{array}{c}-36.165^{* * *} \\
(3.150)\end{array}$ & $\begin{array}{c}-13.531^{* * *} \\
(2.527)\end{array}$ & $\begin{array}{c}-11.946^{* * *} \\
(2.570)\end{array}$ & $\begin{array}{c}-9.384^{* * *} \\
(1.500)\end{array}$ & $\begin{array}{c}-6.331^{* * *} \\
(1.845)\end{array}$ \\
\hline Observations & 300 & 50 & 50 & 50 & 50 & 50 & 50 \\
\hline Adjusted $R^{2}$ & 0.043 & 0.585 & 0.643 & 0.360 & 0.270 & 0.298 & 0.121 \\
\hline Week Fixed Effects & Yes & No & No & No & No & No & No \\
\hline Week: & Full Sample & Apr26-May2 & May3-May9 & May10-May16 & May17-May23 & May24-May30 & May31-Jun6 \\
\hline
\end{tabular}


Table A.15: Unmet Demand and Missed Payments:MSA Level

Table A.15 reports the results of ordinary least squares (OLS) and instrumental variables (IV) regressions examining the relation between the geographic allocation of PPP funds during the first round and the percentage of businesses reporting missing scheduled payments at the MSA level. In the top panel, the dependent variable is the percentage of firms reporting a missed scheduled loan payment. In the bottom panel, the dependent variable is the percentage of firms reporting a missed other scheduled payment such as rent, utilities, and payroll. \% PPP Requested - \% PPP Received is the difference between the percentage of businesses that applied for PPP funds and the percentage of businesses that received PPP funds at the MSA level. MSA PPPE (Nbr.) is the MSA average of the PPPE based on the number of outstanding loans. All specifications include week fixed-effects. Robust standard errors are presented in parentheses. ***, **, and *, represent statistical significance at $1 \%, 5 \%$, and $10 \%$ levels, respectively.

Panel A: Missing Loan Payments

\begin{tabular}{|c|c|c|c|c|}
\hline & (1) & $(2)$ & (3) & (4) \\
\hline & OLS & Reduced Form & \multicolumn{2}{|l|}{ IV } \\
\hline & & & First-Stage & Second-Stage \\
\hline Dep. Variable: & \% Missing Loan Payments & \% Missing Loan Payments & \% PPP Request - \% PPP Received & \% Missing Loan Payments \\
\hline \% PPP Requested - \% PPP Received & $\begin{array}{c}0.166^{* * *} \\
(0.013)\end{array}$ & & & $\begin{array}{c}0.258^{* * *} \\
(0.067)\end{array}$ \\
\hline MSA PPPE (Nbr.) & & $\begin{array}{l}-5.902^{* * *} \\
(1.583)\end{array}$ & $\begin{array}{l}-22.911^{* * *} \\
(6.526)\end{array}$ & \\
\hline Observations & 298 & 298 & 298 & 298 \\
\hline Adjusted $R^{2}$ & 0.380 & 0.039 & 0.043 & 0.265 \\
\hline FStat & & & & 12.325 \\
\hline Week Fixed Effects & Yes & Yes & Yes & Yes \\
\hline
\end{tabular}

Panel B: Missing Other Scheduled Payments (Rent, Utilities, Payroll)

\begin{tabular}{|c|c|c|c|c|}
\hline & $(1)$ & $(2)$ & (3) & (4) \\
\hline & OLS & Reduced Form & \multicolumn{2}{|l|}{ IV } \\
\hline & & & First-Stage & Second-Stage \\
\hline Dep. Variable: & \% Missing Schd. Payments & \% Missing Schd. Payments & \% PPP Request - \% PPP Received & \% Missing Schd. Payments \\
\hline \% PPP Requested - \% PPP Received & $\begin{array}{c}0.258^{* * *} \\
(0.020)\end{array}$ & & & $\begin{array}{c}0.642^{* * *} \\
(0.155)\end{array}$ \\
\hline MSA PPPE (Nbr.) & & $\begin{array}{c}-14.753^{* * *} \\
(2.438)\end{array}$ & $\begin{array}{c}-22.987^{* * *} \\
(6.526)\end{array}$ & \\
\hline Observations & 300 & 300 & 300 & 300 \\
\hline Adjusted $R^{2}$ & 0.355 & 0.099 & 0.043 & -0.434 \\
\hline FStat & & & & 12.406 \\
\hline Week Fixed Effects & Yes & Yes & Yes & Yes \\
\hline
\end{tabular}


Table A.16: Unmet Demand and Cash-on-Hand: MSA Level

Table A.16 reports the results of ordinary least squares (OLS) and instrumental variables (IV) regressions examining the relation between the geographic allocation of PPP funds during the first round and the percentage of businesses reporting at least two months or more of cash-on-hand at the MSA level. The dependent variable is the fraction of businesses with cash on hand to sustain operations for two months or more. \% PPP Requested - \% PPP Received is the difference between the percentage of businesses that applied for PPP funds and the percentage of businesses that received PPP funds at the MSA level. All specifications include week fixed-effects. Robust standard errors are presented in parentheses. ***, **, and *, represent statistical significance at $1 \%$, $5 \%$, and $10 \%$ levels, respectively.

\begin{tabular}{|c|c|c|c|c|}
\hline & $\begin{array}{l}\text { (1) } \\
\text { OLS }\end{array}$ & $\begin{array}{c}\text { (2) } \\
\text { Reduced Form }\end{array}$ & (3) & (4) \\
\hline & & & First-Stage & Second-Stage \\
\hline Dep. Variable: & \% Cash 3 months & $\%$ Cash 3 months & \% PPP Request - \% PPP Received & $\%$ Cash 3 months \\
\hline \% PPP Requested - \% PPP Received & $\begin{array}{c}-0.203^{* * *} \\
(0.019)\end{array}$ & & & $\begin{array}{c}0.245 \\
(0.156)\end{array}$ \\
\hline MSA PPPE (Nbr.) & & $\begin{array}{c}-5.628^{* *} \\
(2.468)\end{array}$ & $\begin{array}{c}-22.987^{* * *} \\
(6.526)\end{array}$ & \\
\hline Observations & 300 & 300 & 300 & 300 \\
\hline Adjusted $R^{2}$ & 0.247 & 0.014 & 0.043 & -0.972 \\
\hline FStat & & & & 12.406 \\
\hline Week Fixed Effects & Yes & Yes & Yes & Yes \\
\hline
\end{tabular}

